\title{
Non cell-autonomous effect of astrocytes on cerebral cavernous malformations
}

Miguel Alejandro Lopez-Ramirez ${ }^{1,2^{*}}$, Shady Ibrahim Soliman ${ }^{1 \&}$, Preston Hale $^{1 \&}$, Catherine Chinhchu Lai ${ }^{1, \&}$, Angela Pham ${ }^{1}$, Esau Estrada ${ }^{1}$, Sara McCurdy $^{1}$, Romuald Girard ${ }^{3}$, Riya Verma ${ }^{1}$, Thomas Moore ${ }^{3}$, Rhonda Lightle ${ }^{3}$, Nicholas Hobson ${ }^{3}$, Robert Shenkar ${ }^{3}$, Orit Poulsen ${ }^{4}$, Gabriel G. Haddad ${ }^{4,5,6}$, Richard Daneman ${ }^{2}$, Brendan Gongol ${ }^{1}$, Hao Sun $^{1, \dagger}{ }^{\dagger}$, Frederic Lagarrigue ${ }^{1, \dagger}$, Issam A. Awad ${ }^{3, \dagger}$, Mark H. Ginsberg ${ }^{1}$.

${ }^{1}$ Department of Medicine, University of California, San Diego, La Jolla, California, USA.

${ }^{2}$ Department of Pharmacology, University of California, San Diego, La Jolla, California, USA.

${ }^{3}$ Neurovascular Surgery Program, Section of Neurosurgery, Department of Surgery, The

University of Chicago Medicine and Biological Sciences, Chicago, Illinois, USA.

${ }^{4}$ Department of Pediatrics, University of California, San Diego, La Jolla, California, USA.

${ }^{5}$ Department of Neuroscience, Division of Respiratory Medicine, University of California, San

Diego, La Jolla, California, USA.

${ }^{6}$ Rady Children's Hospital, San Diego, California, USA.

${ }^{*}$ Correspondence should be addressed to M.A.L.R: $\underline{\text { malopezramirez@health.ucsd.edu }}$

Telephone: 858-534-4425, FAX: 858-822-6458

$\stackrel{\uparrow}{\&}$ Contributed equally

Conflict of interest statement: The authors have declared that no conflict of interest exists 


\begin{abstract}
:
Cerebral cavernous malformations (CCMs) are common neurovascular lesions caused by lossof-function mutations in one of three genes, including KRIT1 (CCM1), CCM2, and PDCD10 (CCM3), and generally regarded as an endothelial cell-autonomous disease. Here we report that proliferative astrocytes play a critical role in CCM pathogenesis by serving as a major source of VEGF during CCM lesion formation. An increase in astrocyte VEGF synthesis is driven by endothelial nitric oxide (NO) generated as a consequence of KLF2 and KLF4-dependent elevation of eNOS in CCM endothelium. The increased brain endothelial production of NO stabilizes HIF$1 \alpha$ in astrocytes, resulting in increased VEGF production and expression of a "hypoxic" program under normoxic conditions. We show that the upregulation of cyclooxygenase-2 (COX-2), a direct HIF-1 $\alpha$ target gene and a known component of the hypoxic program, contributes to the development of CCM lesions because the administration of a COX-2 inhibitor significantly prevents progression of CCM lesions. Thus, non-cell-autonomous crosstalk between CCM endothelium and astrocytes propels vascular lesion development, and components of the hypoxic program represent potential therapeutic targets for CCMs.
\end{abstract}

\title{
Introduction
}

Cerebral cavernous malformations (CCMs) are caused by gross brain endothelial changes that lead to blood-brain barrier (BBB) dysfunction, resulting in significant morbidity and mortality(1, 2). CCMs affect $\sim 1 / 200$ children and adults, causing a lifelong risk of chronic and acute hemorrhage and consequent disabilities from neurological deficits, for which there is no current effective pharmacologic therapy(3-6). Inherited germline and somatic loss of function mutations in the genes KRIT1 (Krev1 interaction trapped gene 1, CCM1), CCM2 (Malcavernin), PDCD10 (Programmed cell death protein 10, CCM3) are associated with CCMs (5, 7-9). Notably, CCMs 
have been recognized as an endothelial cell-autonomous disease because endothelial-specific inactivation of murine Krit1, Ccm2 or Pdcd10, results in brain and retinal vascular lesions similar to those in CCM patients(10-13). These murine studies are also supported by the finding of a "second hit" on the normal KRIT1 or PDCD10 allele in the CCM endothelium $(14,15)$. However, there has been to date no compelling mechanistic explanation for the propensity of CCM lesions to form in the central nervous system (CNS).

Recent studies have shown that loss of CCM genes in neuroglia or stromal cells may contribute to CCM pathogenesis through non-cell-autonomous mechanisms (16-18). Although CCM is a disease that affects the neurovascular unit, there is a limited understanding of the crosstalk between the CCM endothelium and astrocytes, (17, 19, 20). Astrocytes are the most abundant cell in the CNS and form part of the neurovascular unit that maintains a functional $\mathrm{BBB}(21-23)$. Additionally, astrocytes respond to multiple forms of insults and diseases by a process called reactive astrogliosis or astrocytosis, which involves changes in morphology, function and gene expression $(24,25)$. Reactive astrogliosis increases secretion of VEGF and can contribute to the development and progression of CNS disease (26-28). Previous studies have demonstrated elevated levels of angiogenic factor VEGF in CCM lesions, and in the plasma of individuals with the hereditary and sporadic form of the disease(29-32). VEGF signaling mediates disruption of the brain endothelial barrier by disassembly of inter-endothelial junctions(33) and can cause hemorrhages $(34,35)$, both prominent features of $\operatorname{CCM}$ lesions $(2,6,10,36,37)$. We and others found that CCM led to a dramatic increase in VEGF signaling and that blocking VEGF signaling prevents subsequent formation of $\operatorname{CCMs}(6,38)$. However, despite these emerging studies, the mechanism and source of VEGF production in CCM lesions in vivo remain elusive.

Endothelial nitric oxide synthase (eNOS, the product of the NOS3 gene) is an enzyme that generates nitric oxide (NO) and it is responsible for vascular remodeling, angiogenesis and 
vascular tone $(39,40)$. Previous studies indicate that eNOS contributes to VEGF-induced angiogenesis and vascular permeability $(41)$ through NO production $(42,43)$. Here we show that astrocytes are a major source of VEGF during CCM pathogenesis and that depletion of proliferative astrocytes prevents CCM lesion development. We show that CCM endotheliuminduced elevation of astrocyte-derived VEGF in neonatal and juvenile brains occurs through elevation of brain eNOS/NO-dependent signaling. Production of NO in CCM endothelium contributes to normoxic stability of HIF-1 $\alpha$ in astrocytes. Our findings indicate that the eNOS increase in human CCM endothelium is ascribable to the elevation of the transcription factors KLF2 and KLF4, previously implicated in the CCM pathogenesis(6, 13, 37, 44, 45). Furthermore, genetic inactivation of one copy of the Nos3 gene is sufficient to attenuate CCM endothelial NO production, HIF-1 $\alpha$ protein stability and astrocyte-derived VEGF expression. Our results further reveal that CCM tissue results in increased HIF activity under normoxic conditions. We show that pharmacological inhibition of a HIF-1 $\alpha$ regulated gene, cyclooxygenase-2, ameliorates the development of CCM lesions in animal models. Overall, these findings indicate that a non-cell-autonomous mechanism mediated by CCM endotheliumdriven normoxic stabilization of HIF-1 $\alpha$ and increase of VEGF in astrocytes makes a major contribution to CCM pathogenesis. Understanding the crosstalk between dysfunctional brain vasculature and components of the neurovascular unit (e.g., astrocytes) has the potential to lead to the development of novel therapeutic strategies for CCM disease as exemplified by our finding that inhibition of HIF1-driven COX-2 by an approved and a well-tolerated drug can ameliorate murine models of CCM disease.

\section{Results}

Astrocytes contribute to cerebral cavernous malformations development 
CCMs have been studied as an endothelial cell-autonomous disease $(6,14,15)$, marked by changes in the CNS vasculature due to the loss of endothelial PDCD10, KRIT1 or CCM2 (1012). Although it is a disease that affects the neurovascular unit, we know little about whether astrocytes influence CCM pathogenesis $(17,19)$. This prompted us to investigate the relationship between astrocytes and CCM lesion development in murine CCMs (Fig. 1A,B, fig. S1). Neonatal endothelial-specific inactivation of murine Pdcd10, producing $P d c d 10^{E C K O}$ mice(37), results in cerebellar vascular lesions detected in sections stained by hematoxylin and eosin (Fig. 1A,B, fig. S1) or by observing dramatic vascular dilation by staining the endothelial marker CD34 at P9 (Fig. 1A,B). CCM lesions have high propensity to develop in GFAP-positive fibrous astrocytes(46) (Fig. 1A) in the white matter of $P d c d 10^{E C K O}$ hindbrains (fig. S1). Moreover, P8 Krit1 ${ }^{E C K O}$ hindbrains show the same spatial distribution of CCM lesions among astrocytes positive for GFAP on the white matter tract (fig. S1). To examine the role of astrocytes, we generated Pdcd10 ${ }^{E C K O} ;$ GFAP-TK mice (Pdgfb-iCreERT2;Pdcd10 f/ffl; GFAP-TK (Thymidine kinase) mice) in which proliferative astrocytes are selectively depleted in a time-controlled manner, by administration of antiviral agent ganciclovir $(\mathrm{GCV})(47,48)$. Administration of 20 $\mathrm{mg} / \mathrm{Kg}$ of GCV to neonatal mice at P7 markedly reduced hindbrain vascular lesions in P9 Pdcd $10^{E C K O} ;$ GFAP-TK mice when compared with GCV-treated littermate Pdcd $10^{E C K O}$ controls (Fig. 1C). To quantify CCM formation, we imaged P9 hindbrains using contrast-enhanced, highresolution x-ray micro-computed tomography (micro-CT), and measured lesion volumes using semiautomated software(49). Blinded measurement of total CCM lesion volume showed that GCV-treated Pdcd10 ECKO;GFAP-TK mouse hindbrains exhibited significant reduction of CCM lesions compared with GCV-treated $P d c d 10^{E C K O}$ mouse hindbrains littermates (Fig. 1D). These data suggest that in CCM disease, proliferative astrocytes participate in vascular lesions formation.

\section{Astrocyte-derived VEGF is increased during CCM development}


CCMs exhibit increased VEGF signaling $(6,30,31)$ due to the loss of an anti-angiogenic checkpoint(6). To ascertain a potential source of increased expression of VEGF, we introduced a VEGF reporter, Vegfa ${ }^{\text {tm1.1Nagy }}$, in CCM animal models. Vegfa ${ }^{\text {tm1.1Nagy }}$ carries a nuclear-localized beta-galactosidase ( $\beta$-gal) knock-in at the 3' UTR of the Vegfa gene locus that permits singlecell monitoring of VEGF expression(50). We observed an increase in $\beta$-gal/VEGF expression, as shown by X-gal staining, in areas surrounding CCM lesions in P10 Pdcd10 ECKO; Vegfatm1.1Nagy hindbrains when compared with Pdcd10 $0^{f / f l} ; V$ egfa ${ }^{t m 1.1 N a g y}$ littermate control (Fig. 2A). We found that most $\beta$-gal/VEGF+ cells colocalized with the GFAP marker of fibrous astrocytes and Bergman glia located within Purkinje cell layer(46) in Pdcd10 ECKO; Vegfa ${ }^{\text {tm1.1Nagy }}$ (Fig. 2A). We also observed that calbidin-positive Purkinje neurons exhibited increased $\beta$-gal/VEGF expression near CCM lesions (Data not shown). Consistent with results observed using $\beta$ gal/VEGF reporter mice, high-resolution in situ hybridization (ISH) analysis confirmed an increase in VEGF expression near and around the CCM lesion colocalized with the GFAP marker of astrocytes (Fig. 2B, fig. S2). Moreover, we observed that $P d c d 10^{E C K O}$ hindbrains exhibited $\sim 1.8$-fold increase in Vegfa mRNA levels compared with littermate Pdcd $10^{f / f f l}$ control (Fig. 2C). Administration of GCV to neonatal mice at P7 significantly reduced Vegfa mRNA levels in vascular lesions in $\mathrm{P} 10 \mathrm{Pdcd10}{ }^{\mathrm{ECKO}}$;GFAP-TK mice compared with GCV-treated littermate Pdcd10 ${ }^{E C K O}$ controls (Fig. 2C). We next tested the effect of depletion of proliferative astrocytes at the developmental stage when vascular lesions are present in Pdcd10 ${ }^{E C K O}$. Our data indicate that administration of GCV to neonatal mice between P9 to P12 significantly reduced Vegfa mRNA levels and CCM lesion burden in P15 Pdcd10 ECKO;GFAP-TK mice when compared with GCV-treated littermate Pdcd10 ECKO controls (Fig. 2D,E). Since the retinal blood vessels is another vascular bed affected by the loss of Pdcd10 in endothelial cells, we also compared the subcellular expression of VEGF. Deletion of the endothelial Pdcd10 gene at P3 prominently increase $\beta$-gal/VEGF expression in GFAP+ retinal astrocytes at the leading edge of blood vessel growth and immediately ahead of the plexus in P9 Pdcd10 ECKO; Vegfa ${ }^{\text {tm1.1Nagy }}$ 
retinas (fig. S2,S3). We observed that the enhanced expression of $\beta$-gal/VEGF was associated with impaired extension of the developing superficial vascular plexus(51) in P9 Pdcd10 ECKO; $V_{e g f a} a^{t m 1.1 N a g y}$ retinas when compared with Pdcd10 $0^{f / f l} ; V_{e g f a}^{t m 1.1 N a g y}$ littermate control (fig. S3). Moreover, defect on the extension of the vascular plexus in P12 Pdcd10 ECKO; Vegfatm1.1Nagy retinas was reduced compared with $P d c d 10^{f / f f l} ; V_{e g f a}^{t m 1.1 N a g y}$ littermate control, whereas the endothelial density and an increase in $\beta$-gal/VEGF expression in GFAP+ retinal astrocytes were elevated (fig. S3). These data suggest that increased expression of astrocyte-derived VEGF could account for a contribution of astrocytes to CCM lesion formation.

\section{Astrocyte-derived VEGF increases during CCM formation in juvenile mice}

The previous studies showed increased VEGF expression in an acute neonatal CCM model. Recent studies have emphasized that chronic models may be more reflective of the course of the human disease(52-54). We therefore, investigated the expression of VEGF increased in perilesional astrocytes in juvenile Pdcd $10^{E C K O} ;$ Vegfa ${ }^{\text {tm1.1Nagy }}$ mice. Similar to neonatal mice, we observed an increase in $\beta$-gal/VEGF expression in areas surrounding CCM lesions in P30 Pdcd10 ECKO; Vegfat ${ }^{\text {tm1.1Nagy }}$ cerebellar tissue (Fig. 3A). We found that most $\beta$-gal/VEGF+ cells colocalized with the GFAP astrocyte marker in Pdcd10 ECKO; Vegfatm1.1Nagy mice (Fig. 3A). Consistent with results observed using $\beta$-gal/VEGF reporter mice, $P d c d 10^{E C K O}$ cerebellar tissue showed a significant increase in Vegfa mRNA levels when compared with littermate Pdcd10 fl/fl control (Fig. 3B). In contrast to neonatal Pdcd10 ${ }^{E C K O}$ mice, $P d c d 10^{E C K O}$ juvenile mice develop CCM lesions in the cerebrum $(52,53,55)$ and these were accompanied by a marked increase in $\beta$-gal/VEGF expression in GFAP+ astrocytes and in SOX-9+ astrocytes in P30 Pdcd10 ECKO; Vegfa $^{\text {tm1.1Nagy }}$ brains (Fig. 3A, fig. S3). We also observed a significant increase in Vegfa mRNA in the cerebrum of $P d c d 10^{E C K O}$ mice (Fig. 3C). Additionally, we found elevated levels of VEGF in plasma from P30 Pdcd10 ECKO mice when compared with Pdcd1 $10^{f / f l}$ littermate control (Fig. 3D). These data support the idea that astrocyte-derived VEGF contributes to CCM lesions(29-32). 


\section{Increase in normoxic HIF-1 $\alpha$ stabilization in CCM astrocytes}

Transcription factor HIF-1 $\alpha$ regulates expression of $\operatorname{VEGF}(27,56-58)$. Therefore, we next investigated whether the significant increase of VEGF in astrocytes during CCMs is due to elevation of HIF-1 $\alpha$. For this studies, we first prepared co-culture studies to better understand the interaction between CCM endothelium and astrocytes (Fig. 4A) and the level of HIF-1 $\alpha$ in purified astrocytes (fig.S4) co-cultured with Pdcd10 ECKO or Pdcd10 f/ffl BMECs was determined. Immunocytochemistry revealed that the level of HIF-1 $\alpha$ was elevated in astrocytes co-cultured with Pdcd10 ${ }^{E C K O}$ BMECs compared to those co-cultured with control Pdcd10 $0^{f / f l}$ BMECs (Fig. 4A,B, fig. S4). Consistent with this observation, Western blot analysis of $P d c d 10^{E C K O}$ hindbrains at P10 confirmed an increase in HIF-1 $\alpha$ protein levels when compared with Pdcd $10^{f / f f l}$ litermate controls (Fig. 4C). Furthermore, we observed an increase in HIF-1 $\alpha$ activity in Pdcd $10^{E C K O}$ hindbrains (Fig. 4D). RT-qPCR analysis revealed a significant induction of HIF-1 $\alpha$ regulated genes involved in inflammation(59), including cyclooxygenase-2 (Cox2) and monocyte chemoattractant protein 1 (Mcp1) as well as genes involved in hypoxia $(56,60)$ metabolic reprograming such as glucose transporter 1 (solute carrier family 2, S/c2a1, GLUT-1), lactic acid and pyruvate transporter (solute carrier family 16, Slc16a3, also known as monocarboxylate transporter 4 MCT4). In addition, we also observed a significant increase in HIF-1 $\alpha$ regulated genes involved in angiogenesis(56, 60), including a cell-surface glycoprotein Cd44, Lysyl oxidase-like 2 (Lox/2) and angiopoietin-like 4 (Angpt/4) (Fig. 4D). Importantly, our findings in the CCM animal model were extended to human CCM because we also detected the elevation of HIF $1 \alpha$ regulated genes in human CCM lesions in comparison with lesion-free brain tissue from a CCM patient or noneurological disease control (Fig. 4E). Since we observed that COX-2 is increased at mRNA (Fig. 4D) and protein (Data not shown) levels in Pdcd10 ${ }^{E C K O}$ hindbrains and at the mRNA level in human CCM lesions (Fig. 4E), we next investigated the effect of using celecoxib $(40 \mathrm{mg} / \mathrm{Kg})$, a nonsteroidal anti-inflammatory 
drug (NSAID) that primarily inhibits COX-2 activity, in two preclinical CCM models. Blinded measurements using microCT analysis of neonatal celecoxib-treated $P d c d 10^{B E C K O}$ mice compared with vehicle-treated littermate $P d c d 10^{B E C K O}$ mice control indicated a reduction in vascular lesion volume principally in the cerebrum (Fig. 5A). Histological analysis of the hippocampal area in $\mathrm{P} 13 \mathrm{Pdcd} 10^{B E C K O}$ mice further demonstrates the high propensity of CCM lesions to develop surrounded by GFAP+ astrocytes, and inhibition of COX-2 reduced the CCM lesions' density in Pdcd10 ${ }^{B E C K O}$ mice (Fig. 5B, fig. S5). Next, we investigated the effect of using celecoxib for 15 days in juvenile $P d c d 10^{B E C K O}$ mice. Notably, blinded measurements of microCT analysis confirmed reduction in CCM in cerebrum and cerebellum of P80 celecoxib-treated Pdcd10 $10^{B E C K O}$ mice (Fig. 5C). Moreover, histological analysis of the cerebellum and hippocampal area in P80 celecoxib-treated $P d c d 10^{B E C K O}$ mice confirmed a decrease in CCM lesions' density and in GFAP-immunoreactivity (Fig. 5D, fig. S5). Similar to the CCM lesions detected in brain, we observed that P80 Pdcd10 ${ }^{B E C K O}$ mice develop gross CCM lesions through the spinal cord (fig. S6), and with high propensity to develop in GFAP+ astrocytes areas. In addition, P80 Pdcd10 spinal cords exhibited $\sim 1.6$-fold increase in Vegfa mRNA levels that it is prevented in P80 celecoxib-treated $P d c d 10^{B E C K O}$ mice (Fig. 5E), whereas the elevation of Nos3 mRNA remain unchanged (Fig. 5F). Collectively, these results suggest that CCM endothelium can induce HIF$1 \alpha$ dependent hypoxia and angiogenesis programs in astrocytes and that this non-cellautonomous mechanism contributes to disease. Moreover, the capacity of celecoxib to ameliorate two murine CCM models underscores the potential of therapeutic strategies to emerge from these insights.

\section{Loss of brain endothelial Pdcd10 or Krit1 increases the expression of eNOS}

Previous work has demonstrated that eNOS contributes to VEGF-induced angiogenesis and vascular permeability(41) potentially through stabilization of HIF1- $\alpha$ by Nitric Oxide (NO). Genetic inactivation of $P d c d 10\left(P d c d 10^{E C K O}\right)$ or Krit1 (Krit1 $\left.{ }^{E C K O}\right)$ results in increased Nos3 mRNA levels(6, 
61). When we co-cultured Pdcd10 ECKO endothelial cells with astrocytes we observed a dramatic upregulation of Nos3 mRNA ( 19.2 fold increase) associated with increased eNOS protein expression ( 8.9 fold increase) in Pdcd10 ${ }^{E C K O}$ BMECs when compared to $P d c d 10^{f / f f}$ BMEC control as assessed by Western blot analysis (fig. S7). Similar results were observed in Krit ${ }^{\text {ECKO }}{ }^{\mathrm{BMECs}}$ a $\sim 7.4$ fold increase Nos3 mRNA was associated with increased eNOS protein expression ( 1.9 fold increase) (fig. S7). These results indicate that upon genetic inactivation of Pdcd10 or Krit1 in BMECs, there is a significant increase in eNOS mRNA and protein.

To investigate the distribution and expression of eNOS during CCMs in vivo, we first used neonatal $P d c d 10^{E C K O}$ mice. Consistent with results observed in vitro, $P d c d 10^{E C K O}$ hindbrains showed $\sim 3.3$ fold increase in Nos3 mRNA levels compared with littermate Pdcd $10^{f / f l}$ controls (Fig. $6 \mathrm{~A})$. Furthermore, Western blot analysis showed a $\sim 5.8$ fold increase in eNOS protein expression in $P d c d 10^{E C K O}$ hindbrains relative to $P d c d 10^{f / f I I}$ hindbrains (Fig. 6B). Immunohistochemistry analysis of hindbrain sections revealed that eNOS was upregulated in CCM lesions. As showed in Fig. 6C, we observed that eNOS staining was increased in $P d c d 10^{E C K O}$ dilated vasculature as showed by colocalization of antibodies specific against eNOS and isolectin B4-FITC staining, which specifically labels the brain vasculature (Fig. 6C). Moreover, we analysis of the distribution and expression of eNOS in juvenile CCM animal model indicated that Nos3 mRNA levels were elevated in brain tissue in Pdcd10 ${ }^{E C K O}$ mice (Fig. 6D,E). We also observed robust and focal upregulation of eNOS protein in the lesions of $P d c d 10^{E C K O}$ mice (Fig. 6F). Together, these results demonstrate that eNOS mRNA and protein expression is increased in CCM lesions.

\section{Increased eNOS expression in human CCMs is regulated by KLF2 and KLF4}

In human CCM brain tissue, there was a $\sim 3$ fold increase in NOS3 mRNA levels in comparison to lesion-free brain tissue (Fig. 7A). We also observed that eNOS staining was increased in human CCM endothelium in comparison with lesion-free brain tissue (Fig. 7B). Transcription factors KLF2 
and KLF4 are regulators of eNOS $(62,63)$. Therefore, we confirmed that the changes in brain endothelial eNOS, at the protein and mRNA levels, were associated with an increase in transcription factors KLF2 and KLF4 (Fig. 7C,D). Moreover, we observed that reducing the expression of KLF2 and KLF4(37) prevented increased eNOS expression in KRIT1-depleted human brain endothelial cells (Fig. 7E). These results suggest that the increase in KLF2 and KLF4 increased brain endothelial eNOS in CCMs (Fig. 7F).

\section{Loss of brain endothelial Pdcd10 increases nitric oxide production via eNOS}

Endothelial cells metabolize L-arginine via eNOS to produce nitric oxide (NO), therefore we next investigated if eNOS upregulation increases $\mathrm{NO}$ production in Pdcd10 ECKO BMEC. Using a colorimetric assay to quantitatively measure total $\mathrm{NO}_{2}$ and $\mathrm{NO}_{3}$ (nitrites and nitrates) in the culture media, we observed that $P d c d 10^{E C K O}$ BMEC possessed a $\sim 1.7$ fold increase in NO release when compared with Pdcd10 fl/fl BMEC control (NO basal levels: $\sim 3 \mu \mathrm{M}$ ) (Fig. 8A). The increase in NO release is ascribable in part to the upregulation of eNOS, because genetic inactivation in one copy of the Nos3 gene $\left(\mathrm{Nos}^{+/-}\right.$) significantly reduced NO production in Pdcd10 ECKO BMEC (Fig. 8B). Consistent with these results, low levels of Nos3 mRNA (data not shown) and eNOS protein in Pdcd10 ${ }^{E C K O} ;$ Nos3 $^{+/-}$BMEC were observed (Fig. 8C). Moreover, addition of a nitric oxide synthase (NOS) inhibitor, L-NAME, reduced NO production (Fig. 8B) without changing eNOS mRNA and protein levels (data not shown). Taken together, these studies show that the loss of Pdcd10 in BMECs leads to an increase in eNOS expression and subsequent endothelial NO release.

\section{Brain endothelial nitric oxide induces astrocyte-derived VEGF following loss of Pdcd10}

We showed evidence of increased levels in VEGF expression in GFAP+ brain and retinal astrocytes in Pdcd10 ${ }^{E C K O}$ mice (Fig. 2A,C,D,3A,B, fig. S2,3). However, our in vivo experiments did not unequivocally exclude expression of VEGF in other CNS-resident cells during CCMs, including neurons, microglia and pericytes. Thus, we complemented those studies by performing 
co-culture experiments between CCM endothelium and astrocytes. First, NO donors, such as DETANONOate, promote brain angiogenesis by upregulation of VEGF signaling(43). To investigate whether NO stimulates the expression of VEGF in astrocytes during CCMs, we prepared primary mouse astrocyte cultures from Vegfa ${ }^{\text {tm1.1Nagy }}$ mice (Fig. 8D). We observed that the purity of cultured astrocytes was high as determined by cells that are double positive for specific astrocyte markers GFAP and integrin B5 (fig. S4). We also observed that our primary astrocyte cultures respond to exogenous NO (0.5mM DetaNONOate (NO donor)) and that elevated levels of NO can increase astrocyte-derived VEGF (as assessed by increase in $\beta$ gal/VEGF expression) (fig. S8). We next investigated whether elevated brain endothelial NO in Pdcd10 ECKO results in increased astrocyte-derived VEGF levels. Therefore, we co-cultured purified astrocytes in the presence of $P d c d 10^{E C K O}$ or Pdcd1 $10^{f / f l}$ BMECs in serum-free conditions supplemented with L-arginine, and measured changes in $\beta$-gal/VEGF expression in astrocytes. We observed that $P d c d 10^{E C K O}$ BMEC significantly increase $\beta$-gal/VEGF expression in astrocytes in a co-culture system (Fig. 8D,E). These results were consistent with increased levels of $\beta$-gal and Vegfa mRNA levels in astrocytes co-cultured with Pdcd10 ECKO BMEC compared to cocultured with Pdcd10 fl/fl BMEC control (Fig. 8E,F). Furthermore, genetic inactivation of one copy of the Nos3 gene in Pdcd10 ECKO BMEC was sufficient to prevent stability of HIF-1 $\alpha$ and subsequent Vegfa/ $\beta$-gal upregulation in astrocytes indicating that the increase in astrocytederived Vegfa/ß-gal mRNA levels were specific to the upregulation of eNOS (Fig. 8E,F) and dependent of HIF-1 $\alpha$ stability (Fig. 8G).

We next investigated whether the increase in astrocyte-derived VEGF during CCMs was associated with elevation of eNOS in mice. Vegfa ${ }^{\text {tm1.1Nagy }}$ mice were intercrossed with CCM animal models and with animals deficient in one copy of the Nos3 gene (eNOs+/-). We observed that CCM lesions were slightly reduced and with a partial decrease in $\beta$-gal/VEGF expression in P10 
Pdcd10 ${ }^{\text {ECKO}} ;$ Vegfa $^{\text {tm1.1Nagy }} ;$ Nos3 $^{+/-}$hindbrains when compared with $P d c d 10^{\text {ECKO; }}$ Vegfa $^{\text {tm1.1Nagy }} ; \mathrm{Nos}^{+/+}$littermate control (Fig. 8H). However, the strong induction of Nos3 expression following loss of brain endothelial Pdcd10 (Fig. 8I) suggest that a substantial level of eNOS/NO signaling could contribute to partial elevation in VEGF expression in Pdcd10 ECKO; $\mathrm{Nos}^{+/-}$hindbrains (Fig. 8J) and an incomplete rescue (Data not shown). Altogether our data provide key insights into understanding a circuit of neurovascular dysfunction during CCM disease mediated between the CCM endothelium and astrocytes (Fig. 9). These data provide strong evidence that the nitric oxide (NO) production as a consequence of the elevation of eNOS in CCM endothelium, through elevation of KLF2/KLF4, contributes to the normoxic stability of HIF-1 $\alpha$ and subsequent elevation in astrocyte-derived VEGF. Our findings further support that the hypoxic program components, such as COX-2, represent potential therapeutic targets for CCMs disease (Fig. 9).

\section{Discussion}

The propensity of CCM lesions to form in the CNS parenchyma has never been mechanistically clarified. Our study shows that astrocytes respond to CCM endothelium to initiate a non-cellautonomous enhancement of CCM formation mediated by astrocyte hypoxia and angiogenesis programs. Our experiments show that elevation of eNOS in CCM endothelium contributes to increase in astroglia-derived VEGF and HIF-1 $\alpha$ protein stabilization in astrocytes during CCM disease. The increase in eNOS expression was ascribable to an elevation of the KLF2 and KLF4 transcription factors in CCM. eNOS production in the CCM endothelium results in a sustained elevation of NO that leads to normoxic HIF-1 $\alpha$ protein stabilization and increase in HIF activity in CCM tissue. We therefore propose that astrocytes contribute to CCM disease by a non-cell-autonomous mechanism mediated by CCM endothelium-driven hypoxia and angiogenic programs. 
Our in vivo observations in the neonatal CCM animal model, using endothelial-specific inactivation of $P d c d 10$ or Krit1, revealed that lesion development is spatially restricted to zones of fibrous astrocytes, which are prevalent in the white matter of the CNS(46), and that the selective ablation of proliferative astrocytes(48) markedly reduced CCM lesion and an increase in VEGF expression, prompting the suggestion that a subset of proliferative astrocytes supports $\mathrm{CCM}$ lesions in the developing hindbrain. Moreover, our observations in the chronic CCM animal model(53, 54), using brain endothelial-specific inactivation of Pdcd10(64), further revealed the high propensity of CCM lesions to develop surrounded by GFAP+ astrocytes throughout the CNS, including the cerebellum, cerebrum, and spinal cord. Earlier reports have shown that loss of Pdcd10 in neuroglia cells leads to formation of CCM lesions through non-cellautonomous mechanisms, implicating a role of neural cells in the CCM pathogenesis(17). Consistent with these findings, astrogliosis has been shown to intermingle with granulation tissue in human $\mathrm{CCM}(65)$. However, while some subsets of reactive and proliferative astrocytes can be detrimental and contribute to CNS pathologies while other subsets of reactive astrocytes can be beneficial by supporting CNS recovery $(24,48,66,67)$. The mechanisms that contribute to functional heterogeneity in reactive astrocytes are not completely understood. Recent studies have shown that microglia control astrocyte pathogenic activities during neuroinflammation by releasing of VEGF-B and TGFalpha (68), and during neurodegeneration by secreting of II1alpha, TNF and C1q (24). Our findings revealed that the CCM endothelium controls astrocyte responses through increasing the levels of eNOS and subsequent release of brain endothelial NO. Vascular eNOS has important roles in regulating endothelial homeostasis by producing tonic NO levels, but upregulation of the eNOS gene or activated form has been previously implicated in vascular permeability, angiogenesis and neuroinflammation(26, 42, 43, 69). Here we show that eNOS is increased in human CCM endothelium and the upregulation in endothelial KLF2 and KLF4 can account for the augmented eNOS expression at the 
transcriptional level (63). However, these studies do not exclude the possibility that the elevation of endothelial VEGF signaling during $\operatorname{CCM}(6)$ may also contribute to a sustained eNOS activation $(41,70)$ by posttranslational modification via $\mathrm{PI} 3 \mathrm{~K} / \mathrm{AKT}, \mathrm{Ca}^{2+} /$ calmodulin signaling (71) during long-term adaptations, and this notion needs to be further tested.

CCMs are hypersensitive to angiogenesis due to increase in VEGF signaling, the loss of an anti-angiogenic checkpoint protein, TSP1 $(6,38)$, augmented secretion of angiopoietin-2(11), and deregulation of Notch signaling(72). The increase in VEGF signaling maybe associated with elevated levels of angiogenic factor VEGF in CCM lesions of individuals with the hereditary and sporadic form of the disease(29-32). We found that CCM endothelium-induced elevation of astrocyte-derived VEGF in neonatal and juvenile brains, and elevation of VEGF levels are dependent on eNOS signaling. Notably, an increase in astrocyte-derived VEGF can contribute to the development and progression of CNS disease (26-28) by disassembly of interendothelial junctions $(6,73,74)$. Importantly, early studies show that eNOS contributes to VEGF-induced angiogenesis through the intercellular messenger $\mathrm{NO}(41-43,75)$. Furthermore, it has also been shown that NO-mediated astrocyte HIF-1 $\alpha$ stabilization modulates transcriptional and metabolic activities $(75,76)$. In agreement with this, we observed elevated levels of eNOS protein and NO bioavailability in Pdcd $10^{E C K O}$ BMEC that increased levels of HIF-1 $\alpha$ in co-cultured astrocytes. Loss of one copy of the gene Nos3 in $\mathrm{Pdcd} 10^{E C K O} \mathrm{BMEC}$ is sufficient to attenuate astrocytes HIF-1 $\alpha$ stabilization in the co-culture system. Importantly, although we found that astrocytes respond to CCM endothelium, other cells of the neurovascular unit (e.g., neurons, pericytes, and microglia) may also contribute to CCM disease in a non-cell-autonomous manner through normoxic stabilization of HIF-1 $\alpha$ protein. It is tempting to speculate that CCM endothelium may harmonize cell activation in the neurovascular unit by elevation of NO during CCM disease. Because, NO can reach cells millimeters away from where it is produced, and this in turn can 
stabilize HIF-1 $\alpha$ protein $(77,78)$ from degradation by several mechanisms; directly by HIF-1 $\alpha$ nitrosylation or also indirectly by increasing production of reactive oxidative species or by binding to the iron co-factor required for prolyl hydroxylases activity(79). HIF-1 $\alpha$ can translocate to the nucleus where it dimerizes with HIF-1 $\beta$ and binds to the hypoxia-responsive element in the promoter region of several target genes(60). Our data indicate that in mouse and human CCM tissue there is an activation of the HIF-1 $\alpha$ program associated with the glycolytic pathway by increasing GLUT-1 that guarantees rapid energy production, and an increase in MCT4 that promotes efficient removal of lactic acid, an end product of glycolysis metabolism(60). Elevated HIF activity in CCM tissue was also associated with increases in several pro-angiogenic and inflammatory factors produced by glial cells, including ANGPTL4 that can induce vascular dysfunction in CNS pathologies by triggering angiogenesis $(80,81)$ and COX-2 an enzyme that catalyzes the biosynthesis of prostanoids during inflammation(59). We focused on studying COX-2 inhibition during CCM because it has been shown that COX-2 inhibition can suppress angiogenesis in vitro and in vivo $(82,83)$. Moreover, selective COX-2 inhibitors are safe and well-tolerated drugs that can be repurposed for therapy for CCM disease. Our results show that pharmacological inhibition of COX-2 significantly reduced vascular lesion formation in two models of CCM disease. Importantly, we notice that the inhibition of COX-2 in the chronic CCM animal model results not only in a decrease in CCM lesions' density but also in GFAPimmunoreactivity, suggesting that amelioration of lesion genesis counterparts astrocyte activity in the lesions. In line with these results, a recent retrospective cohort study reported that the use of NSAIDs was correlated with lower risk of hemorrhage among patients affected by CCMs(84). However, this uncontrolled association cannot be interpreted as proof of therapeutic benefit, as patients with recent CCM hemorrhages were inherently less likely to be taking NSAIDs. Cox-2 inhibitors must be investigated for safety and effectiveness in prospective controlled trials, and specific dose-effect and duration of treatment must be carefully defined. A platform for trial 
readiness, exploring proof of concept effect on lesional bleeding in human subjects, is currently being developed, and can efficiently be applied to repurposed drugs, like NSAIDs(85). The precise role of NSAIDs in reducing CCM risk of hemorrhage version lesion formation remains incompletely understood. The COX-2-prostaglandin pathway has been implicated in vascular sprouting, migration, and induction of growth factors and proteolytic enzymes that alter angiogenesis $(82,83,86,87)$, suggesting that COX-2 could be an important therapeutic target for pathological angiogenesis(82). Moreover, inhibition of COX-2 augment VEGF pathway blockade during refractory tumor angiogenesis(88), suggests that combinatorial COX-2/VEGF pathway inhibition could be used as a potential approach to ameliorate/prevent CCMs. In addition, Sulindac metabolites, a NSAID, has been shown to inhibit b-catenin-stimulate transcription of endothelial-mesenchymal transition markers and development of CCMs(89). However, additional studies will be required to determine whether COX-2 inhibitors prevent an increase in astroglia-derived VEGF in response to CCM endothelium. Collectively our data are consistent with the notion that reciprocal communication between CCM endothelium and astrocytes drive CCM lesion formation and contribute to neurovascular dysfunction. These observations point to the possibility of designing therapeutic approaches aimed at preventing endothelial dysfunction and astroglia activation as an intervention to reduce the burden of CCM disease in humans.

\section{Materials and Methods}

\section{Human tissue and genetically modified mice}

Human brain samples of patients with $\mathrm{CCM}$ and control without neurological disease were obtained from the Angioma Alliance Tissue Bank. Endothelial-specific conditional Pdcd10-null mice were generated by crossing a Pdgfb promoter-driven tamoxifen-regulated Cre recombinase (iCreERT2)(90) with loxP-flanked Pdcd10 (Pdcd10 f/ff; generous gift from Wang Min, Yale University; Pdgfb-iCreERT2;Pdcd10f/fl) mice. Brain endothelial-specific conditional Pdcd10-null 
mice were generated by crossing a S/co1c1 promoter-driven tamoxifen-regulated Cre recombinase(64) (iCreERT2, generous gift from Markus Schwaninger) with Pdcd10 fl/fl mice. eNOS-deficient mice $\left(\mathrm{Nos}^{-/-}\right)$were obtained from Jackson Laboratory and crossed with PdgfbiCreERT2;Pdcd10 fl/fl mice to generate Pdgfb-iCreERT2; Pdcd10 $0^{f / f f} ; N_{o s} 3^{-/-}$and Pdgfb-iCreERT2; Pdcd10 f/f/Fos ${ }^{+/-}$mice. On postnatal day 3, mice were administered $50 \mu \mathrm{g}$ of 4-hydroxi-tamoxifen [H7904; Sigma-Aldrich] by intragastric injection to induce genetic inactivation of the endothelial Pdcd10 gene in littermates with Pdgfb-iCreERT2 $\left(P d c d 10^{E C K O}\right)$, and $P d c d 10^{f / f t}$ mice were used as littermate controls. For CCM in juvenile animals, On postnatal day 6, mice were administered 100 $\mu \mathrm{g}$ of 4-hydroxi-tamoxifen [H7904; Sigma-Aldrich] by intragastric injection to induce genetic inactivation of the endothelial Pdcd10 gene in littermates with Pdgfb-iCreERT2 (Pdcd10 ECKO), and $P d c d 10^{f / f l}$ mice were used as littermate controls. On postnatal day 1 , mice were administered 50 $\mu \mathrm{g}$ of tamoxifen [H7904; Sigma-Aldrich] by intragastric injection to induce genetic inactivation of endothelial Pdcd10 gene in littermates with Slco1c1-iCreERT2; (Pdcd10 $\left.{ }^{B E C K O}\right)$, and Pdcd10 $0^{f / f t}$ mice were used as littermate controls. Vegfa ${ }^{\text {tm1.1Nagy }}$ mice, expressing a B-galactosidase (LacZ) reporter gene inserted into the 3' untranslated region of the Vegfa gene(50), were obtained from the Jackson Laboratory. The GFAP-TK mice line was used to selectively ablate proliferative astrocytes (Glial fibrillary acidic protein-Thymidine kinase, generous gift from Michael V. Sofroniew)(47, 48).

For celecoxib treatment, Brain endothelial-specific conditional Pdcd10-null mice were randomized (by flipping a coin) to celecoxib $(40 \mathrm{mg} / \mathrm{Kg}$, celebrex) or vehicle treatment $(0.5 \%$ methylcellulose plus $0.025 \%$ tween20). For neonatal experiments, $100 \mu$ l celecoxib or vehicle was administered by intragastric injection on P6,P7,P8,P9 and animals were sacrifice at P13. For adult experiments, males and females brain endothelial-specific conditional Pdcd10-null mice were randomized (by flipping a coin) to celecoxib (40 mg/Kg, celebrex) or vehicle 
treatment $(0.5 \%$ methylcellulose plus $0.025 \%$ tween 20$)$. Celecoxib or vehicle was administered by oral gavage administration for fifteen consecutive days P55 to P70 and animals were sacrifice at P80.

\section{Isolation of primary astrocytes}

$V_{e g f a} a^{\text {tm1.1Nagy }}$ mice or Hif-1 $\alpha^{f / f l}$ mice with transgenic mice expressing the tamoxifen-inducible recombinase CreERT2 under the control of the astrocyte Aldh1/1 promoter at postnatal day 5-7 were sacrificed, and their brains were isolated and placed into cold solution $A(0.5 \%$ bovine serum albumin (BSA) in DMEM and $1 \mu \mathrm{g} / \mu \mathrm{l}$ glucose, 10mM HEPES, 1x penicillin-streptomycin). Brain cortices were separated from the brain and rolled on dry filter paper to detach and remove the meninges. Cortices from 8-11 mice were pooled and minced with scissors in solution A, and the tissue was centrifuged at $215 \mathrm{~g}$ for 5 minutes at $4^{\circ} \mathrm{C}$. The tissue pellet was digested with a papain solution $(0.7 \mathrm{mg} / \mathrm{ml}$ papain suspension [LS003126; Worthington], 20units $/ \mathrm{ml}$ DNase I [11284932001; Sigma-Aldrich], and 0.150 $\mu \mathrm{g} / \mathrm{ml}$ tosyl-lysine-chloromethyl-ketone [T7254; SigmaAldrich]) at $37^{\circ} \mathrm{C}$ for $25 \mathrm{~min}$ with vigorous shaking every $10 \mathrm{~min}$. The tissue suspension was triturated using thin-tipped Pasteur pipettes until partially homogenous and centrifuged at $215 \mathrm{~g}$ for 5 minutes. The pellet was resuspended with solution B $(25 \%$ BSA in DMEM and $1 \mu \mathrm{g} / \mu \mathrm{lglucose}$, $10 \mathrm{mM}$ HEPES, $1 \mathrm{x}$ penicillin-streptomycin) and centrifuged at $1000 \mathrm{~g}$ for $20 \mathrm{~min}$ at $4^{\circ} \mathrm{C}$. The lighter phase containing astrocytes was extracted, resuspended in $50 \mathrm{ml}$ of solution C (DMEM-1 $1 \mu \mathrm{g} / \mu \mathrm{l}$ glucose, 10mM HEPES, 1x penicillin-streptomycin), and centrifuged at 215g for 10 minutes at $4^{\circ} \mathrm{C}$. The pellet was resuspended again in $50 \mathrm{ml}$ of solution $\mathrm{C}$ and centrifugation was repeated.

\section{Astrocyte culture conditions}

The purified primary astrocytes were plated on a Poly-L lysine-coated plate cultured in astrocyte media comprised of $1: 1$ Neurobasal media and DMEM $(1 \mu \mathrm{g} / \mu \mathrm{l}$ glucose) supplemented with the 
following: $0.1 \mathrm{mg} / \mathrm{ml} \mathrm{BSA,} 0.1 \mathrm{mg} / \mathrm{ml}$ transferrin, $0.016 \mathrm{mg} / \mathrm{ml}$ putrescine, $0.025 \mu \mathrm{g} / \mathrm{ml}$ progesterone, $0.016 \mu \mathrm{g} / \mathrm{ml}$ sodium selenite, $5 \mathrm{ng} / \mathrm{ml} \mathrm{H}-\mathrm{BEGF}, 5 \mu \mathrm{g} / \mathrm{ml}$-acetyl cysteine, $1 \mathrm{mM}$ sodium pyruvate, 1x penicillin-streptomycin, and $292 \mu \mathrm{g} / \mathrm{ml} \mathrm{L-glutamine(24).} \mathrm{The} \mathrm{primary} \mathrm{astrocyte} \mathrm{culture} \mathrm{identity}$ and purity were confirmed by GFAP and integrin $\beta 5$ immunofluorescence.

\section{Growth surface preparation}

Poly-L lysine (P8920-100ml, 0.1\% (w/v) in $\mathrm{H}_{2} 0$, Sigma-Aldrich) stock solution was diluted 1 in 10 in Hank's balanced salts solution plus calcium (HBSS+Ca) (14025092, Sigma-Aldrich) and left for $1 \mathrm{~h}$ at $37^{\circ} \mathrm{C}$ on the plastic surface of 6 -well plate format. Collagen type I (C8919, $0.1 \%(\mathrm{w} / \mathrm{v})$ in 0.1 $\mathrm{M}$ acetic acid) stock solution was diluted 1 in 20 in HBSS+Ca and left for $1 \mathrm{~h}$ at room temperature (RT) on the plastic surface of 6-well plate format. For experiments that used transwell polyester membrane inserts (0.4 $\mu \mathrm{m}$ pore, CLS3450 24mm or CLS3460 12mm diameter, Corning Costar), the filters were first coated with Poly-L lysine as described. Coating solutions were removed, and cells were seeded onto the plastic surface or inserts.

\section{Isolation of primary brain microvasculature endothelial cells}

Adult mice 2-4 months old were sacrificed, and brains were isolated and placed into cold solution A. Meninges and choroid plexus were detached and removed, and the brains of 5-6 mice were pooled together and minced with scissors in solution A. Brain tissue suspension was centrifuged at $215 \mathrm{~g}$ for 5 minutes at $4^{\circ} \mathrm{C}$. The tissue was digested with a collagenase/dispase solution (1mg/ml collagenase/dispase [10269638001; Sigma-Aldrich], 20 units/ml DNase I [11284932001; Sigma-Aldrich], and 0.150 $\mathrm{g} / \mathrm{ml}$ tosyl-lysine-chloromethyl-ketone [T7254; Sigma-Aldrich] in DMEM]) at $37^{\circ} \mathrm{C}$ for $1 \mathrm{~h}$ with vigorous shaking every $10 \mathrm{~min}$. Then the tissue suspension was triturated using thin-tipped Pasteur pipettes until fully homogenous and centrifuged at $215 \mathrm{~g}$ for 5 minutes. The pellet was resuspended in cold solution B and 
centrifuged at $1000 \mathrm{~g}$ for $20 \mathrm{~min}$ at $4^{\circ} \mathrm{C}$. The lighter phase was discarded and the heavy phase containing the brain microvasculature was digested in collagenase/dispase a second time for $30 \mathrm{~min}$ at $37^{\circ} \mathrm{C}$ with vigorous shaking every $10 \mathrm{~min}$. After incubation, the suspension was centrifuged ( $215 \mathrm{~g}$ for $5 \mathrm{~min}$ at $\left.4^{\circ} \mathrm{C}\right)$ and the pellet was resuspended in BMEC-media that comprised of EBM-2 medium (Lonza) supplemented with the following: $0.025 \%$ recombinant human EGF, $0.1 \%$ insulin-like growth factor, $0.1 \%$ gentamicin, $0.04 \%$ ascorbic acid, $0.04 \%$ hydrocortisone, and $20 \%$ FBS. The BMECs were plated in collagen-coated wells $(0.005 \%$ collagen in HBSS [C8919, Sigma-Aldrich]) and cultured in $10 \mu \mathrm{g} / \mathrm{ml}$ of puromycin for 2 days, followed by $2 \mu \mathrm{g} / \mathrm{ml}$ for 2 days(91). Primary BMEC culture identity and purity were confirmed by RNA expression levels of endothelial-specific genes, morphology, and immunofluorescence.

\section{Inactivation of Krit1 or Pdcd10 gene in primary BMECs}

After 5 days in culture at $37^{\circ} \mathrm{C}$ in $95 \%$ air and $5 \% \mathrm{CO}_{2}$, primary BMEC from mice bearing $P d c d 10^{f / f f l}$ or Pdgfb-iCreERT2;Pdcd10 ${ }^{f / f l}$ were passaged to equal confluency $\left(\sim 2.5 \times 10^{5}\right.$ cells $)$ on collagencoated 6-well plates. On day 6-7 from initial culture, Pdgfb-iCreERT2;Pdcd1 $10^{f / f l}$ BMECs were treated with $5 \mu \mathrm{M}$ of 4 -hydroxy-tamoxifen (H7904; Sigma-Aldrich) for $48 \mathrm{~h}$ to delete Pdcd10 $\left(P d c d 10^{E C K O}\right)$. Pdcd10 $0^{f / f l}$ BMECs were also treated with 4-hydroxy-tamoxifen and used as a control. The deletion of Pdcd10 in Pdcd10 ECKO BMECs was verified by RT-qPCR analysis. The medium was replaced with fresh BMEC-media (2.5 Isolation of primary brain microvasculature endothelial cells) and changed again every two days(91).

\section{Co-culture of BMECs and astrocytes}

$\operatorname{Pdcd} 10^{E C K O}$ and $P d c d 10^{f / f l}$ BMECs at passage 1-3 were plated on collagen-coated 6-well plates and maintained in BMEC-media for 15-20 days, while mouse primary astrocytes $\left(\sim 3.5 \times 10^{5}\right.$ cells) were seeded on poly-L-lysine coated transwell filters (3450; Sigma-Aldrich) and maintained in 
astrocyte-media. Astrocytes were maintained for 3 days before transwells were placed onto the BMEC wells containing astrocyte media supplemented with $500 \mu \mathrm{M}$ L-arginine. BMEC and astrocytes were maintained in co-culture for the time indicated in each experiment.

\section{Immunofluorescence microscopy}

Astrocytes were grown on poly-L-lysine coated 12-well transwell filters (CLS3460; Sigma-

Aldrich) or cover glasses (12-545-81; Thermo Fischer Scientific). For $\beta$-gal staining, cells were fixed for $5 \mathrm{~min}$ at RT in a $\beta$-gal fixation solution (5mM EGTA, $2.5 \mathrm{mM} \mathrm{MgCl}, 0.2 \%$

Glutaraldehyde, 1.3\% PFA in PBS) and washed for 5 min at RT with $\beta$-gal washing buffer (2mM $\mathrm{MgCl}_{2}, 0.02 \% \mathrm{NP}-40$ in PBS). A $\beta$-gal staining was performed at $37^{\circ} \mathrm{C}$ for $3 \mathrm{~h}$ in $0.02 \% \mathrm{X}-\mathrm{Gal}$, $5 \mathrm{mM} \mathrm{K}_{3} \mathrm{Fe}(\mathrm{CN})_{6}, 5 \mathrm{mM} \mathrm{K} \mathrm{Fe}_{4}(\mathrm{CN})_{6}, 2 \mathrm{mM} \mathrm{MgCl}_{2}$ in PBS. After staining, astrocytes were fixed again with 4\% PFA for 10 min at RT, pH 7.4, and permeabilized with $0.5 \%$ Triton X-100 in PBS for $5 \mathrm{~min}$. For astrocytes not undergoing $\beta$-gal staining, the cells were fixed for $10 \mathrm{~min}$ at $\mathrm{RT}$ with 4\% PFA in PBS, pH 7.4, and permeabilized with $0.5 \%$ Triton X-100 in PBS for 5 min. The cells were blocked with $0.5 \%$ BSA for $30 \mathrm{~min}$ and incubated with rat polyclonal antibodies anti-GFAP (1:80; 13-0300; Thermo Fischer Scientific), sheep polyclonal antibodies anti-IT $\beta 5$ (1:40, R\&D Systems), rabbit polyclonal antibodies anti-HIF-1 $\alpha$ (1:150; NB100-134; Novus Biologicals), and goat polyclonal antibodies anti-SOX-9 (1:40; AF3075; R\&D Systems) overnight at RT. Cells were washed four times with PBS and incubated with anti-rabbit Alexa Fluor 594, and anti-rat Alexa Fluor 488 secondary antibodies (1:300; Thermo Fischer Scientific) or anti-Goat Alexa Fluor 594, anti-rabbit Alexa fluor 488 secondary antibodies (1:300; Jackson ImmunoResearch) in PBS for $1 \mathrm{~h}$ at RT. Astrocyte nuclei were stained with DAPI and mounted with Fluoromount-G mounting medium (SouthernBiotech). Human tissue was obtained after informed consent from patients undergoing lesion resection, under protocol \#10- 295-A, approved by the University of Chicago Institutional Review Board. Human tissue, CCM lesions, and lesion-free brain tissues 
were snap-frozen and sectioning using a cryostat (Leica). Specimens were air dry for 15 min and fixed in 4\% PFA at room temperature for $15 \mathrm{~min}$ and washed three times in PBS. The specimens were blocked and permeabilized using permeabilization buffer for $2 \mathrm{~h}$ and incubated with rabbit polyclonal antibody anti-eNOS (1:200; PA1-037; Thermo Fisher Scientific) and goat polyclonal antibody anti-collagen IV (1:100, AB769; Millipore) in PBS at room temperature overnight. Preparations were washed four times in PBS and incubated at room temperature for $1 \mathrm{~h}$ with suitable secondary anti-rabbit Alexa Fluor 594 and anti-goat Alexa Fluor 488 antibodies (1:300; Thermo Fisher Scientific) in PBS. Cell nuclei were stained with DAPI (SouthernBiotech).

\section{Immunohistochemistry}

Brains from $P d c d 10^{E C K O}$ and littermate control $P d c d 10^{f / f f l}$ mice at postnatal day 10 were isolated and fixed in $4 \%$ PFA at $4^{\circ} \mathrm{C}$ overnight. After cryoprotection in $30 \%$ sucrose dissolved in PBS, brains were embedded and frozen in O.C.T compound (23-730-571; Fischer Scientific). Cerebellar tissues were cut into 12- $\mu \mathrm{m}$ coronal sections onto Superfrost Plus slides (12-550-15; VWE International). Sections were blocked and permeabilized in a permeabilization solution (0.5\% Triton $\mathrm{X}-100,5 \%$ goat serum, $0.5 \%$ BSA, in PBS) for $2 \mathrm{~h}$ and incubated in rabbit polyclonal antibodies against eNOS (1:200; PA1-037; Thermo Scientific), rabbit polyclonal antibodies against GFAP (1:250; GA524; Agilent Dako), mouse monoclonal antibody against MBP (1:500; SMI99; Biolegend), rat polyclonal antibodies against CD31 (1:80; 553370; BD Biosciences), rat monoclonal antibody against CD34 (1:100; 119302; Biolegend) in PBS at room temperature overnight. Preparations were washed one time in brain-Pblec buffer (PBS, 1mM $\mathrm{CaCl}_{2}, 1 \mathrm{mM} \mathrm{MgCl} 2,0.1 \mathrm{mM} \mathrm{MnCl}_{2}$, and $0.1 \%$ Triton X-100) and incubated with isolectin B4 FITC conjugated (1:80, L2895; Sigma-Aldrich) in brain-Pblec buffer at 4C overnight. Tissue sections were washed four times in PBS and incubated with suitable Alexa Fluor coupled secondary antibodies (1:300, Thermo Fischer Scientific) in PBS for $1 \mathrm{~h}$ at RT. Cell nuclei were 
stained with DAPI and mounted with Fluoromount-G mounting medium (SouthernBiotech). For $\beta$-gal staining, brains were fixed for $5 \mathrm{~min}$ at RT in PFA $2 \%$ and washed with PBS. After cryoprotection in 15\% sucrose dissolved in PBS, brains were embedded and frozen in O.C.T compound. A $\beta$-gal staining was performed at $37^{\circ} \mathrm{C}$ for $6 \mathrm{~h}$ in $0.02 \% \mathrm{X}-\mathrm{Gal}, 5 \mathrm{mM} \mathrm{K} \mathrm{F}_{3} \mathrm{Fe}(\mathrm{CN})_{6}$, $5 \mathrm{mM} \mathrm{K}_{4} \mathrm{Fe}(\mathrm{CN})_{6}, 2 \mathrm{mM} \mathrm{MgCl}_{2}$ in PBS and tissue sections were washed with cold PBS and fixed in 4\% PFA at RT for 30 min. Immunohistochemistry was performed after the $\beta$-gal staining. Except for immunohistochemistry for SOX-9 in which a $\beta$-gal staining was performed at $37^{\circ} \mathrm{C}$ for 3h followed by fixation with PFA $4 \%$ for 30 min at RT and incubation with unmasking antigen solution (927901; Biolegend). Sections were blocked and permeabilized in a permeabilization solution for $2 \mathrm{~h}$ and incubated in goat polyclonal antibodies against SOX-9 (1:40; AF3075; R\&D Systems) and rabbit polyclonal antibodies against GFAP (1:250; GA524; Agilent Dako) overnight at RT. Tissue sections were washed four times in PBS and incubated with suitable Alexa Fluor coupled secondary antibodies (1:300, Thermo Fischer Scientific) in PBS for $1 \mathrm{~h}$ at RT. The slides were viewed with a high-resolution SP8 confocal microscope (Leica Microsystems), and the images were captured with Leica application suite software (Leica Microsystems).

\section{In Situ Hybridisation}

Brains from $P d c d 10^{E C K O}$ and littermate control $P d c d 10^{f / f f l}$ mice at postnatal day 10 were isolated and fixed in $4 \%$ PFA at $4^{\circ} \mathrm{C}$ overnight. Brains were washed in cold RNAse free PBS and after cryoprotection in $30 \%$ sucrose dissolved in RNAse free PBS, brains were embedded and frozen in O.C.T compound (23-730-571; Fischer Scientific) and processed for in situ hybridization (ISH) as described previously(92). Immunohistochemistry was performed after the hybridization using rabbit polyclonal antibodies against GFAP (1:250; GA524; Agilent Dako) overnight at RT. Preparations were washed one time in brain-Pblec buffer and incubated with isolectin B4 FITC 
conjugated (1:80, L2895; Sigma-Aldrich) in Pblec buffer at 4C overnight. Tissue sections were washed four times in PBS and incubated with suitable Alexa Fluor coupled secondary antibodies (1:300, Thermo Fischer Scientific) in PBS for $1 \mathrm{~h}$ at RT.

\section{Western blot analysis}

BMECs were lysed using a solution containing $1 \mathrm{mM}$ sodium orthovanadate, protease inhibitor cocktail (11836170001; Roche), and $100 \mu \mathrm{L}$ of radioimmunoprecipitation assay buffer (Thermo Scientific). A Micro BCA protein assay kit (500-0116; Thermo Scientific) was used to determine the protein concentration and $25 \mu \mathrm{g}$ of cell lysates were heated for 5 minutes at $95^{\circ} \mathrm{C}$ to denature all proteins. The cell lysates were subjected to a $4 \%$ to $20 \%$ gradient sodium dodecyl sulfatepolyacrylamide gel electrophoresis (XP04200, Thermo Fischer Scientific) and a wet transfer was used to transfer proteins to nitrocellulose membranes (Amersham). Membranes were blocked for 1h at RT using a blocking solution (TBS 1x, 10\% nonfat milk), and polyclonal rabbit antibodies directed against eNOS (1:500; PA1-037; Thermo Scientific), HIF-1 $\alpha$ (1:150; NB100-134; Novus Biologicals) or monoclonal rabbit (1:100; 12282; Cell Signaling) and polyclonal goat (1:100; PA19032; ThermoFisher) antibodies directed against COX-2 were incubated at $4^{\circ} \mathrm{C}$ overnight. Several washes were performed and then the membranes were incubated with appropriate IRDye/Alexa Fluor-coupled secondary antibodies (1:10,000, 926-68070; 926-32211; Li-COR) for 1h at RT. A mouse monoclonal antibody against beta-actin (1:5000; A5441; Sigma-Aldrich) was used as a control for protein loading. Membranes were imaged and analyzed using Odyssey CLx Infrared Imaging (Li-COR).

\section{RNA isolation}

Total RNA from cultured astrocytes and BMECs were isolated by TRIzole as specified by the manufacturer's protocol (Thermo Fischer Scientific). Briefly, $1 \mathrm{ml}$ of TRIzole reagent was added 
per well. Cell homogenization was completed by pipetting up and down several times throughout the entire surface area where cells were growing. Cell lysates were transferred to Phase Lock Gel 2ml tubes (2302830; VWR). Then, 200 $\mu$ l of chloroform (ICN19400290; Thermo Fischer Scientific) was added to each tube and mixed vigorously for 15 seconds, followed by a 3-minute incubation at room temperature prior to centrifugation at $12,000 \mathrm{~g}$ for 15 minutes at $^{\circ} \mathrm{C}$. The aqueous phase containing RNA was collected and transferred to a $1.5 \mathrm{ml}$ DNAse/RNAse free microfuge tube. To precipitate the RNA, $500 \mu$ l of isopropanol was added, resuspended, and incubated for 10 minutes at room temperature followed by centrifugation at $12,000 \mathrm{~g}$ for 10 minutes at $4^{\circ} \mathrm{C}$. The supernatant was removed, and the pellet was washed with $1 \mathrm{ml}$ of $75 \%$ ethanol followed by centrifugation at $7,500 \mathrm{~g}$ for 5 minutes at $4^{\circ} \mathrm{C}$. The supernatant was removed, and the pellet was air-dried at room temperature and dissolved in $11 \mu \mathrm{l}-20 \mu \mathrm{l}$ of DNAse/RNAse free water. To determine the concentration and purity, $1 \mu$ of each sample was analyzed using UV spectrophotometry at 260 and $280 \mathrm{~nm}$ using NanoDrop 1000 Spectrophotometer.

\section{$R^{2}$-qPCR analysis}

10ng of total RNA was used to produce single-stranded complementary DNA (cDNA) using random primers according to the manufacturer's protocol $(48190011 ; 18080093$; Thermo Fischer Scientific). Briefly, 10ng of RNA was added to a master mix containing 1 X First-Strand buffer, $1 \mu l$ 0.1M DTT, $1 \mathrm{mM}$ dNTPs, $1 \mu$ RNaseOUT recombinant RNase inhibitor, SuperScript III reverse transcriptase, and $0.5 \mu \mathrm{g}$ random primers. The mixture was placed in a thermal cycler (C1000 Touch, Bio-Rad) at $25^{\circ} \mathrm{C}$ for 10 minutes, and then incubated at $50^{\circ} \mathrm{C}$ for 1 hour followed by inactivation of the reaction by heating at $70^{\circ} \mathrm{C}$ for 15 minutes. 300 ng of cDNA was run with the Kapa SybrFast qPCR mix (Kapa Biosystems) using $50 \mu \mathrm{M}$ of primers to distinguish between the relative levels of genes in each condition. The PCR reaction was placed in a thermal cycler (C1000 Touch, Bio-Rad) using an initial step at $95^{\circ} \mathrm{C}$ for 15 minutes, followed by 40 cycles (30sec 
at $95^{\circ} \mathrm{C}, 30 \mathrm{sec}$ at $55^{\circ} \mathrm{C}$, and $30 \mathrm{sec}$ at $72^{\circ} \mathrm{C}$ ). Analysis of the data was performed using the $2^{-\Delta \Delta \mathrm{CT}}$ method.

\section{NO Determination}

Pdcd $10^{E C K O}$ and Pdcd10 $0^{f / f l}$ BMECs were maintained in BMEC media supplemented with $500 \mu \mathrm{M}$ L-arginine and deficient in fetal bovine serum and ascorbic acid for 36 hours. Then, the BMEC media was collected, and a colorimetric total nitric oxide assay was performed as specified by manufacturers protocol (KGE001; R\&D Systems). 50 $\mu$ of undiluted BMEC media samples and nitrate $\left(\mathrm{NO}_{3}\right)$ standards ranging $100 \mu \mathrm{M}$ to $1.565 \mu \mathrm{M}$ were plated on clear polystyrene microplates (DY990; R\&D Systems). To measure total nitrites $\left(\mathrm{NO}_{2}\right)$ and nitrates, $25 \mu$ l of nitrate reductase and $25 \mu \mathrm{l}$ of $\mathrm{NADH}$ were added to each well to convert all available nitrates to nitrite. The plate was covered with an adhesive strip and incubated at $37^{\circ} \mathrm{C}$ for 30 minutes. After incubation, $50 \mu l$ of Griess reagent I and Griess reagent II were added to all wells and incubated at room temperature for 10 minutes. A two-step diazotization reaction occurs in which $\mathrm{NO}_{2}^{-}$reacts with sufanilic acid to produce a diazonium ion, which is then coupled to $\mathrm{N}$-(1-naphthyl) ethylenediamine to form an azo-derivative that absorbs light at 540nm. The optical density (O.D.) of each well was read using a microplate reader (Infinite 200 PRO, Tecan) at 540nm with a wavelength correction of $690 \mathrm{~nm}$. Duplicate readings were averaged and normalized to the blank. A standard curve was generated for each experiment by plotting optical density against concentration $(\mu \mathrm{M})$, and total nitrate/nitrite concentrations were determined using the linear trendline.

\section{Statistics}


Statistical analysis for single comparisons was performed using a two-tailed student's $t$-test and analysis for multiple comparisons was performed using ANOVA followed by Tukey's post hoc test. The threshold for statistical significance was set at a $p$-value of 0.05 .

\section{Study approval}

All animal experiments were performed in compliance with animal procedure protocols approved by the University of California, San Diego Institutional Animal Care and Use Committee.

Author contributions: M.A.L.R., S.I.S., P.H., C.C.L., performed and analyzed histology and gene expression experiments in culture and conditional knockout mice; S.I.S., P.H., C.C.L., Substantial contribution to manuscript preparation, writing, analysis of the data and generation of all figures; A.P., R.V., E.E., S.M., Performed histology and treatment of conditional knockout mice; R.G., T.M., R.L., N.H., I.A.A., Performed, analyzed, and interpreted the microCT studies and manuscript editing. S.M., O.P., G.G.H., R.D., Data discussion and manuscript editing; B.G., H.S., F.L., M.H.G., Substantial contribution to manuscript preparation, writing, and interpretation of data; M.AL.R. Designed the experiments, prepared the figures, and with M.H.G. performed overall study design to address the conceptual ideas, analysis and interpretation of the data, and writing of the manuscript.

Acknowledgments: The authors thank Angioma Alliance for providing human CCM specimens; Chelsea Hyun Ju Choi, Alyssa Castillo, Daniel Han and Maryum Haidari for technical assistance; Jennifer Santini and Marcy Erb for microscopy technical assistance; and the UCSD School of Medicine Microscopy Core. Funding: This work was supported by National Institutes of Health, National Heart, Lung, and Blood institute grants K01 HL133530, P01HL151433-01 (M.A.L.-R.), HL139947 (M.H.G.), National Institute of Neurological Disorders and Stroke grant, 
P01 NS092521 (M.H.G., I.A.A., R.G., R.L., N.H., T.M.). This work was also supported by Be

Brave for life foundation (M.A.L.-R.), Future Faculty of Cardiovascular Sciences (FOCUS)

PRIDE program (M.A.L.-R.), as well as by the UCSD School of Medicine Microscopy Core (P30 NS047101).

\section{References:}

1. Spiegler S, Rath M, Paperlein C, and Felbor U. Cerebral Cavernous Malformations: An Update on Prevalence, Molecular Genetic Analyses, and Genetic Counselling. Mol Syndromol. 2018;9(2):60-9.

2. Fischer A, Zalvide J, Faurobert E, Albiges-Rizo C, and Tournier-Lasserve E. Cerebral cavernous malformations: from CCM genes to endothelial cell homeostasis. Trends $\mathrm{Mol}$ Med. 2013;19(5):302-8.

3. Leblanc GG, Golanov E, Awad IA, Young WL, and Biology of Vascular Malformations of the Brain NWC. Biology of vascular malformations of the brain. Stroke. 2009;40(12):e694-702.

4. Gore AV, Lampugnani MG, Dye L, Dejana E, and Weinstein BM. Combinatorial interaction between CCM pathway genes precipitates hemorrhagic stroke. Dis Model Mech. 2008;1(4-5):275-81.

5. Choquet H, Pawlikowska L, Lawton MT, and Kim H. Genetics of cerebral cavernous malformations: current status and future prospects. J Neurosurg Sci. 2015;59(3):211-20.

6. Lopez-Ramirez MA, Fonseca G, Zeineddine HA, Girard R, Moore T, Pham A, et al. Thrombospondin1 (TSP1) replacement prevents cerebral cavernous malformations. $J$ Exp Med. 2017;214(11):3331-46.

7. Denier C, Labauge P, Bergametti F, Marchelli F, Riant F, Arnoult M, et al. Genotypephenotype correlations in cerebral cavernous malformations patients. Ann Neurol. 2006;60(5):550-6.

8. Mikati AG, Khanna O, Zhang L, Girard R, Shenkar R, Guo X, et al. Vascular permeability in cerebral cavernous malformations. J Cereb Blood Flow Metab. 2015;35(10):1632-9.

9. Lant B, Pal S, Chapman EM, Yu B, Witvliet D, Choi S, et al. Interrogating the ccm-3 Gene Network. Cell Rep. 2018;24(11):2857-68 e4.

10. Boulday G, Rudini N, Maddaluno L, Blecon A, Arnould M, Gaudric A, et al. Developmental timing of CCM2 loss influences cerebral cavernous malformations in mice. J Exp Med. 2011;208(9):1835-47.

11. Zhou HJ, Qin L, Zhang H, Tang W, Ji W, He Y, et al. Endothelial exocytosis of angiopoietin-2 resulting from CCM3 deficiency contributes to cerebral cavernous malformation. Nat Med. 2016;22(12):1502.

12. Chan AC, Drakos SG, Ruiz OE, Smith AC, Gibson CC, Ling J, et al. Mutations in 2 distinct genetic pathways result in cerebral cavernous malformations in mice. J Clin Invest. 2011;121(5):1871-81.

13. Zhou Z, Tang AT, Wong WY, Bamezai S, Goddard LM, Shenkar R, et al. Corrigendum: Cerebral cavernous malformations arise from endothelial gain of MEKK3-KLF2/4 signalling. Nature. 2016;536(7617):488.

14. McDonald DA, Shenkar R, Shi C, Stockton RA, Akers AL, Kucherlapati MH, et al. A novel mouse model of cerebral cavernous malformations based on the two-hit mutation hypothesis recapitulates the human disease. Hum Mol Genet. 2011;20(2):211-22. 
15. Akers AL, Johnson E, Steinberg GK, Zabramski JM, and Marchuk DA. Biallelic somatic and germline mutations in cerebral cavernous malformations (CCMs): evidence for a two-hit mechanism of CCM pathogenesis. Hum Mol Genet. 2009;18(5):919-30.

16. Chapman EM, Lant B, Ohashi Y, Yu B, Schertzberg M, Go C, et al. A conserved CCM complex promotes apoptosis non-autonomously by regulating zinc homeostasis. Nat Commun. 2019;10(1):1791.

17. Louvi A, Chen L, Two AM, Zhang H, Min W, and Gunel M. Loss of cerebral cavernous malformation $3(\mathrm{Ccm} 3)$ in neuroglia leads to $\mathrm{CCM}$ and vascular pathology. Proc Natl Acad Sci U S A. 2011;108(9):3737-42.

18. Finetti F, Schiavo I, Ercoli J, Zotta A, Boda E, Retta SF, et al. KRIT1 loss-mediated upregulation of NOX1 in stromal cells promotes paracrine pro-angiogenic responses. Cell Signal. 2020;68:109527.

19. Choquet H, Trapani E, Goitre L, Trabalzini L, Akers A, Fontanella M, et al. Cytochrome P450 and matrix metalloproteinase genetic modifiers of disease severity in Cerebral Cavernous Malformation type 1. Free Radic Biol Med. 2016;92:100-9.

20. Tanriover G, Boylan AJ, Diluna ML, Pricola KL, Louvi A, and Gunel M. PDCD10, the gene mutated in cerebral cavernous malformation 3 , is expressed in the neurovascular unit. Neurosurgery. 2008;62(4):930-8; discussion 8.

21. Daneman R, and Prat A. The blood-brain barrier. Cold Spring Harb Perspect Biol. 2015;7(1):a020412.

22. Weiss N, Miller F, Cazaubon S, and Couraud PO. The blood-brain barrier in brain homeostasis and neurological diseases. Biochim Biophys Acta. 2009;1788(4):842-57.

23. Alvarez JI, Dodelet-Devillers A, Kebir H, Ifergan I, Fabre PJ, Terouz S, et al. The Hedgehog pathway promotes blood-brain barrier integrity and CNS immune quiescence. Science. 2011;334(6063):1727-31.

24. Liddelow SA, Guttenplan KA, Clarke LE, Bennett FC, Bohlen CJ, Schirmer L, et al. Neurotoxic reactive astrocytes are induced by activated microglia. Nature. 2017;541(7638):481-7.

25. Hamby ME, and Sofroniew MV. Reactive astrocytes as therapeutic targets for CNS disorders. Neurotherapeutics. 2010;7(4):494-506.

26. Argaw AT, Asp L, Zhang J, Navrazhina K, Pham T, Mariani JN, et al. Astrocyte-derived VEGF-A drives blood-brain barrier disruption in CNS inflammatory disease. J Clin Invest. 2012;122(7):2454-68.

27. Vangeison G, and Rempe DA. The Janus-faced effects of hypoxia on astrocyte function. Neuroscientist. 2009;15(6):579-88.

28. Chapouly C, Tadesse Argaw A, Horng S, Castro K, Zhang J, Asp L, et al. Astrocytic TYMP and VEGFA drive blood-brain barrier opening in inflammatory central nervous system lesions. Brain. 2015;138(Pt 6):1548-67.

29. Maiuri F, Cappabianca P, Gangemi M, De Caro Mdel B, Esposito F, Pettinato G, et al. Clinical progression and familial occurrence of cerebral cavernous angiomas: the role of angiogenic and growth factors. Neurosurg Focus. 2006;21(1):e3.

30. Jung KH, Chu K, Jeong SW, Park HK, Bae HJ, and Yoon BW. Cerebral cavernous malformations with dynamic and progressive course: correlation study with vascular endothelial growth factor. Arch Neurol. 2003;60(11):1613-8.

31. Abe T, Morishige M, Ooba H, Kamida T, Fujiki M, Kobayashi $H$, et al. The association between high VEGF levels and multiple probable punctuate cavernous malformations. Acta Neurochir (Wien). 2009;151(7):855-9.

32. Girard R, Zeineddine HA, Koskimaki J, Fam MD, Cao Y, Shi C, et al. Plasma Biomarkers of Inflammation and Angiogenesis Predict Cerebral Cavernous Malformation Symptomatic Hemorrhage or Lesional Growth. Circ Res. 2018;122(12):1716-21. 
33. Argaw AT, Gurfein BT, Zhang Y, Zameer A, and John GR. VEGF-mediated disruption of endothelial CLN-5 promotes blood-brain barrier breakdown. Proc Natl Acad Sci U S A. 2009;106(6):1977-82.

34. Cheng SY, Nagane M, Huang HS, and Cavenee WK. Intracerebral tumor-associated hemorrhage caused by overexpression of the vascular endothelial growth factor isoforms VEGF121 and VEGF165 but not VEGF189. Proc Natl Acad Sci U S A. 1997;94(22):12081-7.

35. Josko J. Cerebral angiogenesis and expression of VEGF after subarachnoid hemorrhage (SAH) in rats. Brain Res. 2003;981(1-2):58-69.

36. Awad IA, and Polster SP. Cavernous angiomas: deconstructing a neurosurgical disease. J Neurosurg. 2019;131(1):1-13.

37. Lopez-Ramirez MA, Pham A, Girard R, Wyseure T, Hale P, Yamashita A, et al. Cerebral cavernous malformations form an anticoagulant vascular domain in humans and mice. Blood. 2019;133(3):193-204.

38. DiStefano PV, Kuebel JM, Sarelius IH, and Glading AJ. KRIT1 protein depletion modifies endothelial cell behavior via increased vascular endothelial growth factor (VEGF) signaling. J Biol Chem. 2014;289(47):33054-65.

39. Dimmeler S, Fleming I, Fisslthaler B, Hermann C, Busse R, and Zeiher AM. Activation of nitric oxide synthase in endothelial cells by Akt-dependent phosphorylation. Nature. 1999;399(6736):601-5.

40. Fulton D, Gratton JP, McCabe TJ, Fontana J, Fujio Y, Walsh K, et al. Regulation of endothelium-derived nitric oxide production by the protein kinase Akt. Nature. 1999;399(6736):597-601.

41. Fukumura D, Gohongi T, Kadambi A, Izumi Y, Ang J, Yun CO, et al. Predominant role of endothelial nitric oxide synthase in vascular endothelial growth factor-induced angiogenesis and vascular permeability. Proc Natl Acad Sci U S A. 2001;98(5):2604-9.

42. Jozkowicz A, Cooke JP, Guevara I, Huk I, Funovics P, Pachinger O, et al. Genetic augmentation of nitric oxide synthase increases the vascular generation of VEGF. Cardiovasc Res. 2001;51(4):773-83.

43. Zhang R, Wang L, Zhang L, Chen J, Zhu Z, Zhang Z, et al. Nitric oxide enhances angiogenesis via the synthesis of vascular endothelial growth factor and cGMP after stroke in the rat. Circ Res. 2003;92(3):308-13.

44. Cuttano R, Rudini N, Bravi L, Corada M, Giampietro C, Papa E, et al. KLF4 is a key determinant in the development and progression of cerebral cavernous malformations. EMBO Mol Med. 2016;8(1):6-24.

45. Renz M, Otten C, Faurobert E, Rudolph F, Zhu Y, Boulday G, et al. Regulation of beta1 integrin-KIf2-mediated angiogenesis by CCM proteins. Dev Cell. 2015;32(2):181-90.

46. Leto K, Arancillo M, Becker EB, Buffo A, Chiang C, Ding B, et al. Consensus Paper: Cerebellar Development. Cerebellum. 2016;15(6):789-828.

47. Faulkner JR, Herrmann JE, Woo MJ, Tansey KE, Doan NB, and Sofroniew MV. Reactive astrocytes protect tissue and preserve function after spinal cord injury. $J$ Neurosci. 2004;24(9):2143-55.

48. Anderson MA, Burda JE, Ren Y, Ao Y, O'Shea TM, Kawaguchi R, et al. Astrocyte scar formation aids central nervous system axon regeneration. Nature. 2016;532(7598):195200.

49. Girard R, Zeineddine HA, Orsbon C, Tan H, Moore T, Hobson N, et al. Micro-computed tomography in murine models of cerebral cavernous malformations as a paradigm for brain disease. J Neurosci Methods. 2016;271:14-24.

50. Miquerol L, Gertsenstein M, Harpal K, Rossant J, and Nagy A. Multiple developmental roles of VEGF suggested by a LacZ-tagged allele. Dev Biol. 1999;212(2):307-22. 
51. Scott A, Powner MB, Gandhi P, Clarkin C, Gutmann DH, Johnson RS, et al. Astrocytederived vascular endothelial growth factor stabilizes vessels in the developing retinal vasculature. PLoS One. 2010;5(7):e11863.

52. Malinverno M, Maderna C, Abu Taha A, Corada M, Orsenigo F, Valentino M, et al. Endothelial cell clonal expansion in the development of cerebral cavernous malformations. Nat Commun. 2019;10(1):2761.

53. Cardoso C, Arnould M, De Luca C, Otten C, Abdelilah-Seyfried S, Heredia A, et al. Novel Chronic Mouse Model of Cerebral Cavernous Malformations. Stroke. 2020;51(4):1272-8.

54. Detter MR, Shenkar R, Benavides CR, Neilson CA, Moore T, Lightle R, et al. Novel Murine Models of Cerebral Cavernous Malformations. Angiogenesis. 2020;23(4):651-66.

55. Matthew R Detter RS, Christian R Benavides, Catherine A Neilson, Thomas, and Moore RL, Nicholas Hobson, Le Shen , Ying Cao, Romuald Girard, Dongdong Zhang, Erin Griffin, Carol J Gallione, Issam A Awad, and Douglas A Marchuk. Novel hemorrhage models of cerebral cavernous malformations. bioRxiv. 2020.

56. Majmundar AJ, Wong WJ, and Simon MC. Hypoxia-inducible factors and the response to hypoxic stress. Mol Cell. 2010;40(2):294-309.

57. Semenza GL. Hypoxia-inducible factor 1: oxygen homeostasis and disease pathophysiology. Trends Mol Med. 2001;7(8):345-50.

58. Benita $Y$, Kikuchi $H$, Smith $A D$, Zhang $M Q$, Chung DC, and Xavier RJ. An integrative genomics approach identifies Hypoxia Inducible Factor-1 (HIF-1)-target genes that form the core response to hypoxia. Nucleic Acids Res. 2009;37(14):4587-602.

59. Kaidi A, Qualtrough D, Williams AC, and Paraskeva C. Direct transcriptional upregulation of cyclooxygenase-2 by hypoxia-inducible factor (HIF)-1 promotes colorectal tumor cell survival and enhances HIF-1 transcriptional activity during hypoxia. Cancer Res. 2006;66(13):6683-91.

60. Simon MC. The Hypoxia Response Pathways - Hats Off! N Engl J Med. 2016;375(17):1687-9.

61. Koskimaki J, Girard R, Li Y, Saadat L, Zeineddine HA, Lightle R, et al. Comprehensive transcriptome analysis of cerebral cavernous malformation across multiple species and genotypes. JCI Insight. 2019;4(3).

62. Hamik A, Lin Z, Kumar A, Balcells M, Sinha S, Katz J, et al. Kruppel-like factor 4 regulates endothelial inflammation. J Biol Chem. 2007;282(18):13769-79.

63. SenBanerjee S, Lin Z, Atkins GB, Greif DM, Rao RM, Kumar A, et al. KLF2 Is a novel transcriptional regulator of endothelial proinflammatory activation. J Exp Med. 2004;199(10):1305-15.

64. Ridder DA, Lang MF, Salinin S, Roderer JP, Struss M, Maser-Gluth C, et al. TAK1 in brain endothelial cells mediates fever and lethargy. J Exp Med. 2011;208(13):2615-23.

65. Abe M, Fukudome K, Sugita Y, Oishi T, Tabuchi K, and Kawano T. Thrombus and encapsulated hematoma in cerebral cavernous malformations. Acta Neuropathol. 2005;109(5):503-9.

66. Bardehle S, Kruger M, Buggenthin F, Schwausch J, Ninkovic J, Clevers H, et al. Live imaging of astrocyte responses to acute injury reveals selective juxtavascular proliferation. Nat Neurosci. 2013;16(5):580-6.

67. Anderson MA, Ao Y, and Sofroniew MV. Heterogeneity of reactive astrocytes. Neurosci Lett. 2014;565:23-9.

68. Rothhammer V, Borucki DM, Tjon EC, Takenaka MC, Chao CC, Ardura-Fabregat A, et al. Microglial control of astrocytes in response to microbial metabolites. Nature. 2018;557(7707):724-8.

69. Cirino G, Fiorucci S, and Sessa WC. Endothelial nitric oxide synthase: the Cinderella of inflammation? Trends Pharmacol Sci. 2003;24(2):91-5. 
70. Lin S, Fagan KA, Li KX, Shaul PW, Cooper DM, and Rodman DM. Sustained endothelial nitric-oxide synthase activation requires capacitative $\mathrm{Ca} 2+$ entry. J Biol Chem. 2000;275(24):17979-85.

71. Kimura $\mathrm{H}$, and Esumi $\mathrm{H}$. Reciprocal regulation between nitric oxide and vascular endothelial growth factor in angiogenesis. Acta Biochim Pol. 2003;50(1):49-59.

72. Schulz GB, Wieland E, Wustehube-Lausch J, Boulday G, Moll I, Tournier-Lasserve E, et al. Cerebral Cavernous Malformation-1 Protein Controls DLL4-Notch3 Signaling Between the Endothelium and Pericytes. Stroke. 2015;46(5):1337-43.

73. Stamatovic SM, Sladojevic N, Keep RF, and Andjelkovic AV. PDCD10 (CCM3) regulates brain endothelial barrier integrity in cerebral cavernous malformation type 3: role of CCM3-ERK1/2-cortactin cross-talk. Acta Neuropathol. 2015;130(5):731-50.

74. Engelhardt S, Patkar S, and Ogunshola OO. Cell-specific blood-brain barrier regulation in health and disease: a focus on hypoxia. Br J Pharmacol. 2014;171(5):1210-30.

75. Shi Q, Liu X, Wang N, Zheng X, Fu J, and Zheng J. Nitric oxide from brain microvascular endothelial cells may initiate the compensatory response to mild hypoxia of astrocytes in a hypoxia-inducible factor-1alpha dependent manner. Am J Transl Res. 2016;8(11):4735-49.

76. Brix B, Mesters JR, Pellerin L, and Johren O. Endothelial cell-derived nitric oxide enhances aerobic glycolysis in astrocytes via HIF-1alpha-mediated target gene activation. J Neurosci. 2012;32(28):9727-35.

77. Metzen E, Zhou J, Jelkmann W, Fandrey J, and Brune B. Nitric oxide impairs normoxic degradation of HIF-1alpha by inhibition of prolyl hydroxylases. Mol Biol Cell. 2003;14(8):3470-81.

78. Palmer LA, Gaston B, and Johns RA. Normoxic stabilization of hypoxia-inducible factor1 expression and activity: redox-dependent effect of nitrogen oxides. Mol Pharmacol. 2000;58(6):1197-203.

79. Schleicher M, Yu J, Murata T, Derakhshan B, Atochin D, Qian L, et al. The Akt1-eNOS axis illustrates the specificity of kinase-substrate relationships in vivo. Sci Signal. 2009;2(82):ra41.

80. Chakraborty A, Kamermans A, van Het Hof B, Castricum K, Aanhane E, van Horssen J, et al. Angiopoietin like-4 as a novel vascular mediator in capillary cerebral amyloid angiopathy. Brain. 2018;141(12):3377-88.

81. Katanasaka Y, Kodera Y, Kitamura Y, Morimoto T, Tamura T, and Koizumi F. Epidermal growth factor receptor variant type III markedly accelerates angiogenesis and tumor growth via inducing c-myc mediated angiopoietin-like 4 expression in malignant glioma. Mol Cancer. 2013;12:31.

82. Iniguez MA, Rodriguez A, Volpert OV, Fresno M, and Redondo JM. Cyclooxygenase-2: a therapeutic target in angiogenesis. Trends Mol Med. 2003;9(2):73-8.

83. Gately S, and Li WW. Multiple roles of COX-2 in tumor angiogenesis: a target for antiangiogenic therapy. Semin Oncol. 2004;31(2 Suppl 7):2-11.

84. Flemming KD, Kumar S, Brown RD, Jr., and Lanzino G. Predictors of Initial Presentation with Hemorrhage in Patients with Cavernous Malformations. World Neurosurg. 2020;133:e767-e73.

85. Polster SP, Cao Y, Carroll T, Flemming K, Girard R, Hanley D, et al. Trial Readiness in Cavernous Angiomas With Symptomatic Hemorrhage (CASH). Neurosurgery. 2019;84(4):954-64.

86. Jones MK, Wang H, Peskar BM, Levin E, Itani RM, Sarfeh IJ, et al. Inhibition of angiogenesis by nonsteroidal anti-inflammatory drugs: insight into mechanisms and implications for cancer growth and ulcer healing. Nat Med. 1999;5(12):1418-23.

87. Majima M, Hayashi I, Muramatsu M, Katada J, Yamashina S, and Katori M. Cyclooxygenase-2 enhances basic fibroblast growth factor-induced angiogenesis through 
induction of vascular endothelial growth factor in rat sponge implants. $\mathrm{Br} \mathrm{J}$ Pharmacol. 2000;130(3):641-9.

88. Xu L, Stevens J, Hilton MB, Seaman S, Conrads TP, Veenstra TD, et al. COX-2 inhibition potentiates antiangiogenic cancer therapy and prevents metastasis in preclinical models. Sci Transl Med. 2014;6(242):242ra84.

89. Bravi L, Rudini N, Cuttano R, Giampietro C, Maddaluno L, Ferrarini L, et al. Sulindac metabolites decrease cerebrovascular malformations in CCM3-knockout mice. Proc Natl Acad Sci U S A. 2015;112(27):8421-6.

90. Claxton S, Kostourou V, Jadeja S, Chambon P, Hodivala-Dilke K, and Fruttiger M. Efficient, inducible Cre-recombinase activation in vascular endothelium. Genesis. 2008;46(2):74-80.

91. Hale P, Soliman, S.I., Sun, H., Lopez-Ramirez, MA. Isolation and purification of mouse brain endothelial cells to study Cerebral Cavernous Malformation disease. Springer Nature; 2020.

92. Lopez-Ramirez MA, Wu D, Pryce G, Simpson JE, Reijerkerk A, King-Robson J, et al. MicroRNA-155 negatively affects blood-brain barrier function during neuroinflammation. FASEB J. 2014;28(6):2551-65.

\section{Figures:}




\section{Figure1}
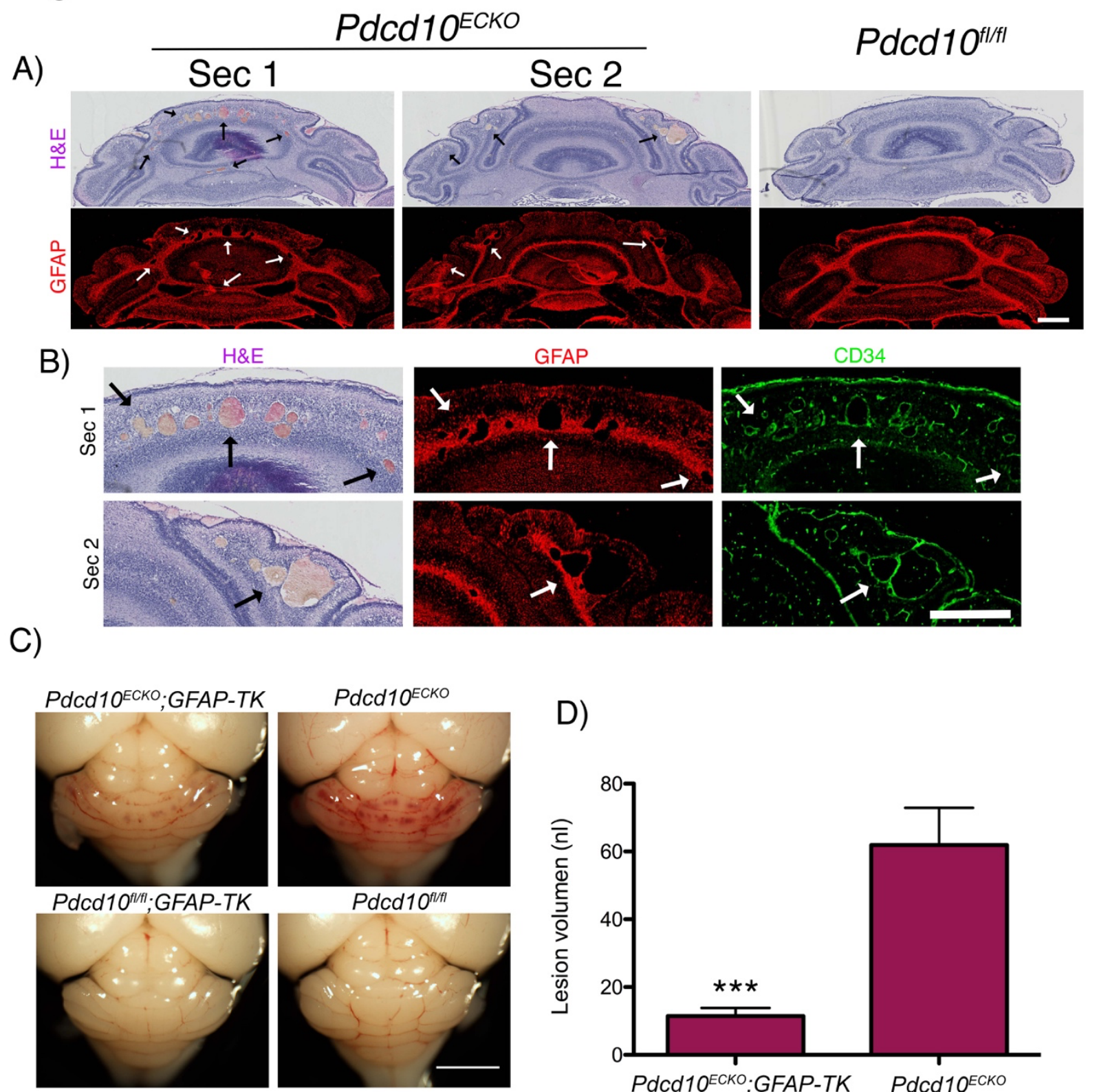

D)

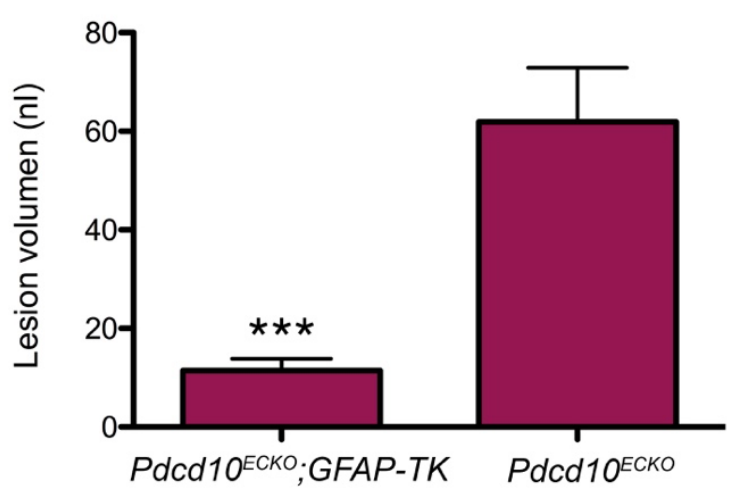

Fig 1. Astrocytes contribute to cerebral cavernous malformations development. (A)Histological analysis of cerebellar sections from P9 Pdcd10 ECKO and littermate control Pdcd $10^{f / f f}$ mice. Low magnification of CCM lesions detected in sections stained by hematoxylin and eosin. CCM lesions spatially developed on fibrous astrocyte areas positive for GFAP immunostaining (red). Arrows indicate CCM lesions. (B) Magnified region from section 1 and 2 (Sec1 and Sec2) from $P d c d 10^{E C K O}$ mice in $A$, dramatic vascular dilation is shown with immunohistochemistry for the endothelial marker CD34 (green). Arrows indicate CCM lesions. (C) Administration of $1.5 \mathrm{mg} / \mathrm{Kg}$ of GCV in neonatal at P7 markedly reduced vascular lesions in P9 
Pdcd10ECKO;GFAP-TK hindbrains when compared with GCV-treated littermate Pdcd10 ECKO control. (D) Quantification of lesion volumes by micro-CT analysis from mice in experiments showed in $C$. $n=8$ or 9 mice in each group. Data are mean \pm SEM. ${ }^{* * *}, P<0.001$; determine by Student's $t$ test. Scale bars: (A and B) $500 \mu \mathrm{m}$; (C) $2 \mathrm{~mm}$.

Figure 2

A)

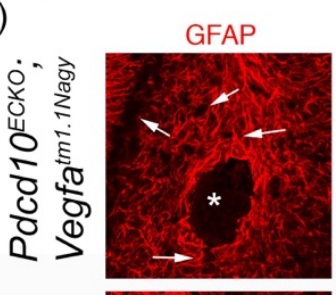
b-Gal-VEGF
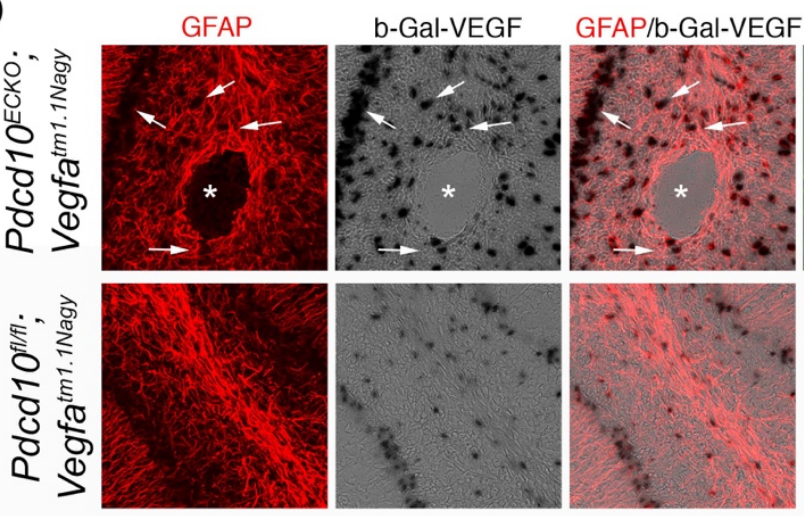

B)
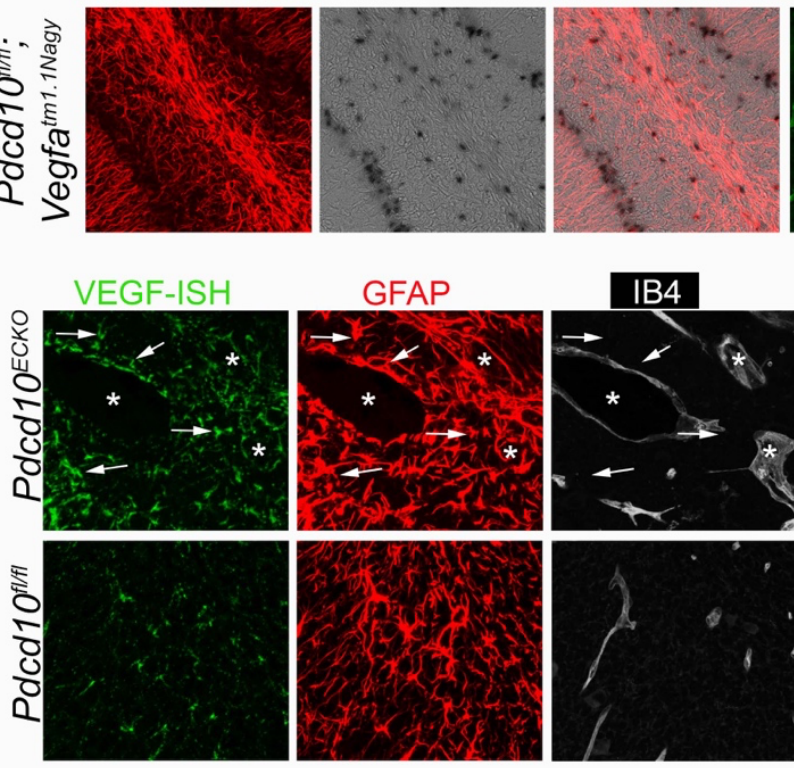

VEGF-ISH

C)
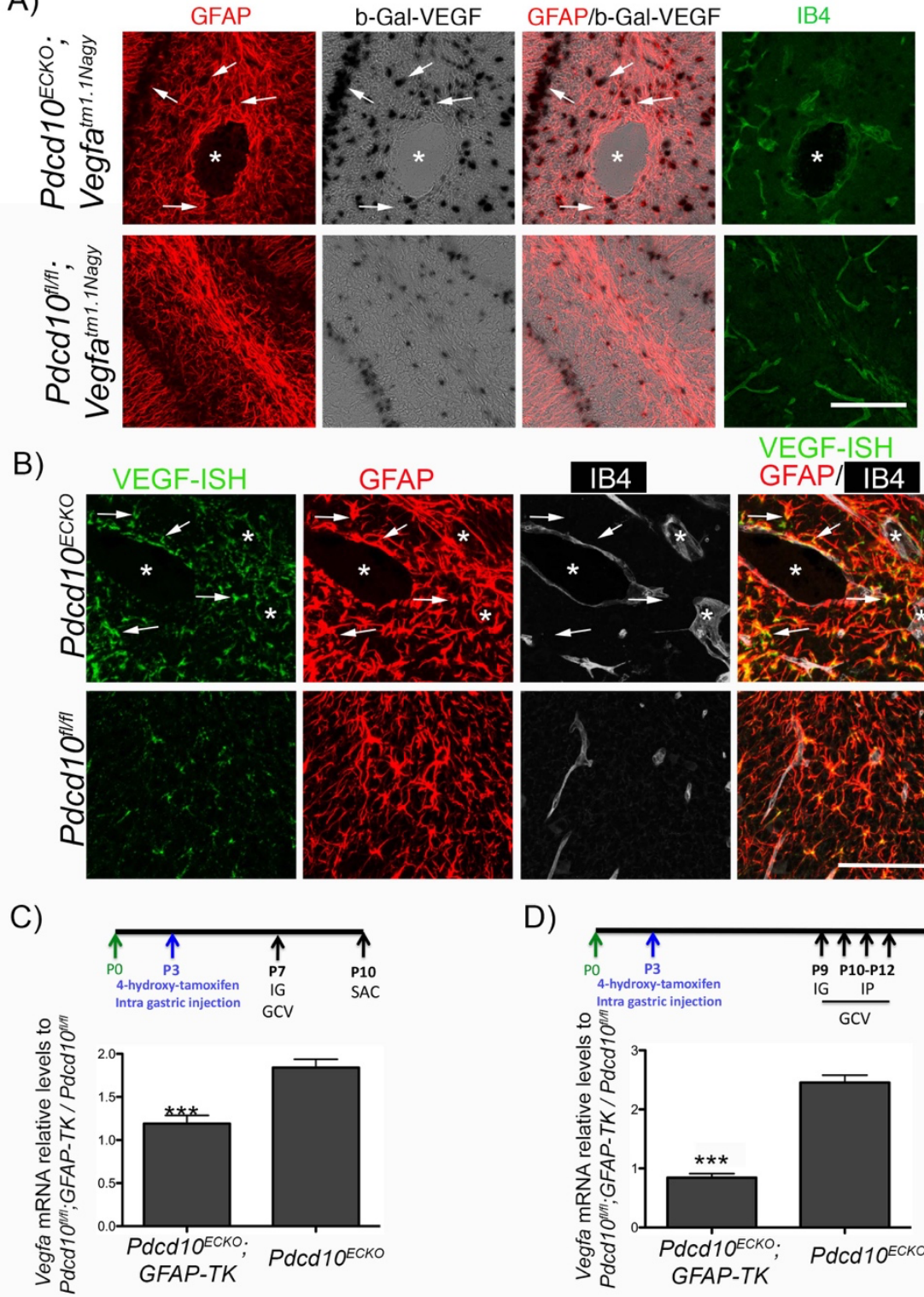

D)
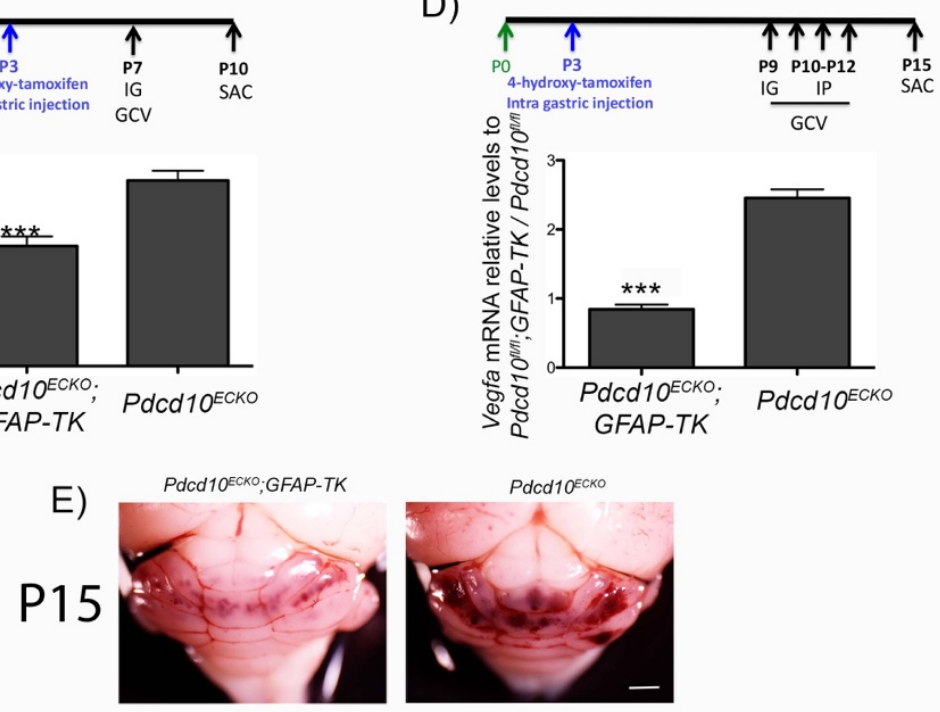

Fig 2. Astrocyte-derived VEGF increased during cerebral cavernous malformations development. (A) Confocal microscopy of cerebellar cortex from P10 Pdcd10 ECKO and littermate control Pdcd10 $0^{f / f l}$ mice stained for GFAP-positive astrocytes (red), $\beta$-gal/VEGF expression 
detected by X-gal staining (black), endothelial marker isolectin B4 (green). Asterisk, vascular lumen of CCM lesion. Arrows indicate $\beta$-gal/VEGF in GFAP-positive astrocytes $(n=4)$. (B) ISH for VEGF (green) combined with immunohistochemistry to identify GFAP-positive astrocytes (red), endothelial marker isolectin B4 (IB4; white). Asterisk, vascular lumen of CCM lesion. Arrows indicate VEGF and GFAP-positive astrocytes co-localization $(n=2)$. (C) Quantification of Vegfa mRNA levels n P10 Pdcd10 ECKO;GFAP-TK and Pdcd10ECKO hindbrains when compared with littermate $P d c d 10^{f / f / l}$;GFAP-TK or Pdcd1 $10^{f / / f l}$ control respectively, as assessed by RT-qPCR. All mice received IG administration of $1.5 \mathrm{mg} / \mathrm{Kg}$ of GCV in neonatal at P7 (SEM, $n=6$ mice in each group). (D) Quantification of Vegfa mRNA levels in P15 Pdcd10ECKO;GFAP-TK and Pdcd10 ECKO hindbrains when compared with littermate $P d c d 10^{f / f f l}$;GFAP-TK or Pdcd1 $0^{f / f f l}$ control respectively, as assessed by RT-qPCR. All mice received IG administration of $1.5 \mathrm{mg} / \mathrm{Kg}$ of GCV in neonatal at P9 and three consecutive doses (P10 to P12) of IP $1.5 \mathrm{mg} / \mathrm{Kg}$ of GCV (SEM, $n=5$ or 6 mice in each group). (E) Prominent lesions are present in the cerebellum of $\mathrm{P} 15 \mathrm{GCV}$-treated $P d c d 10^{E C K O}$ mice, whereas extensive reduction in lesions are observed in GCV-treated Pdcd $10^{E C K O}$;GFAP-TK mice littermate $\left(\mathrm{n}=6\right.$ or 7 ). Data are mean \pm SEM. ${ }^{* * *}, \mathrm{P}<0.001$ (comparison to $P d c d 10^{E C K O}$ littermates); determine by Student's $t$ test. Scale bars: (A, and B) $100 \mu \mathrm{m}$. 


\section{Figure 3}
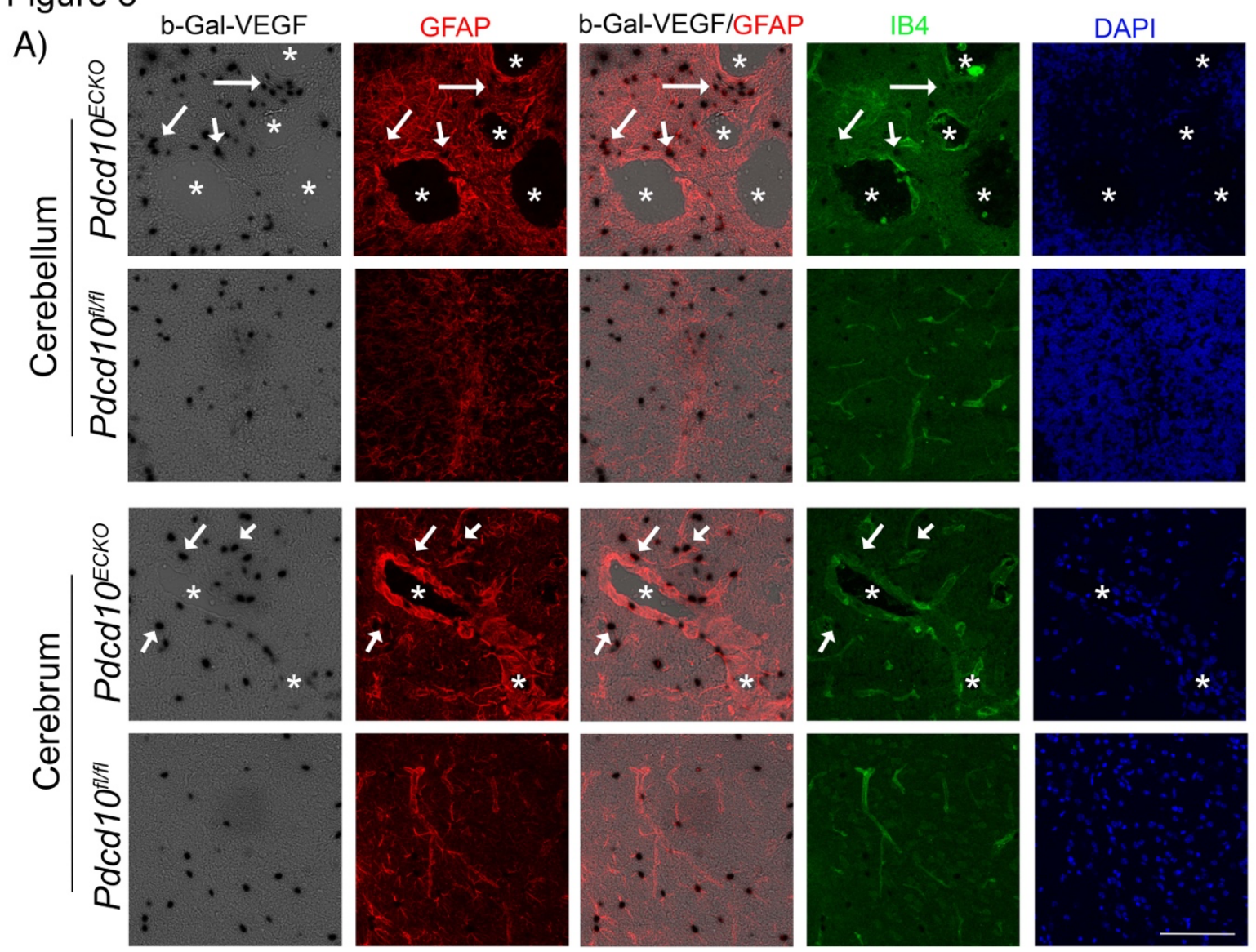

B)
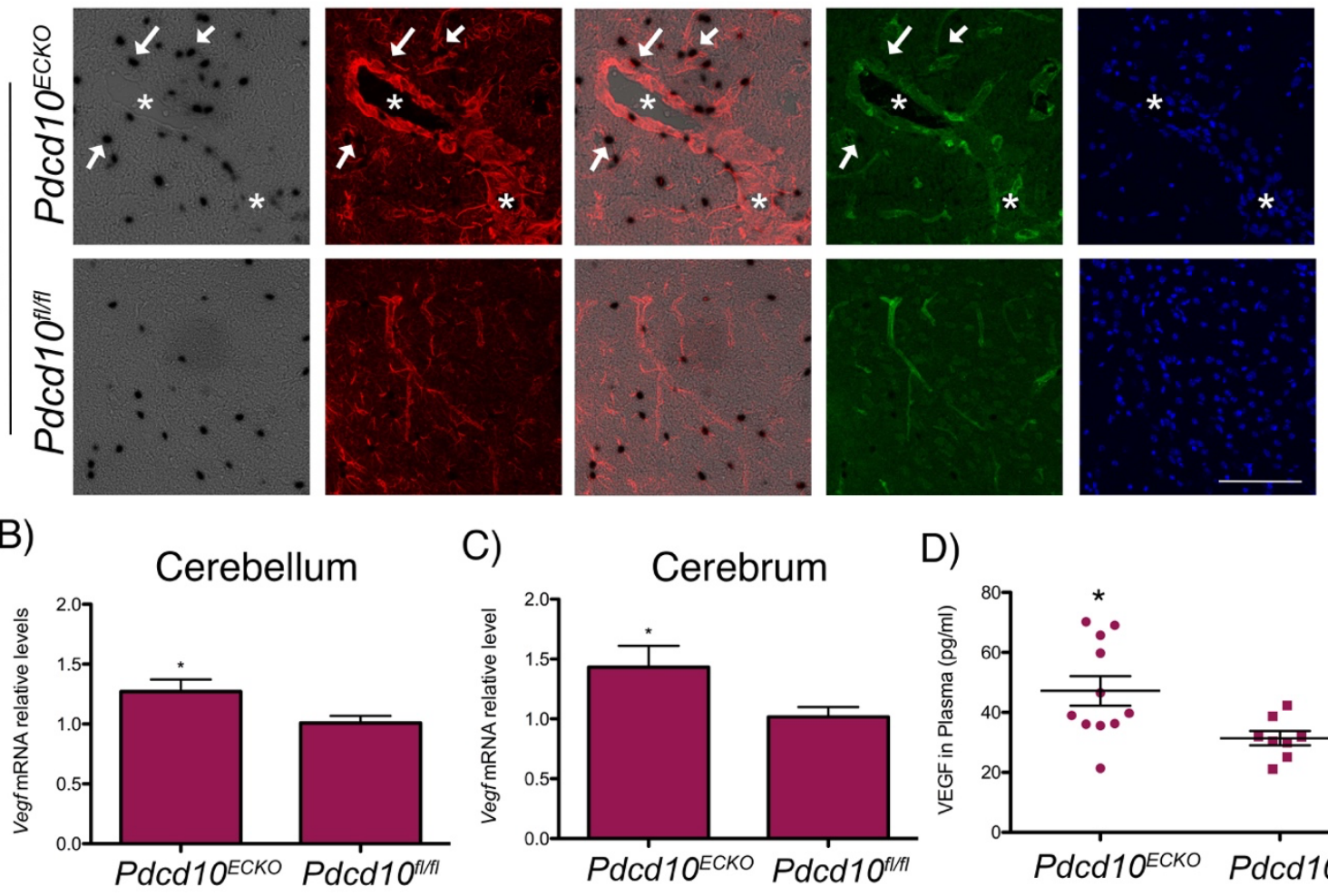

C)

Cerebrum

D)
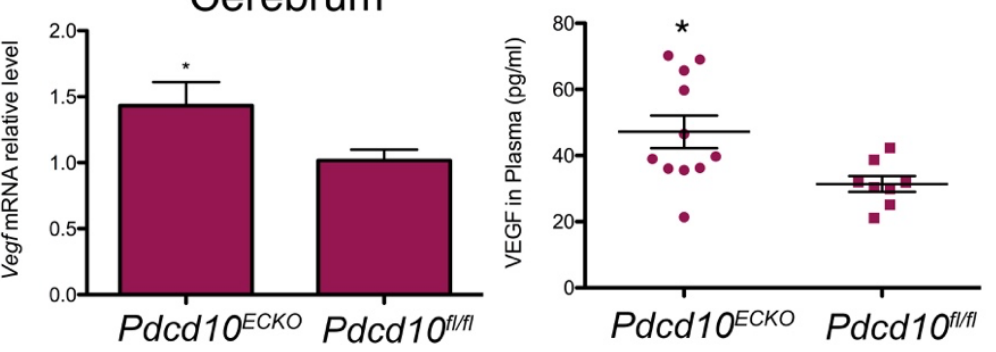

Fig 3. Astrocyte-derived VEGF increased during cerebral cavernous malformations in juvenile animal brain. (A) Confocal microscopy of brain (cerebellum and cerebrum cortex) from $P d c d 10^{E C K O} ; V e g f a^{t m 1.1 N a g y}$ and Pdcd10 $0^{t / f t} ;$ Vegfat ${ }^{t m 1.1 N a g y}$ littermate control stained for $\beta$-gal/VEGF expression detected by X-gal staining (black), GFAP-positive astrocytes (red), isolectin B4 (green), and DAPI for nuclear DNA (blue). Asterisks, vascular lumen of CCM lesions. Arrows indicate $\beta-$ gal/VEGF in GFAP-positive astrocytes. (B-C) Quantification of Vegfa mRNA levels in Pdcd10 ECKO brains when compared with littermate Pdcd1 $0^{f / f t}$ control, as assessed by RT-qPCR (SEM, $n=4$ or 6 mice in each group). (D) VEGF levels in plasma from $P d c d 10^{E C K O}$ mice and littermate $P d c d 10^{f / f t}$ controls, as assessed by ELISA. $n=8$ or 11 mice in each group. Data are mean \pm SEM. * $P<0.05$; determine by Student's $t$ test. Scale bar: (A) $100 \mu \mathrm{m}$. 


\section{Figure 4}

A)
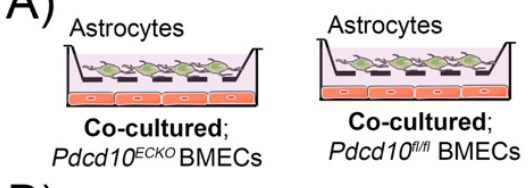

B) Astrocytes in
CoPdcd10 $10^{\text {ECKO BMEC }}$
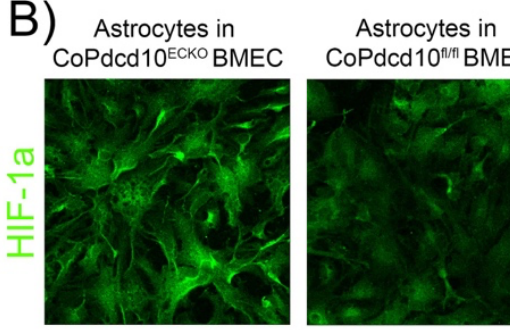

CoPdcd $10^{n / 1 / 1}$ BMEC
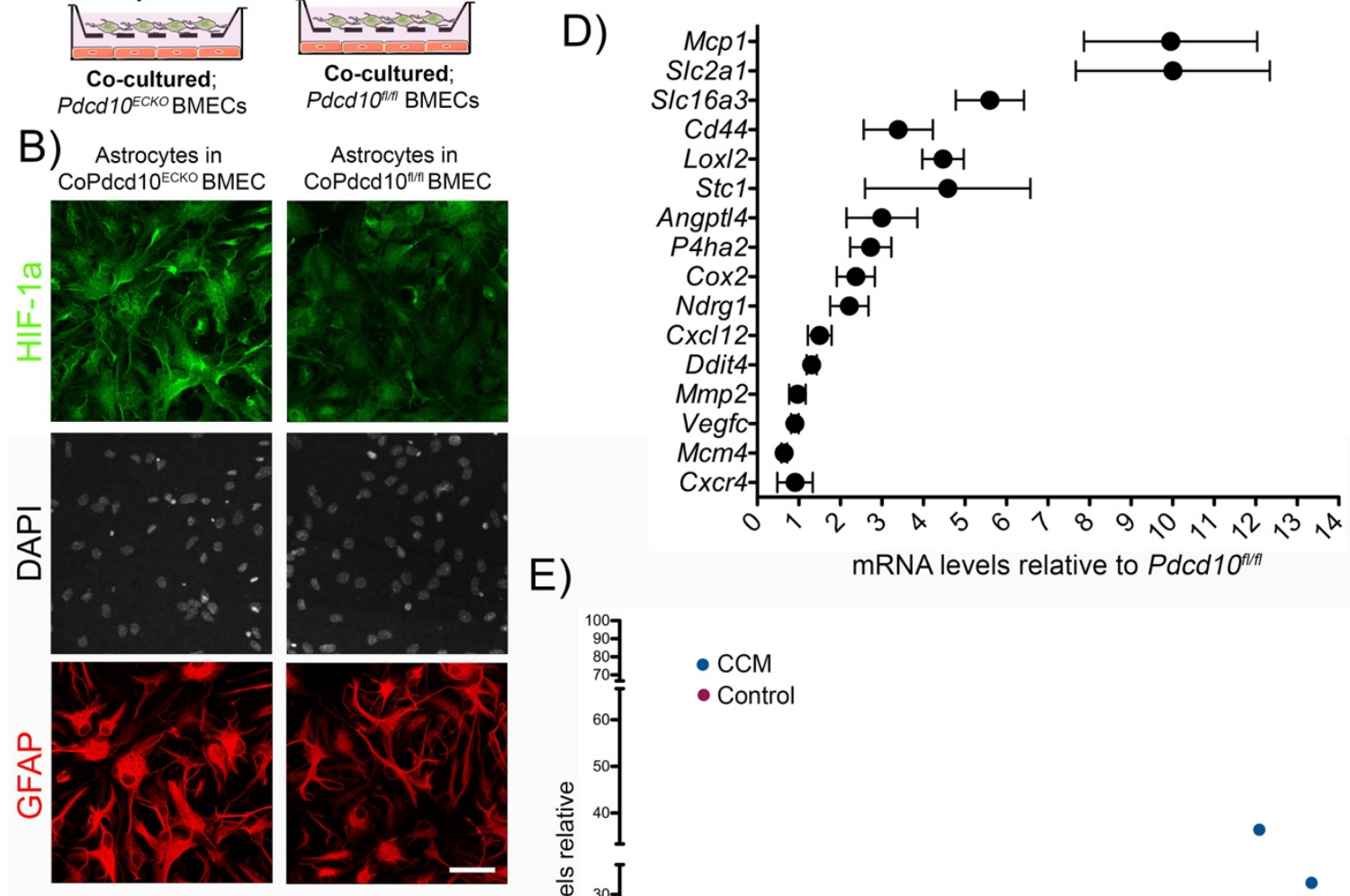

E)
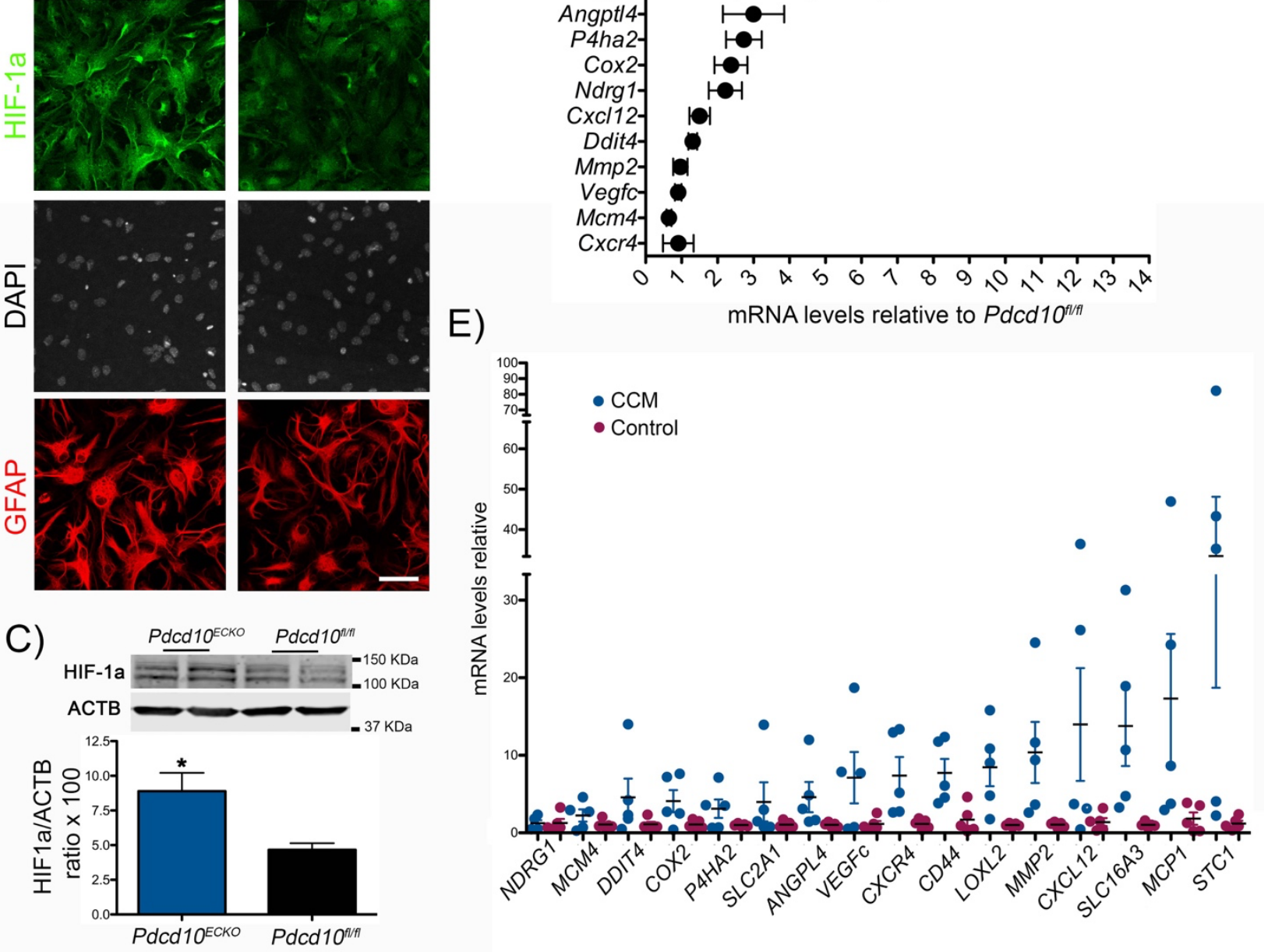

Fig 4. Increase in normoxic HIF-1 $\alpha$ stabilization in astrocyte and COX-2 during CCM . (A) Schematic diagram of astrocytes co-cultured with Pdcd10 ${ }^{E C K O}$ and Pdcd10 $0^{f / f t}$ BMECs. (B) Immunofluorescence staining for HIF-1 $\alpha$ (green), GFAP (red), and DAPI for nuclear DNA (white) of primary astrocytes co-cultured with Pdcd10 ECKO BMEC compared to Pdcd10 $0^{f / f t}$ BMEC control

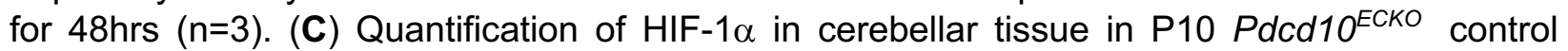
$P d c d 10^{f / f f l}$ littermates, as assessed by Western blot (SEM, $\mathrm{n}=4$ mice in each group). (D) Analysis of HIF-1 $\alpha$-target genes by RT-qPCR in cerebellar tissue from P10 Pdcd10ECKO and control $P d c d 10^{f / f f l}$ littermates (SEM, $\mathrm{n}=5$ or 7 mice in each group). (E) Analysis of HIF-1 $\alpha$-target genes by RT-qPCR in human CCM lesions and control human brain tissue (SEM, n=5). Data are mean \pm SEM. ${ }^{*}, \mathrm{P}<0.05$, determine by Student's $t$ test. Scale bar: (B) $50 \mu \mathrm{m}$. 
Figure 5

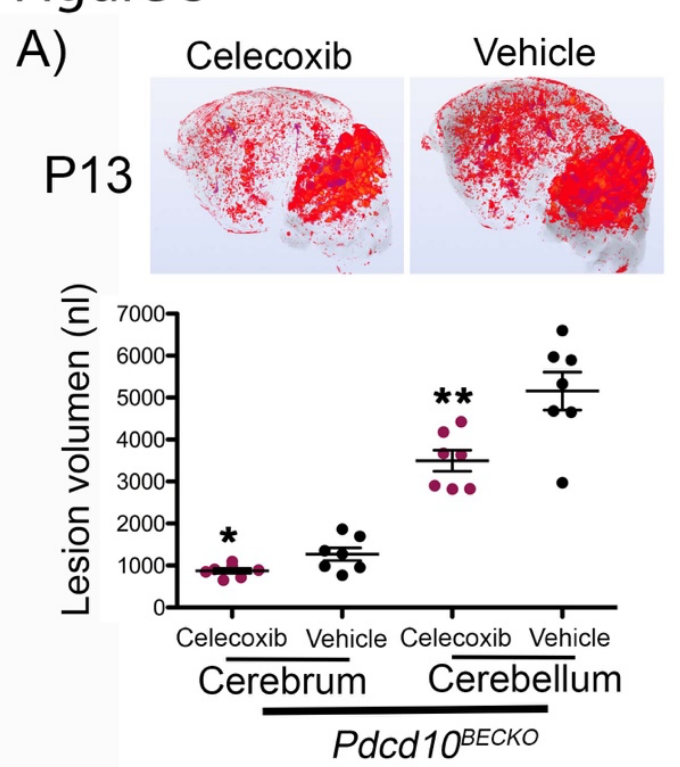

B) Celecoxib Vehicle

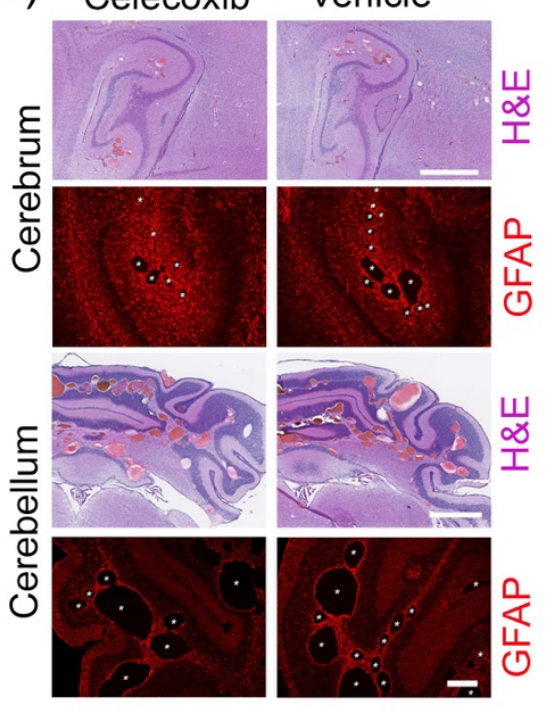

C)
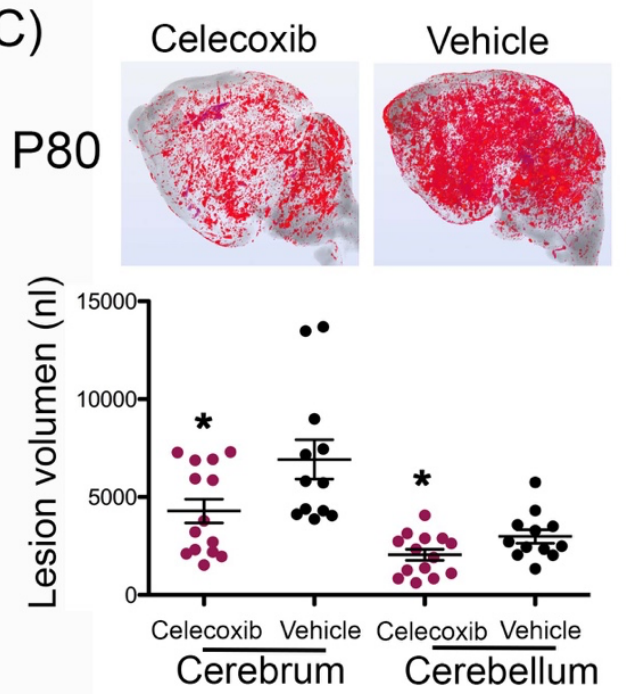

Pdcd10 $10^{\text {BECKO }}$

E)

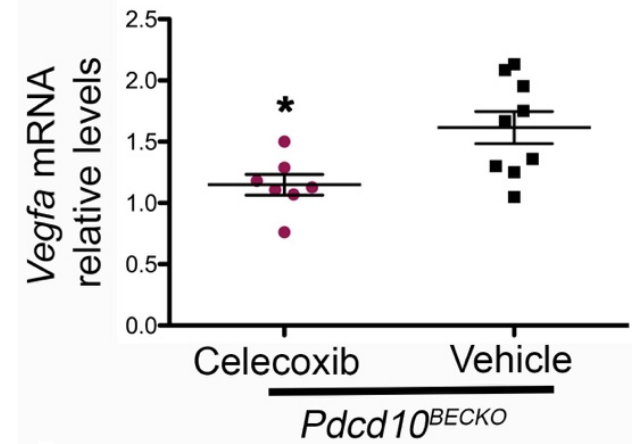

D) Celecoxib Vehicle

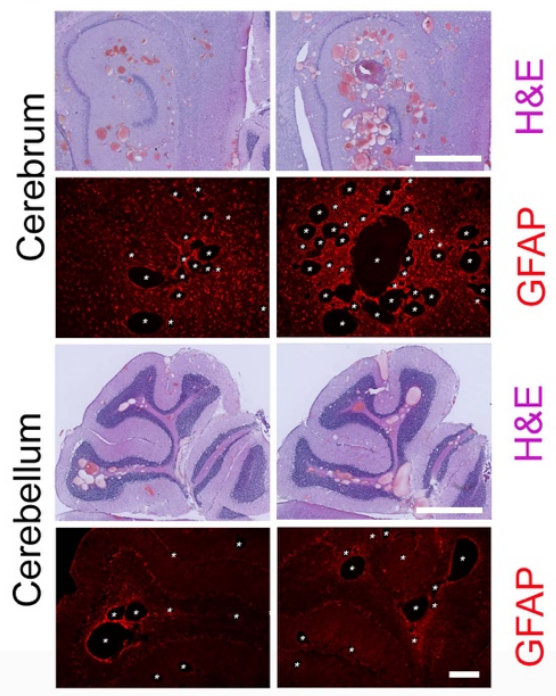

F)

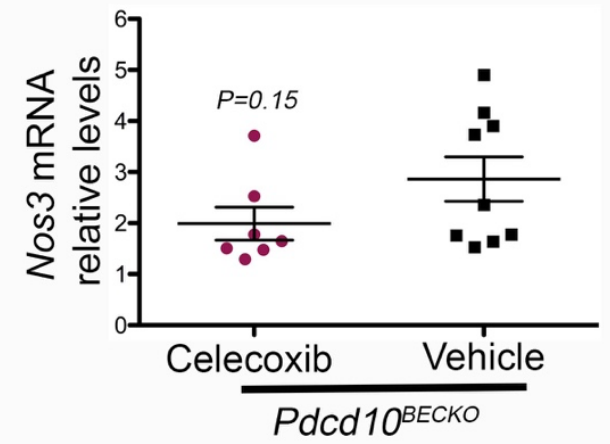


Fig 5. COX-2 inhibition prevent CCM lesions in Pdcd10 ${ }^{B E C K O}$ mice. (A) Prominent lesions are present in the cerebellum and cerebrum of $\mathrm{P} 13 \mathrm{Pdcd} 10^{B E C K O}$ mice. Intragastric administration of $40 \mathrm{mg} / \mathrm{Kg}$ celecoxib for four consecutive days P6 to P9 suppressed lesion formation. Quantification of lesion volumes by micro-CT analysis from mice at P13 treated with celecoxib or vehicle (SEM, $n=7$ mice in each group). (B) Hematoxylin and eosin (pink and purple) or GFAP (red) staining of cerebral (hippocampal area) and cerebellar sections from $P d c d 10^{B E C K O}$ mice after treatment with celecoxib or vehicle $(n=3)$. (C) Prominent lesions are present in the cerebellum and cerebrum of $P 80 P d c d 10^{B E C K O}$ mice. Oral gavage administration of $40 \mathrm{mg} / \mathrm{Kg}$ celecoxib for fifteen consecutive days P55 to P70 suppressed lesion formation. Quantification of lesion volumes by micro-CT analysis from mice at P80 treated with celecoxib or vehicle (SEM, $n=12$ or 14 mice in each group). (D) Hematoxylin and eosin (pink and purple) or GFAP (red) staining of cerebral (hippocampal area) and cerebellar sections from $P d c d 10^{B E C K O}$ mice after treatment with celecoxib or vehicle $(n=3)$. (E-F) Quantification of Vegfa $(\boldsymbol{E})$ or Nos3 $(\boldsymbol{F})$ mRNA levels in P80 Pdcd10 $10^{B E C K O}$ spinal cords after treatment with celecoxib or vehicle from experiments in $C$ (SEM, $n=7$ or 9 mice in each group). Data are mean \pm SEM. *, $\mathrm{P}<0.05$, ${ }^{* *}, \mathrm{P}<0.01$; determine by Student's $t$ test. Scale bar: (B and D) $1 \mathrm{~mm}$ (H\&E) , $200 \mu \mathrm{m}$ (GFAP).

Figure 6

A)

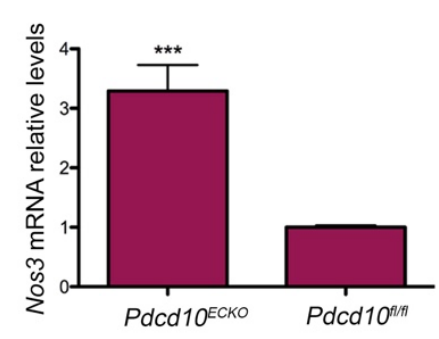

D)

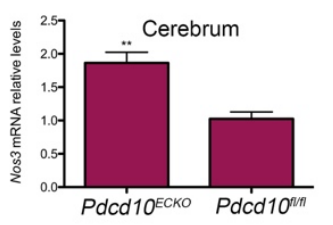

E)

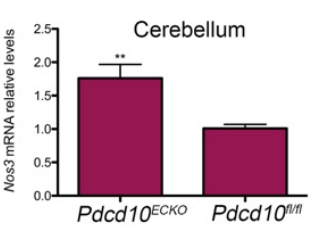

B)

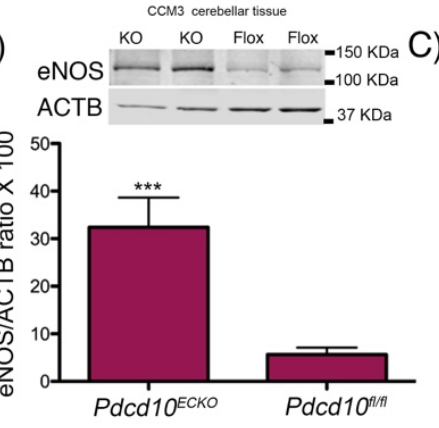

F)
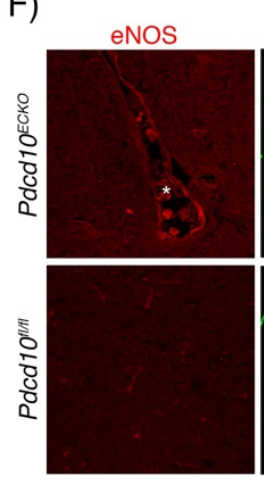
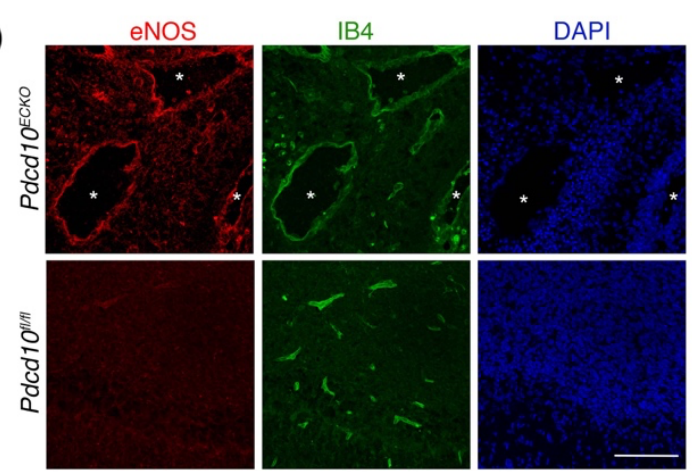

Fig 6. Loss of brain endothelial Pdcd10 increases the expression of eNOS in situ. (A) Analysis of Nos3 mRNA levels by RT-qPCR in hindbrains of P10 Pdcd10 ECKO and littermate $P d c d 10^{f / f t}$ control (SEM, $n=4$ or 5 mice in each group). (B) Analysis of eNOS levels in hindbrains of P10 Pdcd10 ECKO and littermate Pdcd10 $0^{f / f l}$ control, as assessed by Western blot analysis (SEM, $n=4$ or 5 mice in each group). (C) Confocal microscopy of cerebellar cortex P10 stained for eNOS (red), endothelial marker isolectin B4 (green), and DAPI for nuclear DNA (blue). Asterisks indicate vascular lumen of CCM lesions ( $n=4$ mice in each group). (D-E) Analysis of Nos3 mRNA levels 
by RT-qPCR in brains of P30 Pdcd10ECKO and littermate Pdcd10 fl/fl control. (F) Immunofluorescence staining of eNOS (red), endothelial marker cd34 (green), and DAPI for nuclear DNA (blue) ( $n=4$ or 6 mice in each group). Data are mean \pm SEM. ${ }^{* *}, P<0.01,{ }^{* * *}, P<0.001$; determine by Student's $t$ test. Scale bars: (C) $100 \mu \mathrm{m}$; (F) $50 \mu \mathrm{m}$.

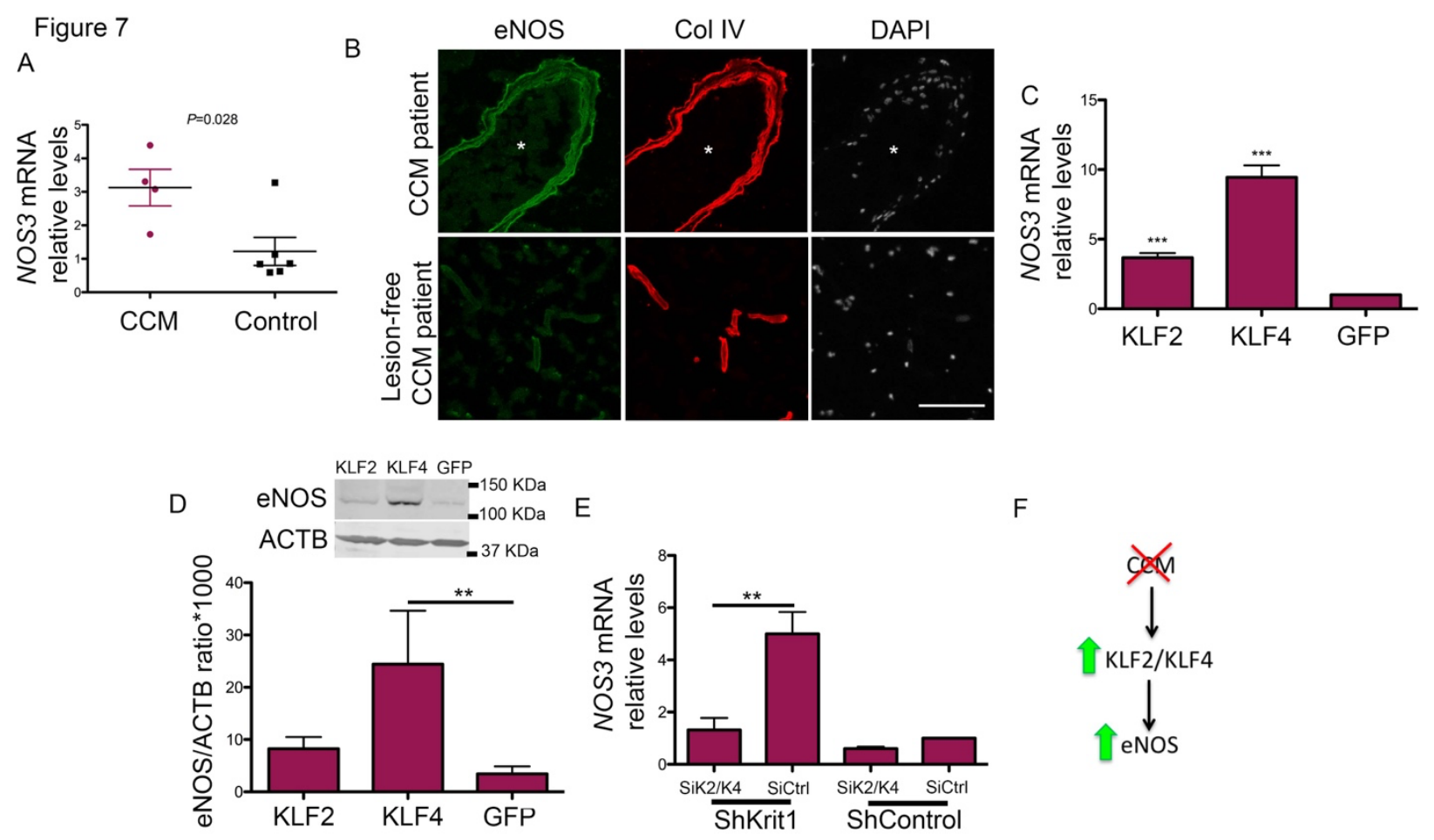

Fig 7. KLF2 and KLF4 regulate increased eNOS expression during CCM. (A) Expression levels of NOS3 mRNA as assessed by RT-qPCR from human CCM lesions and compared to nonneurological disease control (SEM, $n=4$ or 6 in each group). (B) Immunofluorescence staining of eNOS (green) and collagen IV (Col IV; red) of human CCM lesion matched to CCM lesion-free brain tissue $(n=3)$. Asterisks denotate vascular lumen of CCM lesion. Nuclei were counterstained with DAPI (white). (C) Human umbilical vein endothelial cells (HUVECs) were transduced with lentivirus encoding KLF2 or KLF4, as previously reported(6), and analysis of NOS3 mRNA levels by RT-qPCR were determined in cells overexpressing KLF2 or KLF4 and compared with lentivirus encoding GFP as control ( $n=3$ or 4). (D) Analysis of eNOS protein levels in HUVECs transduced with lentivirus encoding KLF2 or KLF4, as determined by Western blot analysis(37); lentivirus encoding GFP was used as control (SEM, $n=3$ ). (E) Analysis of NOS3 mRNA levels by RT-qPCR in hCMEC/D3 cells transduced with lentivirus encoding shKRIT1 or scrambled control, followed by transfection with KLF2 and KLF4-specific small interfering RNAs (siRNA;siK2/K4) or small interfering RNA control (siCtrl) (SEM, $n=4)$. (F) Schematic model. KLF2 and KLF4-mediated elevation of eNOS in CCM endothelium by a cell-autonomous mechanism. Data are mean \pm SEM. ${ }^{* *}, \mathrm{P}<0.01,{ }^{* * *}, \mathrm{P}<0.001$; determine by Student's $t$ test and 1-way ANOVA, followed by the Tukey post hoc test. Scale bar:(B) 100 um. 
Figure 8

A)

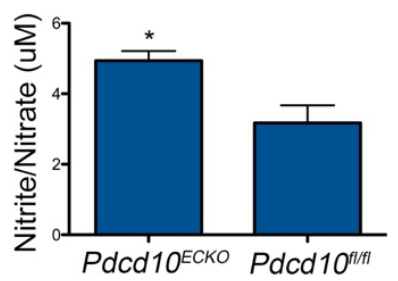

D)
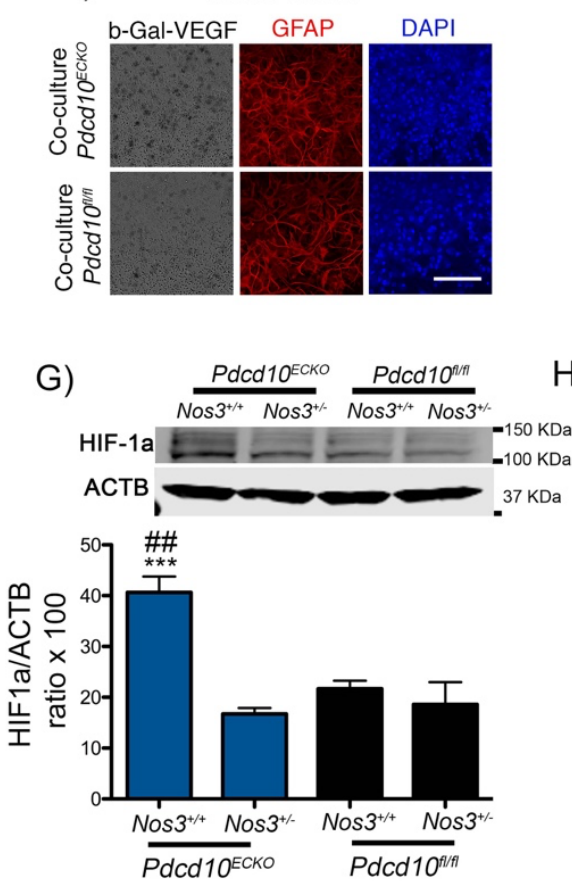

I)

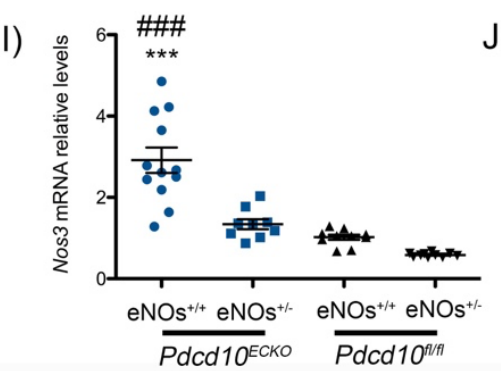

H)

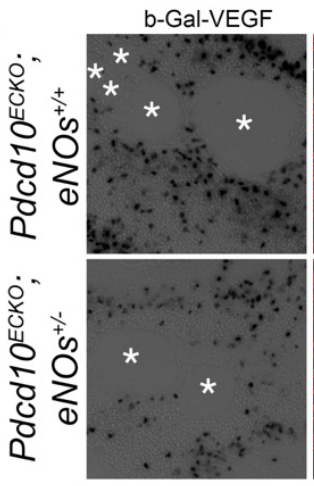

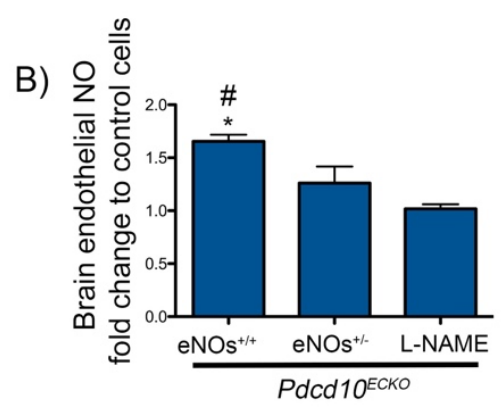

E)

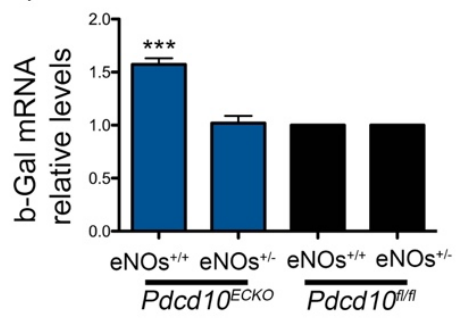

C)

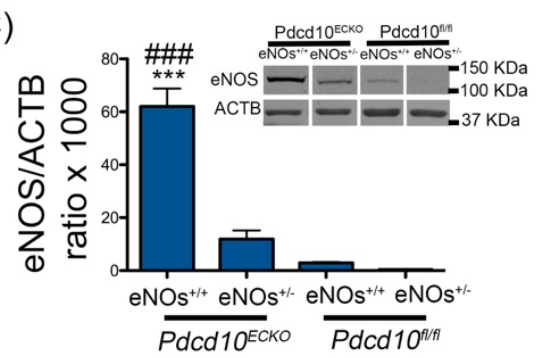

F)

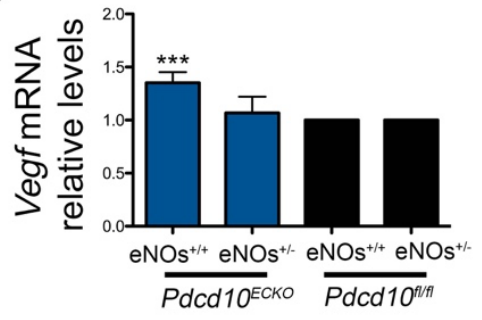

GFAP

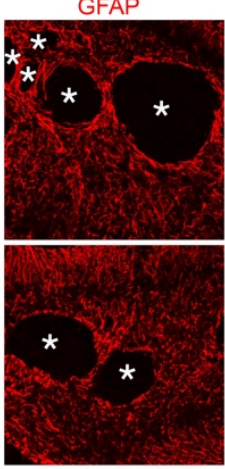

b-Gal-VEGF/GFAP

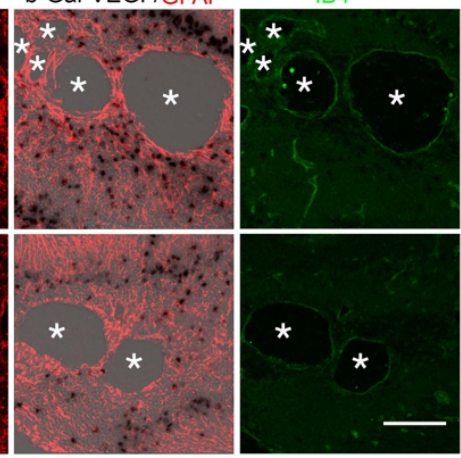

J)

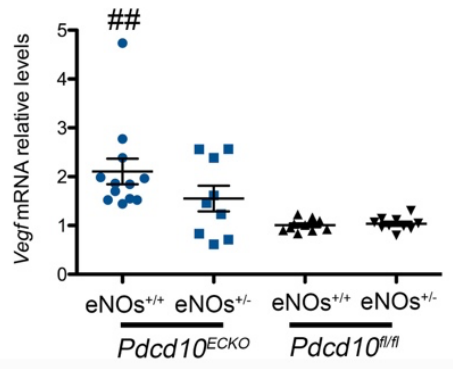

Fig 8. Loss of brain endothelial Pdcd10 increases nitric oxide production and induces astrocyte-derived VEGF. (A) Total nitrite and nitrate concentration as an intermediate of NO production assessed by colorimetric assay analysis from the media of $P d c d 10^{E C K O}$ and $P d c d 10^{f / f t}$ BMEC cultured for $36 \mathrm{hrs}$ (SEM, $\mathrm{n}=7$ ). (B) Increased NO release in $P d c d 10^{E C K O}$ is significantly reduced in Pdcd10 ${ }^{E C K O}$;Nos3+/- BMEC or following incubation with a NOS inhibitor, L-NAME $(150 \mu \mathrm{M})(\mathrm{SEM}, \mathrm{n}=3)$. (C) Quantification of eNOS protein from Pdcd10 ECKO and Pdcd10 ECKO $\mathrm{Nos}^{+/-}$BMECs relative to Pdcd10 $0^{f / f l}$ and $\mathrm{Pdcd} 10^{\mathrm{fl/fl} ;} ; \mathrm{Nos}^{+/-}$BMECs controls (SEM, $\mathrm{n}=5$ ). Culture media was supplemented with 500uM L-Arginine and was deficient in serum. Lanes in this panel were run on the same gel but were noncontiguous. (D) $\beta$-gal/VEGF expression, as shown by X- 
gal staining (black) and immunofluorescence staining for GFAP (red) of primary cultured astrocytes co-cultured with Pdcd10 ${ }^{E C K O}$ BMEC compared to Pdcd10 $10^{f / f l}$ BMEC control for 48hrs $(\mathrm{n}=2)$. (E) RT-qPCR analysis of $\beta$-gal and (F) Vegfa mRNA in primary cultured astrocytes cocultured with $P d c d 10^{E C K O}$ BMEC compared to Pdcd10 $0^{f / f l}$ BMEC control for $24 \mathrm{hrs}$ (SEM, $\mathrm{n}=4$ ). (G) Quantification of HIF-1 $\alpha$ protein from primary astrocytes co-cultured with $P d c d 10^{E C K O}$ BMEC and Pdcd10ECKO;Nos3+/- BMEC relative to astrocyte co-cultured with Pdcd10 fl/ft or Pdcd10 f/ffl ;Nos3 ${ }^{+/-}$BMECs controls for 48hrs (SEM, $\mathrm{n}=4$ ). $(\mathrm{H})$ Confocal microscopy of neonatal hindbrain at P10 from Pdcd10 ${ }^{E C K O} ; \mathrm{Nos}^{+/+} ; V_{\text {Vegfa }}^{\text {tm1.1Nagy }}\left(\mathrm{Pdcd}^{\mathrm{ECKO}} ; \mathrm{eNOS}^{+/+}\right)$and

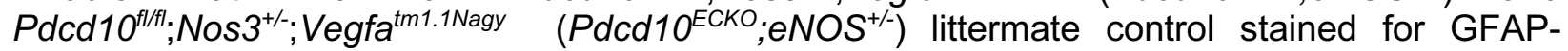
positive astrocytes (red), $\beta$-gal/VEGF expression detected by X-gal staining (black), isolectin B4 (green). Asterisks, vascular lumen of CCM lesions ( $n=3)$. (I-J) Quantification of Nos3 (I) and Vegf

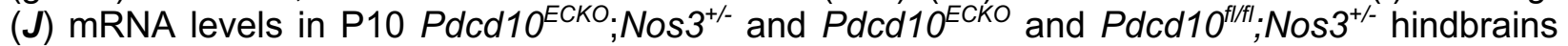
when compared with littermate Pdcd1 $0^{f / / f l}$ controls, as assessed by RT-qPCR (SEM, $\mathrm{n}=9$ or 12 mice in each group). Data are mean \pm SEM. ${ }^{*}, \#, P<0.05$, ${ }^{\# \#, P<0.01, ~}{ }^{* * *}, \# \#, P<0.001$ ( ${ }^{*}$ comparison to Pdcd10 ${ }^{\mathrm{ECKO}}$; Nos3 ${ }^{+/-}$and ${ }^{\#}$ comparison to L-NAME or Pdcd $10^{\mathrm{fl/fl}} ; \mathrm{eNOs}^{+/+}$); determine by Student's $t$ test and 1-way ANOVA, followed by the Tukey post hoc test. Scale bars : (D and H) $100 \mu \mathrm{m}$.

\section{Figure 9}

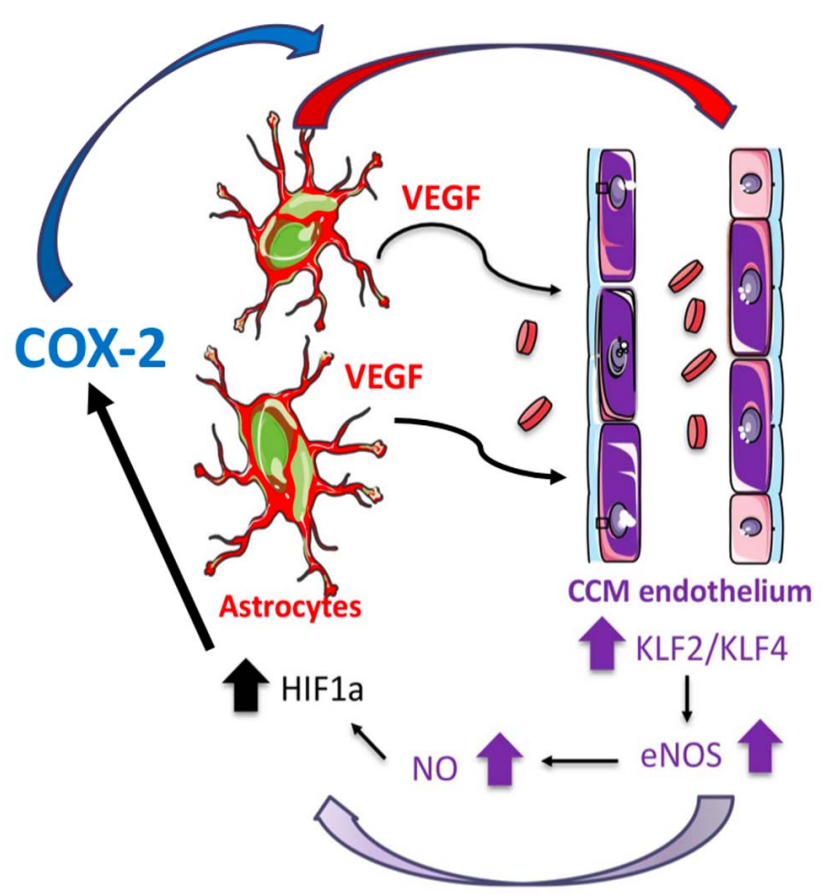

Fig 9. Astrocytes integrate a circuit of neurovascular dysfunction during CCM disease. Model by which astrocytes make a significant contribution to CCM pathogenesis. An increase in astrocyte VEGF synthesis is driven by endothelial nitric oxide (NO) generated due to KLF2 and KLF4-dependent elevation of eNOS in CCM endothelium. Production of NO in CCM endothelium stabilizes HIF-1 $\alpha$ in astrocytes, resulting in increased VEGF production and expression of a "hypoxic" program under normoxic conditions. Pharmacological inhibition of HIF1-driven COX-2 can ameliorate murine models of CCM disease. 


\section{Supplementary Materials:}

Supplemental 1

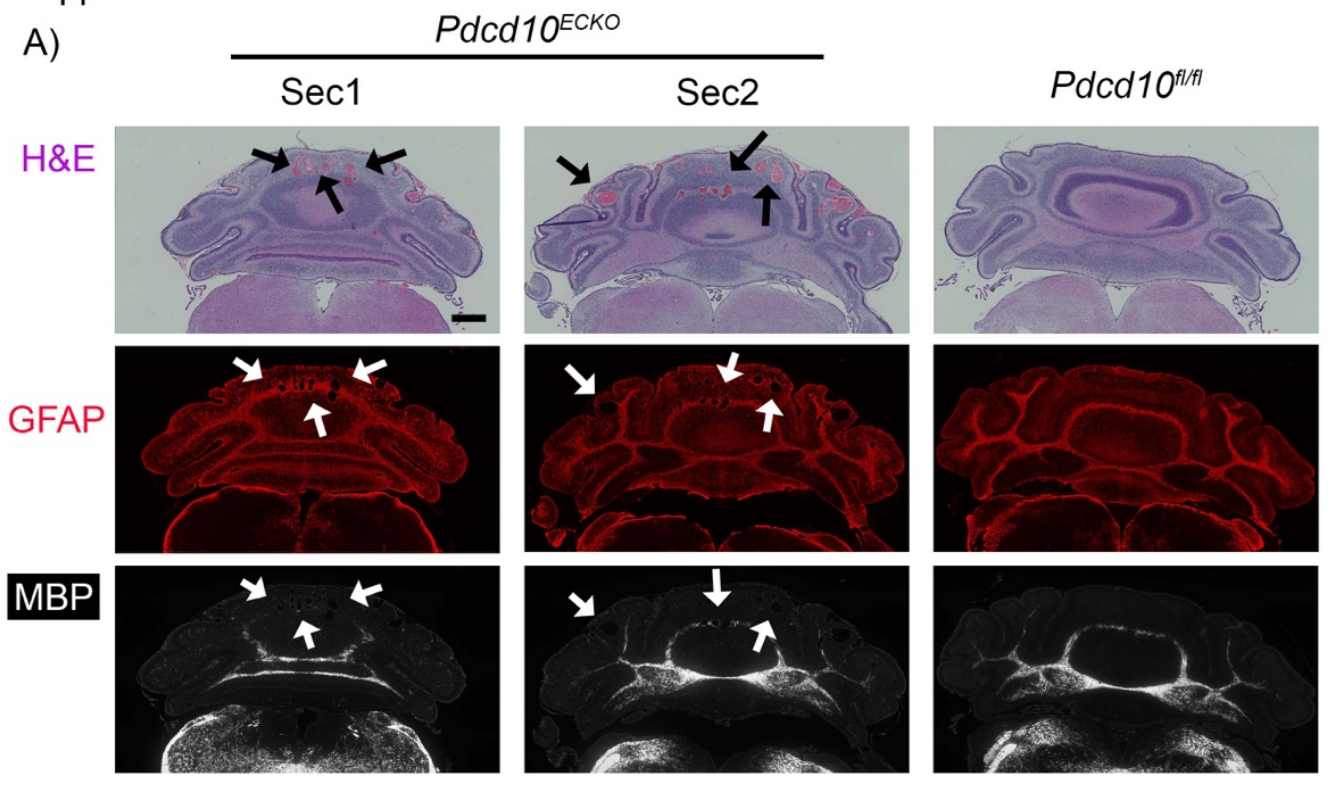

B)

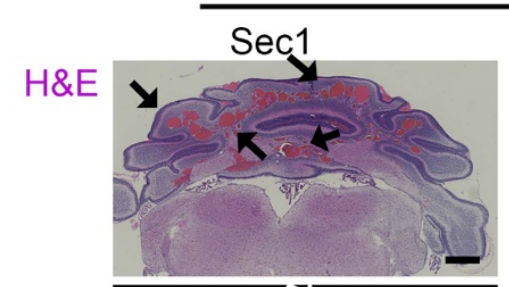

Krit1ECKO
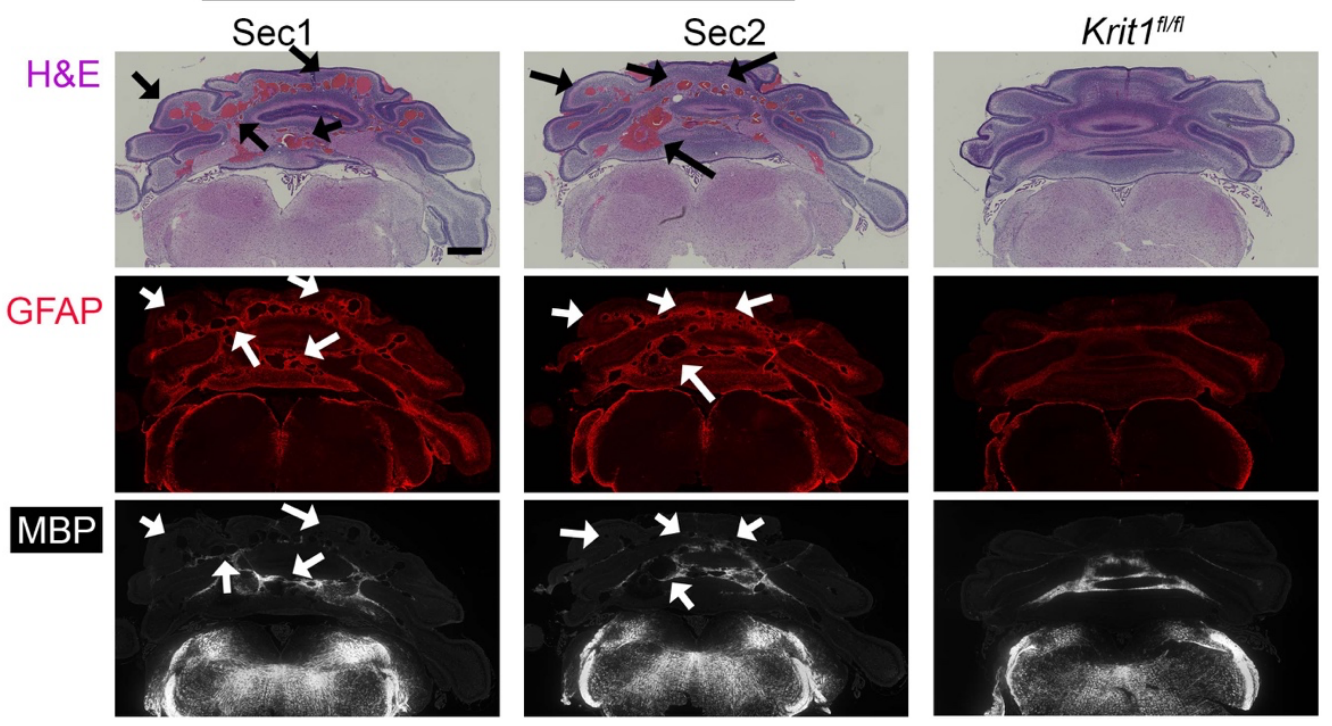

Fig. S1. CCM lesions spatially developed on fibrous astrocytes. (A)Histological analysis of cerebellar sections from P9 Pdcd $10^{E C K O}$ and littermate control Pdcd1 $0^{f / f t}$ mice. Low magnification of CCM lesions detected in sections stained by hematoxylin and eosin. CCM lesions spatially developed on fibrous astrocytes areas positive to GFAP immunostaining (red) and white matter positive to MBP (white). Arrows indicate CCM lesions. (B) Histological analysis of cerebellar sections from P8 Krit $1^{E C K O}$ and littermate control Krit $1^{\mathrm{fl} / \mathrm{fl}}$ mice. Low magnification of CCM lesions detected in sections stained by hematoxylin and eosin. CCM lesions spatially developed on 
fibrous astrocytes areas positive to GFAP immunostaining (red) and white matter positive to MBP (white). Arrows indicate CCM lesions. Scale bar:(A and B) 500 um.

\section{Supplemental 2}

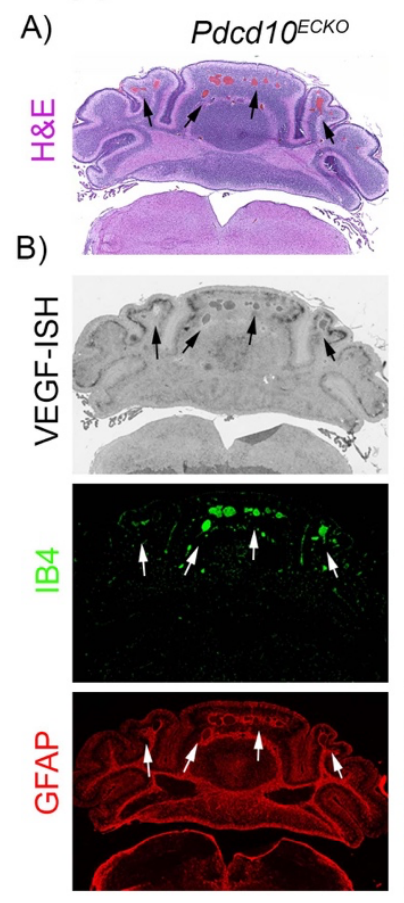

D)

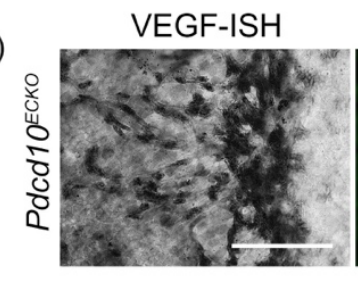

Pdcd10 $0^{\text {flft }}$
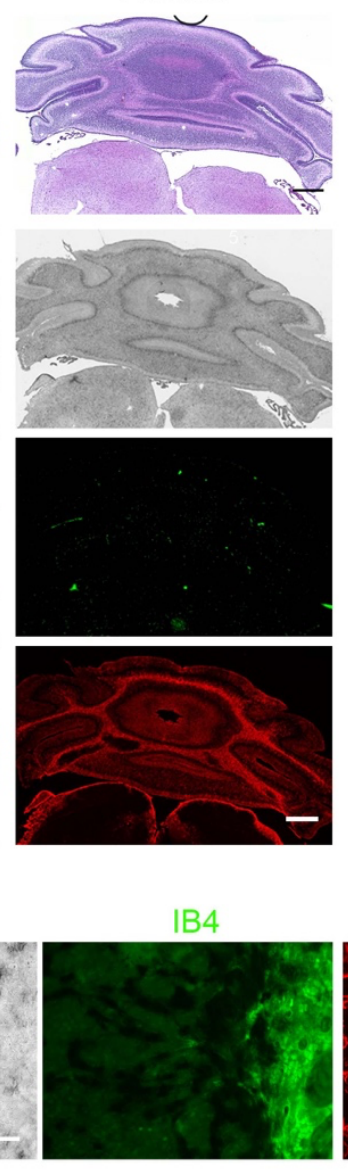

C)
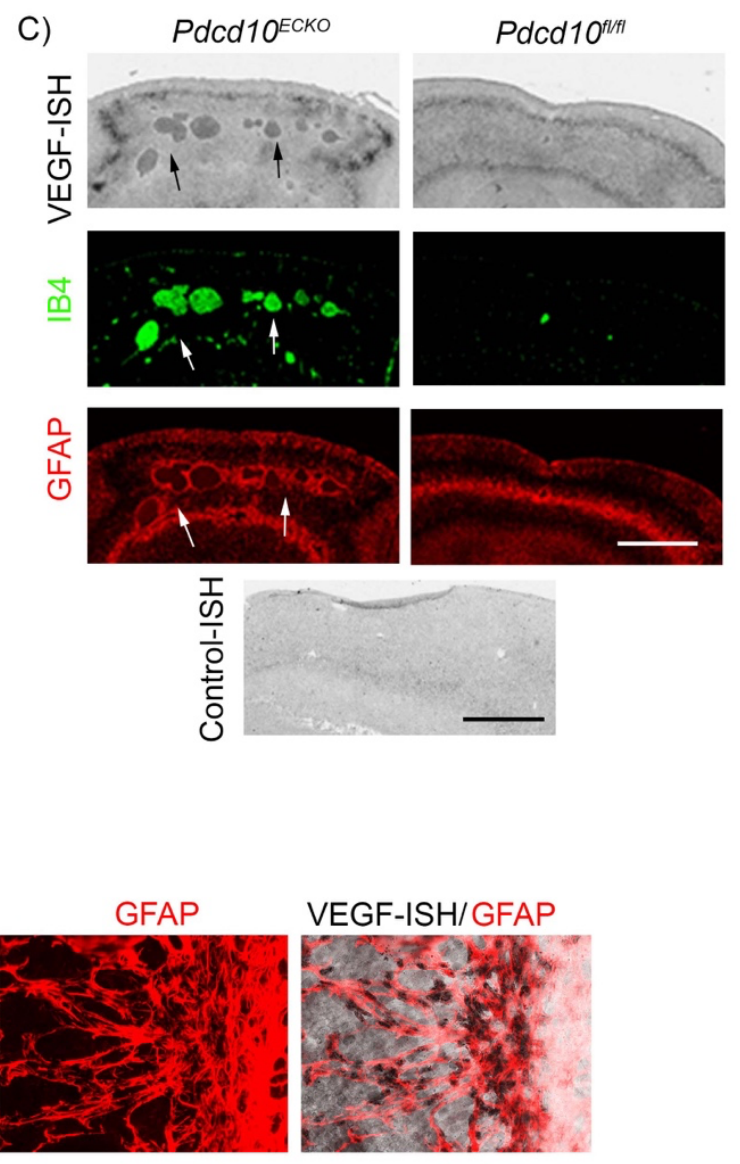

Fig. S2. VEGF increases during cerebral cavernous malformations development. (A)Histological analysis of cerebellar sections from P10 Pdcd10 ECKO and littermate control $P d c d 10^{f / f l}$ mice. Low magnification of CCM lesions detected (Arrows) in sections stained by hematoxylin and eosin. (B) ISH for VEGF (black) combined with immunohistochemistry to identify GFAP-positive astrocytes (red), endothelial marker isolectin B4 (IB4; green) in a serial section from $A$. (C) high magnification of $\boldsymbol{B}$ and control probe for ISH. (D) ISH for VEGF (black) combined with immunohistochemistry to identify GFAP-positive astrocytes (red), endothelial marker isolectin B4 (IB4; green) in P10 Pdcd10 ${ }^{E C K O}$ retinas ( $\mathrm{n}=2$ or 3). Scale bars: (A, B and C) 500 um, (D) $100 \mathrm{um}$. 


\section{Supplemental 3}

A)
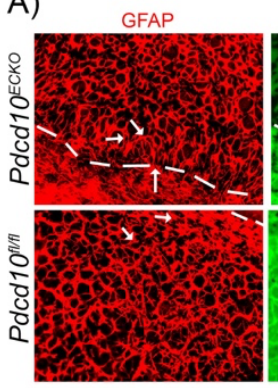

E)

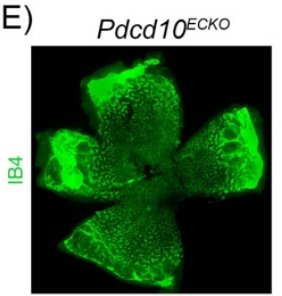

$\operatorname{Pdcd} 10^{f / f t}$

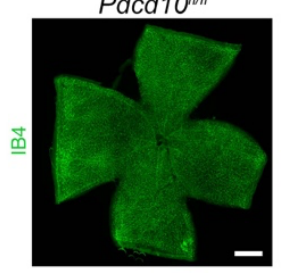

b-Gal//B4
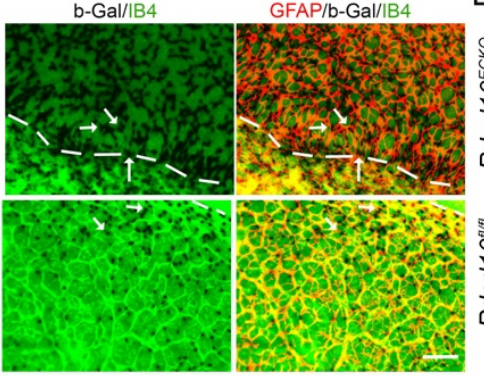

F) $P d c d 10^{E C K O}$;

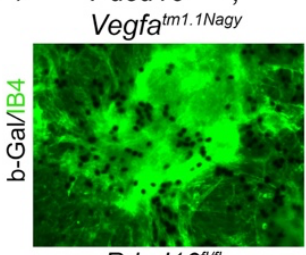

Pdcd10 fl/fi:

Vegfatm1.1Nagy

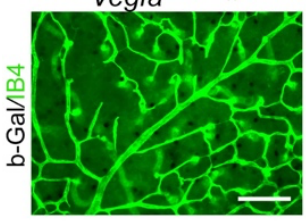

G)
B)

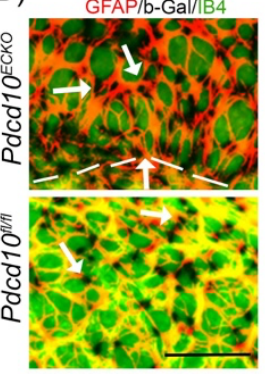

C)

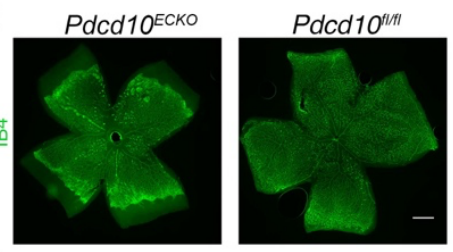

D)

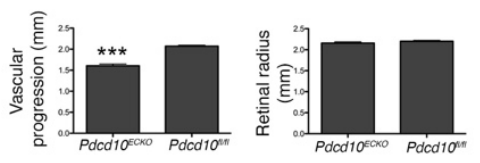

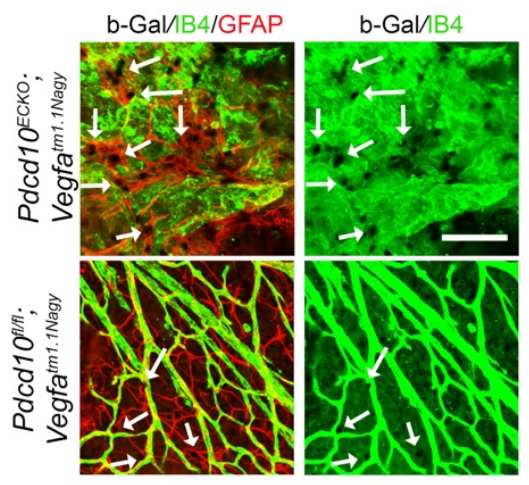

b-Gal/1B4/GFAP
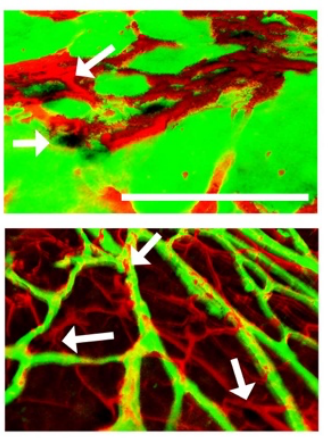

H)

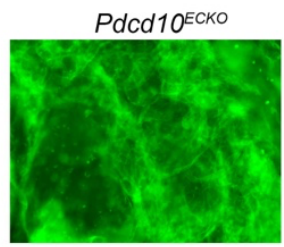

Pdcd10 flff

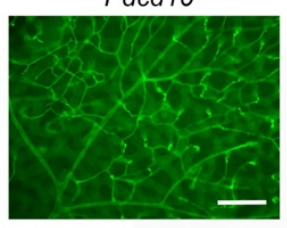

I)

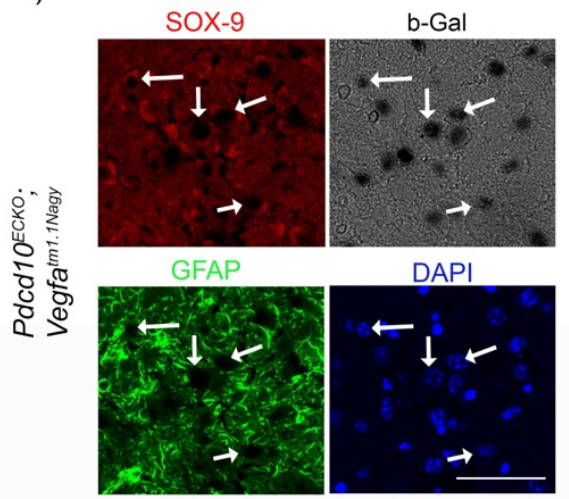

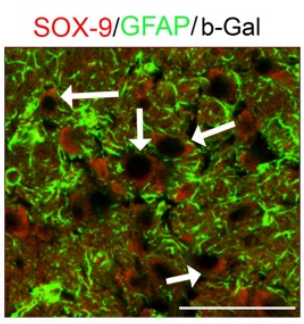

Fig. S3. VEGF increases in retinas during cerebral cavernous malformations. (A) Wholemount retinal vasculature at the angiogenic growth front stained for GFAP (red), Isolectin B4 (green), and $\beta$-gal/VEGF expression detected by $X$-gal staining (black) in P9

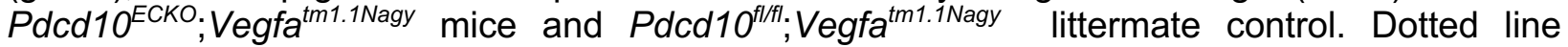
indicated angiogenic front. (B) Magnified whole-mount retinal vasculature in $A$. Arrows indicate $\beta-$ gal/VEGF in GFAP-positive astrocytes. (C) Isolectin B4-stained Pdcd10 ECKO and control Pdcd10 $0^{f / f l}$ $P 9$ retinas and in (D) the quantification of vascular parameters of retinas (SEM, $n=14$ or 17 mice in each group). (E) Whole-mount retinal vasculature by isolectin B4-stained Pdcd10 ECKO and control $P d c d 10^{f / f l} \mathrm{P} 12$ retinas. (F) Magnified whole-mount retinal vasculature indicate $\beta$-gal/VEGF 
expression in P12 Pdcd10 ${ }^{E C K O} ;$ Vegfa ${ }^{\text {tm1.1Nagy }}$ mice and Pdcd10 ${ }^{f / f t /} ;$ Vegfa ${ }^{\text {tm1.1Nagy }}$ littermate control. (G) Correspond to $\beta$-gal control in P12 Pdcd10 ECKO mice and Pdcd10 $0^{f / f l}$ littermate control. (H) Maximum-intensity projection of whole-mount $\mathrm{P} 12$ retinal vasculature from $F$ stained for GFAP (red), Isolectin B4 (green), and $\beta$-gal/VEGF (black). Arrows indicate $\beta$-gal/VEGF in GFAP-positive astrocytes. Surface reconstruction of $\beta$-gal/VEGF in GFAP-positive astrocytes ( $n=3$ or 4 ). (E) Confocal microscopy of cerebrum cortex from Pdcd10 $10^{E C K O} ;$ Vegfa ${ }^{\text {tm1.1Nagy }}$ stained for $\beta$-gal/VEGF expression, SOX-9-positive astrocytes (red), GFAP-positive astrocytes (green), and DAPI for nuclear DNA (blue). Data are mean \pm SEM. ${ }^{* * *}, \mathrm{P}<0.001$; determine by Student's $t$ test. Scale bars: (A, B and H) $100 \mu \mathrm{m}$; (F and G) $200 \mu \mathrm{m}$; (C and E) $500 \mu \mathrm{m}$.

Supplemental 4

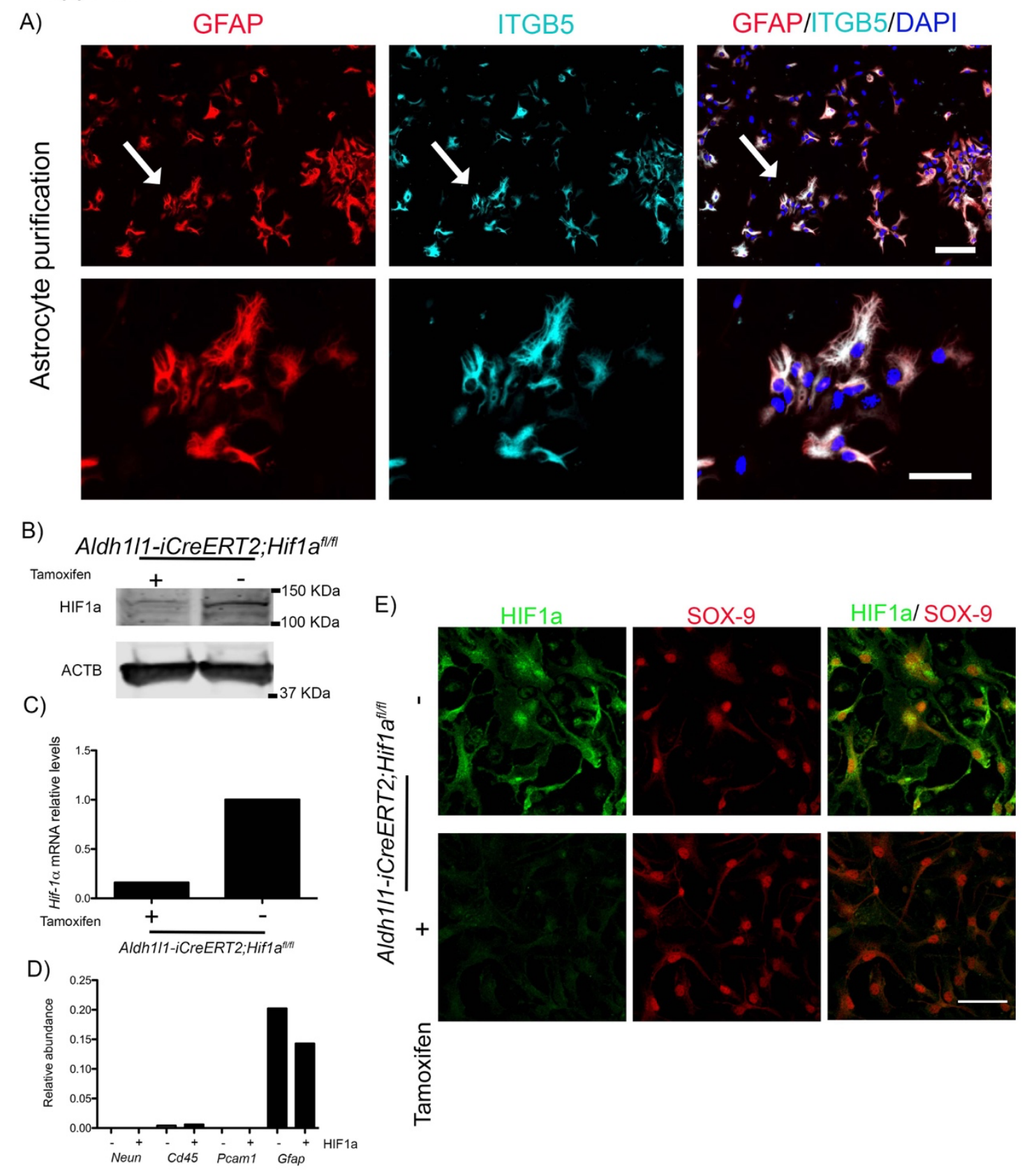


Fig. S4. Mouse primary astrocyte culture characterization and purity. Astrocytes isolated from cortex of postnatal day 5-7 mice. (A) Purity of the isolation was confirm by the presence of GFAP and ITGB5 astrocyte markers visualized by immunofluorescence $(n=5)$. (B) the HIF-1 $\alpha$ antibody specificity by Western blot analysis of primary astrocyte cultures was determined using Aldh1/1-iCreERT2; Hif-1 $\alpha^{f / f l}$ astrocytes in the presence and absence of tamoxifen $(\mathrm{n}=2)$. (C) Inactivation of HIF-1 $\alpha$ was further validated by RT-qPCR that showed $80 \%$ reduction in HIF- $1 \alpha$ mRNA levels in tamoxifen-treated-Aldh1/1-iCreERT2; Hif-1 $\alpha^{f / f l}$ cells $(n=2)$. (D) Gene expression of neuronal marker Neun; leucocyte marker Cd45; endothelial cell marker Pcam1; astrocyte markers Gfap from $C(n=2)$. (E) HIF-1 $\alpha$ antibody specificity by immunocytochemistry of astrocytes was performed by increasing HIF-1 $\alpha$ expression by adding $100 \mathrm{uM}$ of $\mathrm{CoCl} 2$ for $24 \mathrm{~h}$ to the culture medium. SOX-9 immunostaining was used as a nuclear marker for astrocytes. Diffuse and nuclear accumulation of HIF-1 $\alpha$ immunostaining in non-tamoxifen treated-Aldh1/1-iCreERT2; Hif$1 \alpha^{f / f f l}$ cells that is significantly reduced by tamoxifen treatment astrocytes $(n=2)$. Scale bars: $(\mathbf{A}$ and E) $100 \mu \mathrm{m}$. 
Supplemental 5

B)
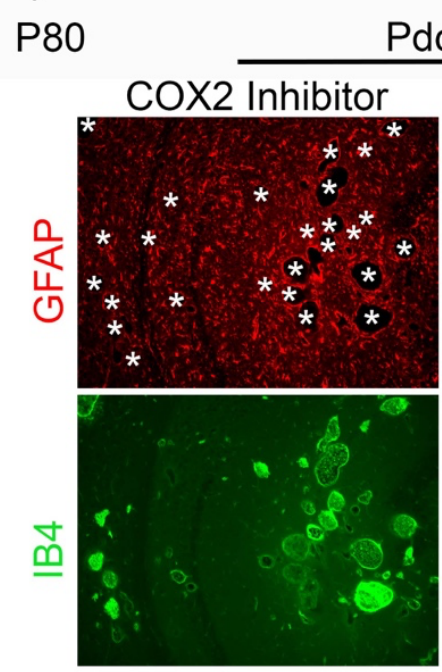

C)

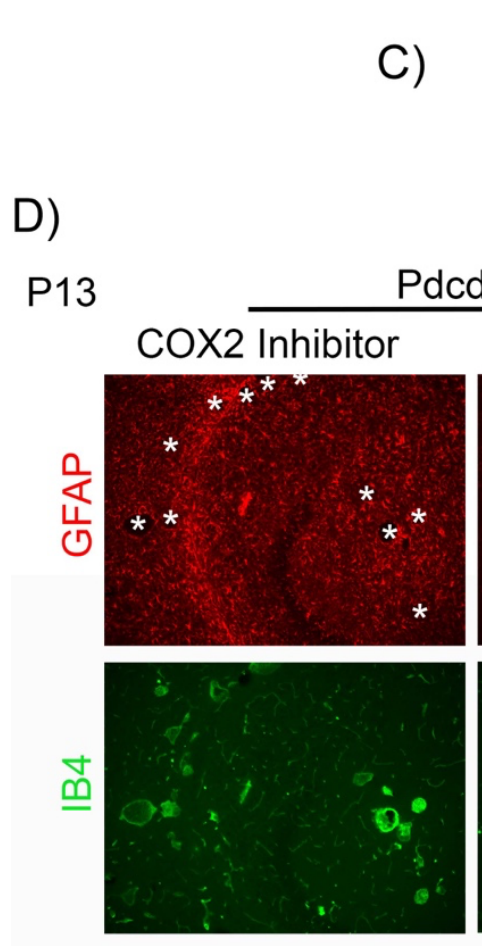

A)

Pdcd10 BECKO
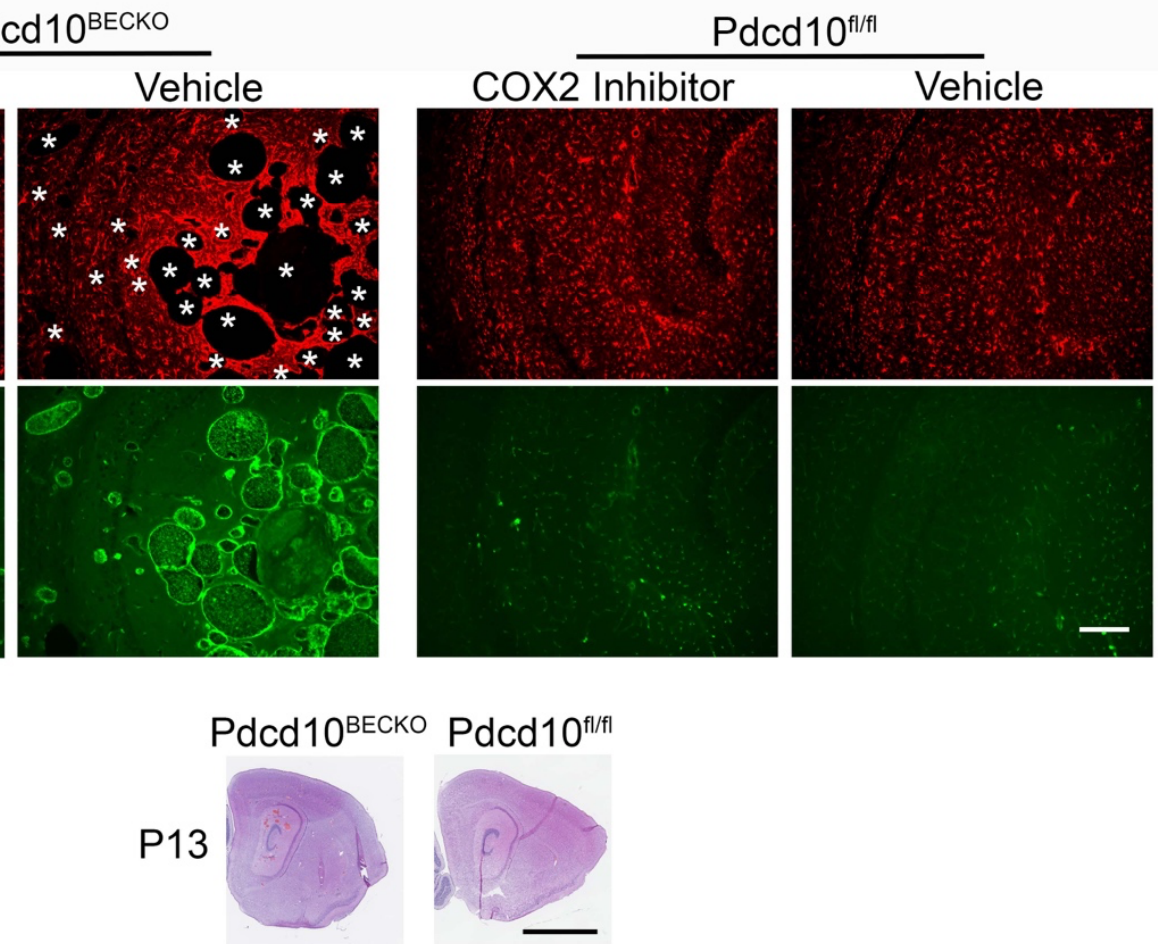

P13

Pdcd10 BECKO

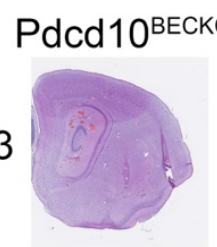

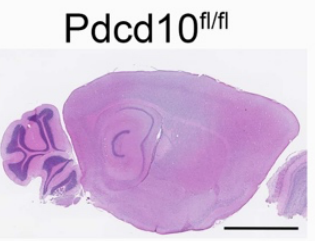


or vehicle for fifteen consecutive days P55 to P70. GFAP astrocyte marker (red) staining and IB4 endothelial marker (green) of mouse hippocampal region at P80. CCM lesions' high propensity to develop surrounded by GFAP+ astrocytes in the hippocampal region in vehicle-treated $P d c d 10^{B E C K O}$ mice. Significant decrease in CCM lesions' density and GFAP-immunoreactivity in celecoxib-treated Pdcd10 ${ }^{B E C K O}$ mice. Arrows indicate CCM lesions $(n=3)$. (C)Histological analysis of brain sections from $\mathrm{P} 13 \mathrm{Pdcd} 10^{B E C K O}$ and littermate control Pdcd1 $10^{f / f l}$ mice. Low magnification of CCM lesions detected throughout the brain sections stained by hematoxylin and eosin in P13 Pdcd10 ${ }^{B E C K O}$ mice. Extensive lesions were prevalent in the hippocampal area $(n=3)$. (D) Intragastric administration of $40 \mathrm{mg} / \mathrm{Kg}$ celecoxib or vehicle for four consecutive days P6 to P9. GFAP astrocyte marker (red) staining and IB4 endothelial marker (green) of mouse hippocampal region at P13. CCM lesions' high propensity to develop surrounded by GFAP+ astrocytes in the hippocampal region in vehicle-treated $P d c d 10^{B E C K O}$ mice. Significant decrease in CCM lesions' density in celecoxib-treated Pdcd10 ${ }^{B E C K O}$ mice $(n=3)$. Asterisks, vascular lumen of CCM lesions. Scale bars: (B and D) $200 \mu \mathrm{m}$.

Supplemental 6

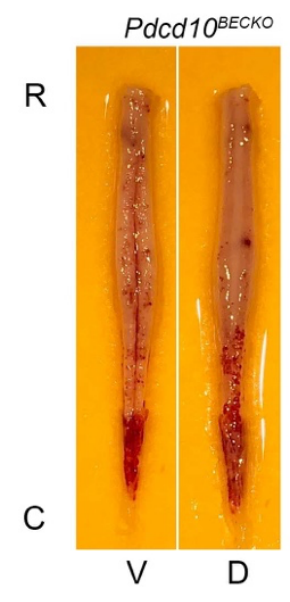

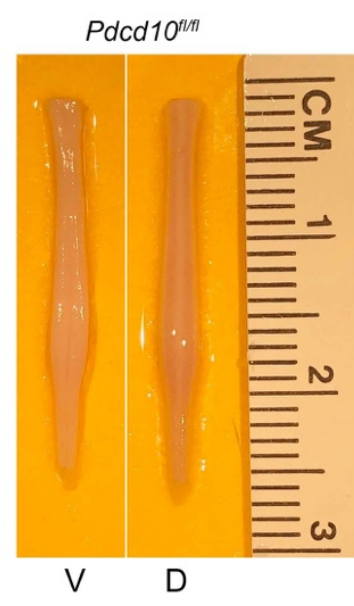
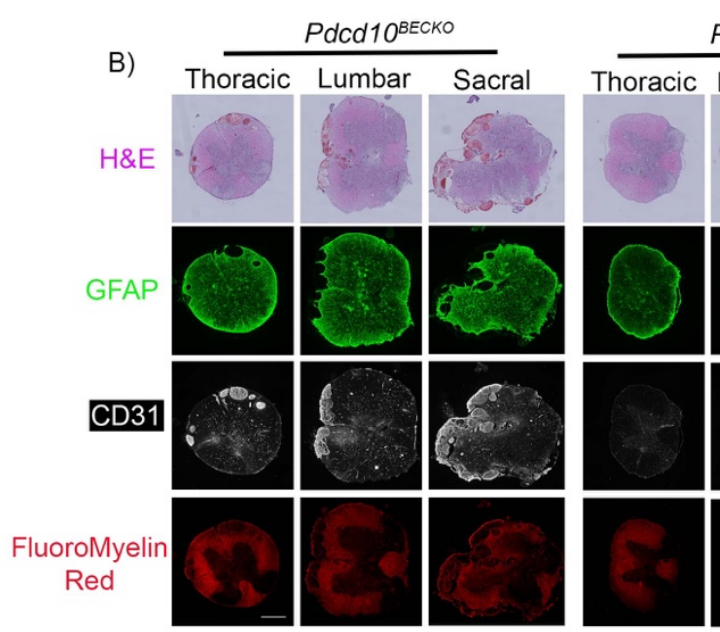

Pdcd10 thit

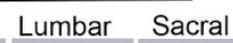

C)

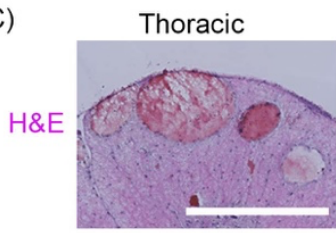

Lumbar

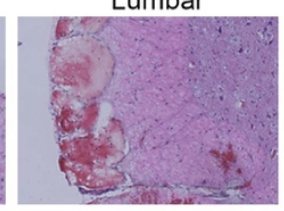

Sacral

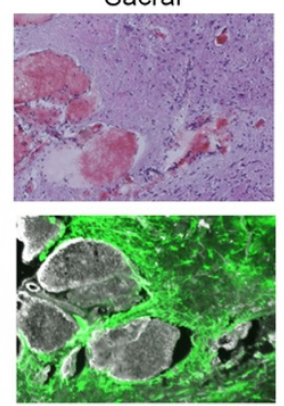

Fig. S6. CCM lesions in the spinal cord of chronic CCM mouse model. (A) Prominent lesions are present along the spinal cord of $\mathrm{P} 80 \mathrm{Pdcd} 10^{B E C K O}$ mice. $\mathrm{R}=$ rostral, $\mathrm{C}=$ caudal, $\mathrm{V}=$ ventral, $D=$ dorsal $(n=14)$. (B) Histological analysis of serial sections of spinal cords from P80 Pdcd10 and littermate control Pdcd10 $0^{f / f l}$ mice. Spinal cord sections stained by hematoxylin and eosin, GFAP astrocyte marker (green), CD31 endothelial marker (white), and myelin staining (red) of a mouse at P80 $(n=2)$. (C) High magnification of CCM lesions, in $B$, present in the thoracic, lumbar, and sacral region of a spinal cord, shown a high propensity to develop surrounded by GFAP+ astrocytes $(n=2)$. Scale bars: (B and C) $500 \mu \mathrm{m}$. 

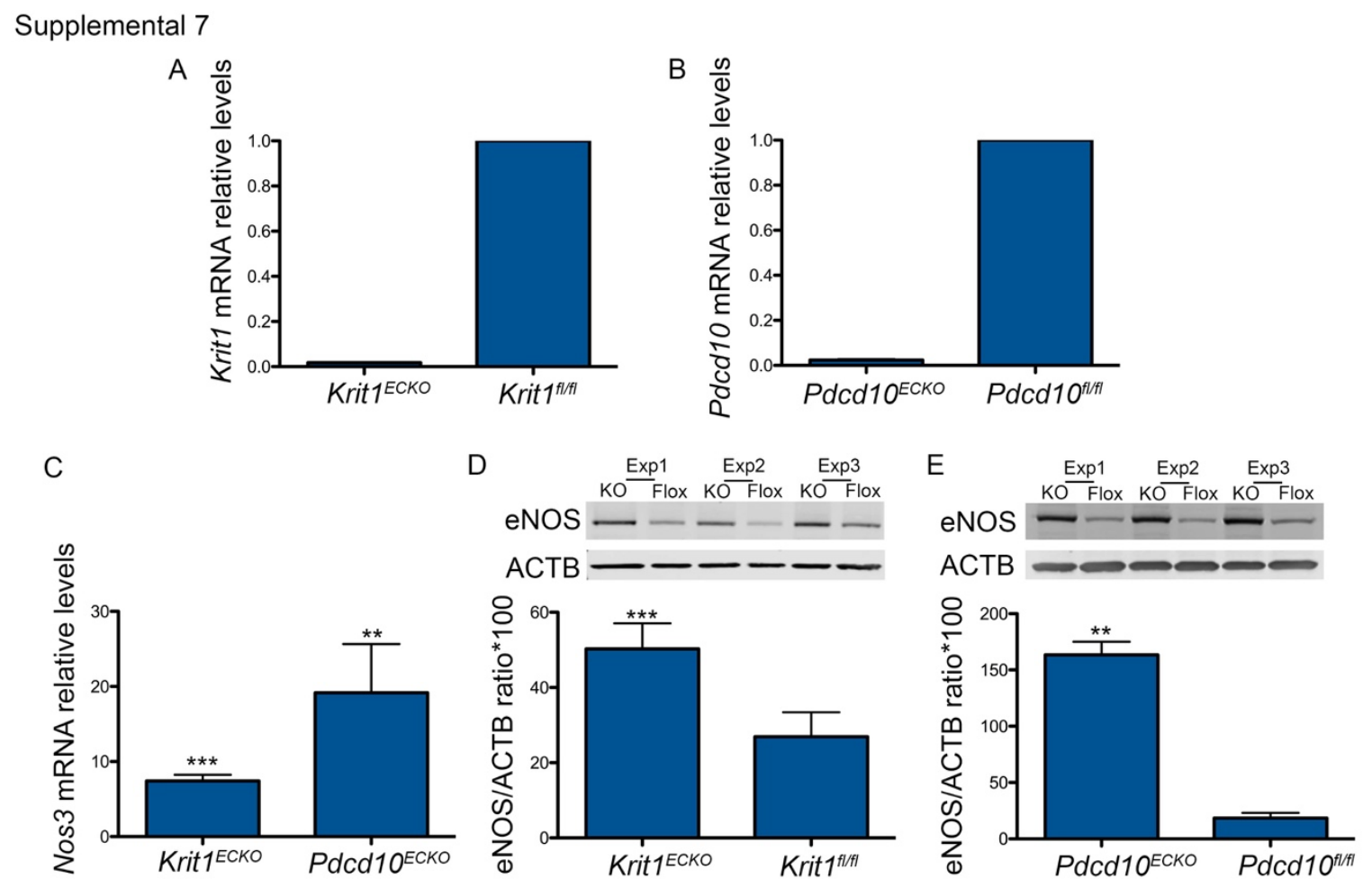

Fig. S7. Loss of brain endothelial Krit1 or Pdcd10 increases the expression of eNOS. (A) Analysis of Krit1 mRNA levels by RT-qPCR in Krit1 ${ }^{E C K O}$ BMEC and Krit1 $1^{f / f l}$ BMEC control (SEM, $n=3)$. (B) Analysis of Pdcd10 mRNA levels by RT-qPCR in Pdcd10 ECKO BMEC and Pdcd10 ${ }^{f / f f l}$ BMEC control (SEM, $n=3$ ). (C) Analysis of Nos3 mRNA levels by RT-qPCR in Krit1 ${ }^{E C K O}$ BMEC and Pdcd10 ${ }^{E C K O}$ BMEC, as compared to Krit1 $1^{f / f l}$ BMEC or Pdcd1 ${ }^{f / / f l}$ BMEC control, respectively (SEM, n=3). (D) Quantification of eNOS protein in Krit1 ${ }^{\text {ECKO }}$ BMEC compared with Krit1 ${ }^{\text {fl/fl}}$ BMEC control (SEM, n=3). (E) Quantification of eNOS protein in Pdcd10 ECKO BMEC compared with $P d c d 10^{f / f f l}$ BMEC control (SEM, $\mathrm{n}=3$ ). Data are mean \pm SEM. ${ }^{* *}, \mathrm{P}<0.01$, ${ }^{* * *}, \mathrm{P}<0.001$; determine by Student's $t$ test. 


\section{Supplementary 8}
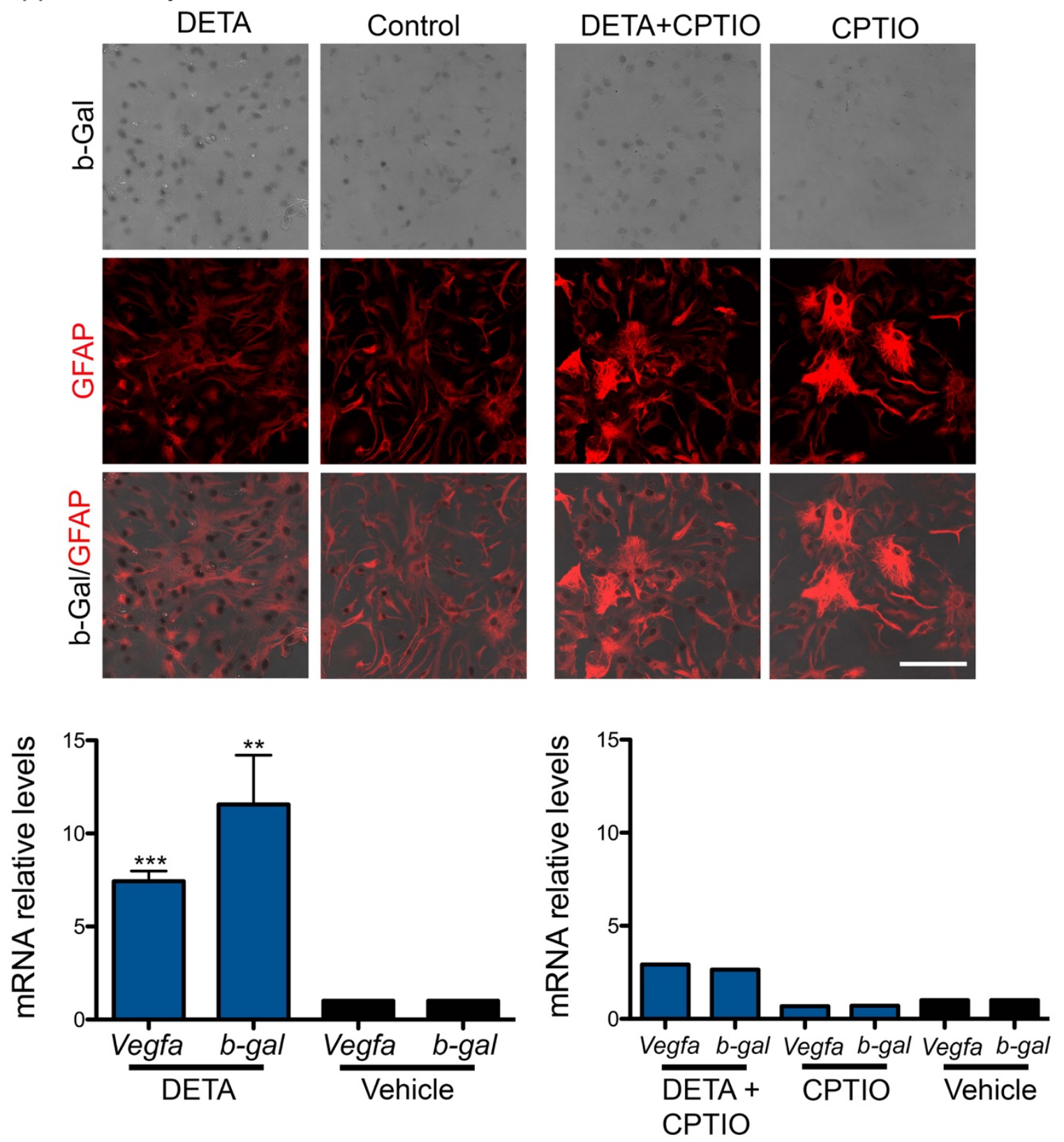

Fig. S8. Primary cultures of astrocytes respond to elevation of NO. (A) Increase in $\beta$ gal/VEGF expression, as shown by X-gal staining (black), in primary cultured astrocytes (GFAPpositive cells, red) treated with $0.5 \mathrm{mM}$ DetaNONOate (NO donor) for $24 \mathrm{~h}$ when compared with vehicle-treated astrocytes. Astrocytes pre-treated with $15 \mu \mathrm{M}$ CPTIO, a NO scavenger, prevented DetaNONOate-induced increase in $\beta$-gal/VEGF expression in astrocytes. (B) DETANONOate in astrocyte culture media induced an $\sim 7$ fold increase in astrocyte Vegfa mRNA and an $\sim 11.50$ fold increase in astrocyte $\beta$-gal mRNA levels, an effect that was prevented in astrocytes pre-treated with CPTIO. Data are mean \pm SEM. ${ }^{* *}, \mathrm{P}<0.01$, ${ }^{* * *}, \mathrm{P}<0.001$; determine by Student's $t$ test. 